
Aus der Klinik für Psychosomatische Medizin und Psychotherapie

(Prof. Dr. med. Ch. Herrmann-Lingen)

im Zentrum Psychosoziale Medizin

der Medizinischen Fakultät der Universität Göttingen

\title{
Der Beitrag der SH2-Domäne von STAT1 zur Regulation transkriptioneller Antworten im Interferon- $\gamma$-abhängigen Signalweg
}

\author{
INAUGURAL-DISSERTATION \\ zur Erlangung des Doktorgrades \\ der Medizinischen Fakultät der \\ Georg-August-Universität zu Göttingen
}

vorgelegt von

Talayeh Giveh Chian Zadeh

aus

Teheran

Göttingen 2014 
Dekan: Prof. Dr. rer. nat. H. K. Kroemer

I. Berichterstatter/in: Prof. Dr. med. Dr. phil. Dr. rer. nat. T. Meyer

II. Berichterstatter/in: Prof. Dr. rer. nat. Dieter Kube

III. Berichterstatter/in: Prof. Dr. Rainer Mausberg

Tag der mündlichen Prüfung: 10. November.2014 


\section{Inhaltsverzeichnis}

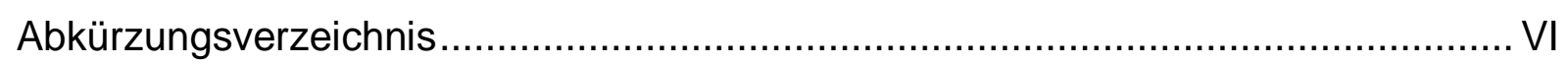

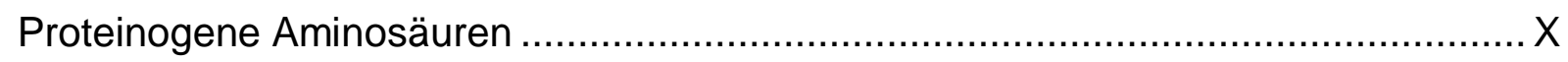

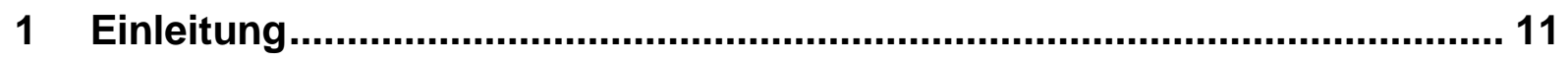

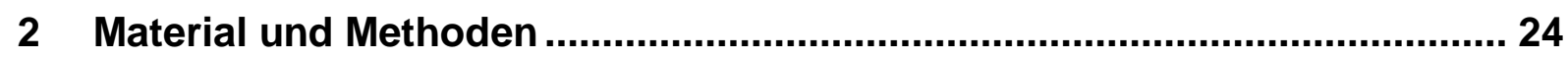

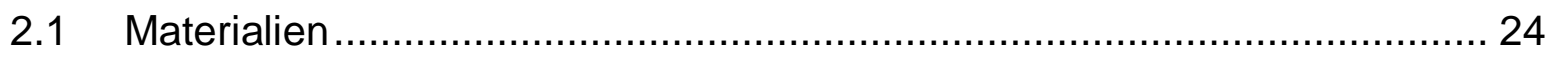

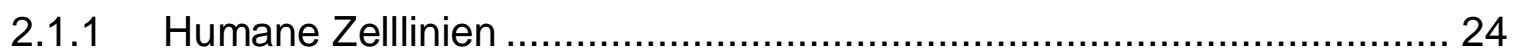

2.1.2 Liste der Chemikalien .................................................................. 24

2.1.3 Medien, Puffer und Lösungen ...................................................... 26

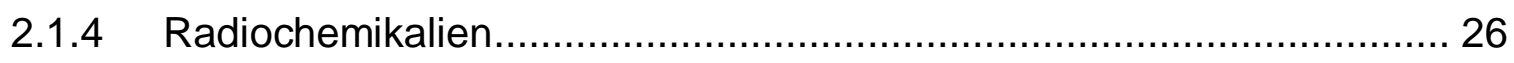

2.1.5 Antikörper und Reaktionskits ....................................................... 26

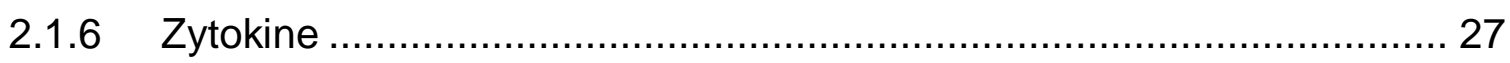

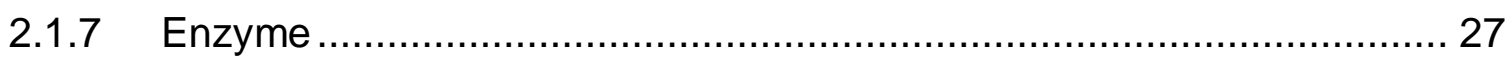

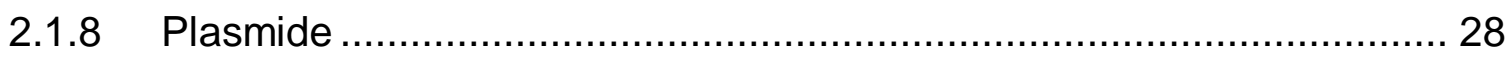

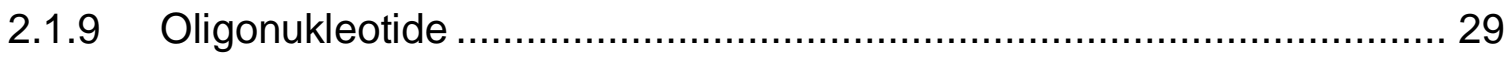

2.1.10 Bakterienstämme und Medien .................................................... 30

2.1.11 Geräte und Verbrauchsmaterialien ............................................... 31

2.2 Methoden

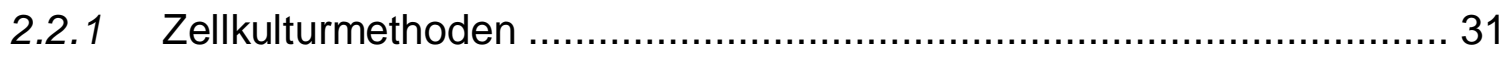

2.2.2 Transfektion der Säugerzellen ......................................................... 33

2.2.3 Behandlung der Zellen mit Inhibitoren und Zytokinen .......................... 33

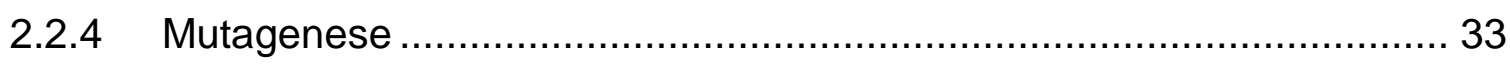

2.2.5 Transformation von Plasmid-DNA ................................................... 34

2.2.6 Plasmid-DNA-Gewinnung aus Bakterien .......................................... 34

2.2.7 Konzentrationsbestimmung isolierter Plasmid-DNA ............................ 35

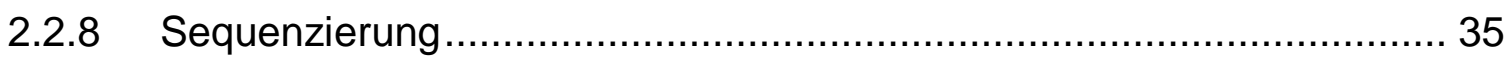

2.2.9 Gewinnung von Gesamtzellextrakten ............................................. 35 
2.2.10 SDS-Polyacrylamid-Gelelektrophorese ........................................... 36

2.2.11 Analyse mittels Western-Blot ....................................................... 37

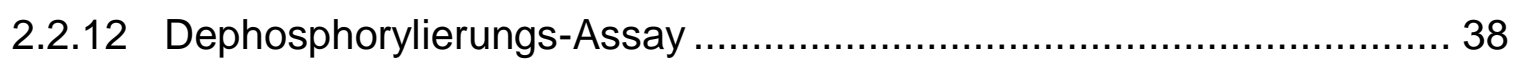

2.2.13 Fluoreszenzmikroskopische Analyse ............................................... 38

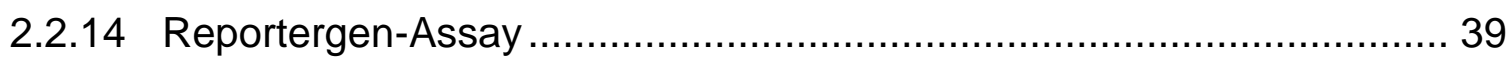

2.2.15 Elektrophoretischer Mobilitätsshift-Assay (EMSA) ….......................... 40

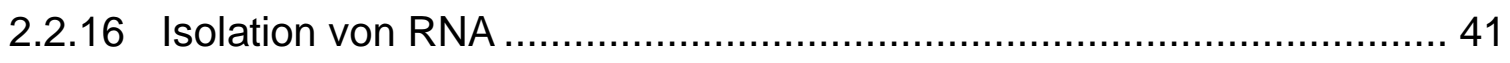

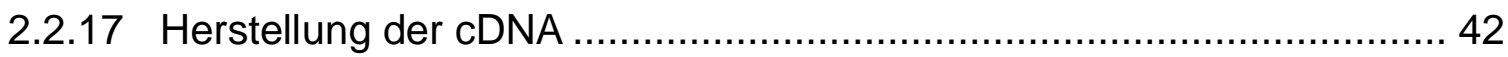

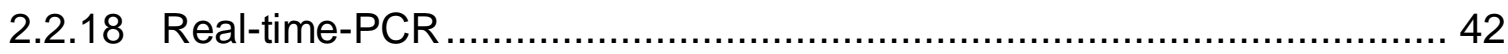

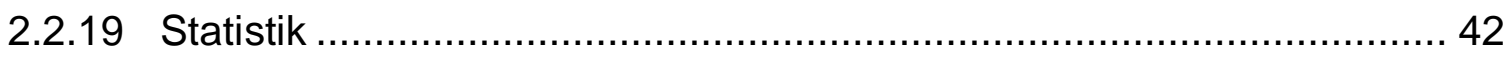

3 Ergebnisse

3.1 Sequenzhomologie von STAT1-E524 ……........................................... 43

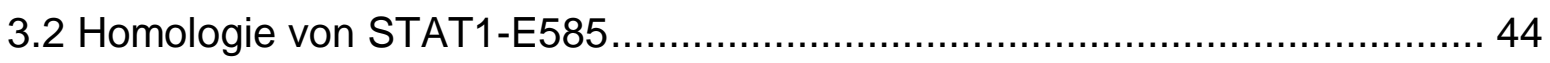

3.3 STAT1-E585A zeigt ein erhöhtes Phosphorylierungsniveau .......................... 44

3.4 Normale Kinetik der IFN-induzierten Kernakkumulation von STAT1-E524A und

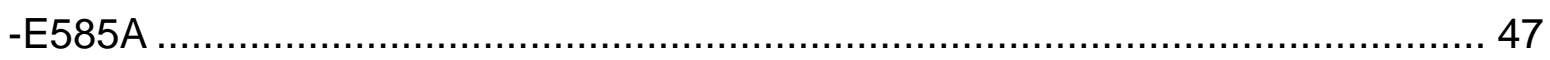

3.5 Die Hyperphosphorylierung führt bei STAT1-E585A zu einer verstärkten DNABindung 49

3.6 STAT1-E524A und STAT1-E585A besitzen eine normale Dissoziationsrate von DNA. 51

3.7 STAT1-E524A und -E585A haben eine normale Affinität zu DNA.................. 52

3.8 Kein Unterschied in der Dephosphorylierungskinetik zwischen STAT1-WT und STAT1-E585A 54

3.9 Die Hyperphosphorylierung führt zu einer geänderten Reportergen-Aktivität von STAT1-E585A . 55

3.10 Erhöhte Expression des mcp1-Gens durch STAT1- E585A......................... 58

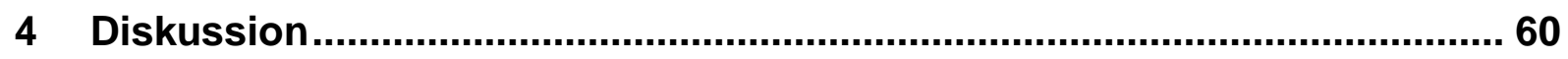

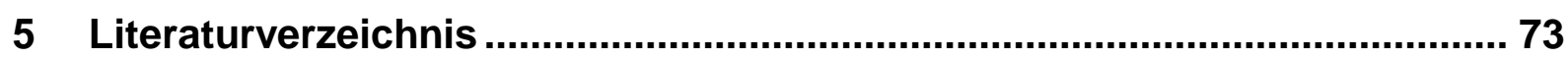




\section{Abkürzungsverzeichnis}

\begin{tabular}{|c|c|}
\hline${ }^{\circ} \mathrm{C}$ & Grad Celsius \\
\hline A & Ampere, Absorption \\
\hline$\AA$ & Ångström \\
\hline APS & Ammoniumperoxodisulfat \\
\hline AS & Aminosäure \\
\hline$\beta$-Gal & $\beta$-Galaktosidase \\
\hline B-Zelle & B-Lymphozyt \\
\hline $\mathrm{bp}$ & Basenpaare \\
\hline BSA & bovines Serumalbumin \\
\hline $\mathrm{Bq}$ & Becquerel \\
\hline c-Cbl & engl.: casitas B-lineage lymphoma proto-oncogene \\
\hline CBP & CREB-bindendes Protein \\
\hline CCD & Coiled-coil-Domäne \\
\hline cDNA & komplementäre DNA \\
\hline CIS & engl.: cytokine-inducible $\mathrm{SH} 2$-containing protein \\
\hline $\mathrm{CO}_{2}$ & Kohlendioxid \\
\hline CREB & engl.: $c A M P$ response element-binding protein \\
\hline CRM1 & engl.: chromosome region maintenance 1 \\
\hline $\mathrm{Da}$ & Dalton \\
\hline DBD & DNA-Bindedomäne \\
\hline DMEM & Dulbecco's modifiziertes Eagle-Medium \\
\hline DMSO & Dimethylsulfoxid \\
\hline DNA & Desoxyribonukleinsäure \\
\hline dNTP & Desoxyribonukleosidtriphosphat \\
\hline DPBS & Dulbecco's Phosphat-gepufferte Salzlösung \\
\hline dsNLS & dimer-spezifisches nukleäres Lokalisationssignal \\
\hline DTT & Dithiothreitol \\
\hline EDTA & Ethylendiamin-N,N,N',N'-Tetraessigsäure \\
\hline EGTA & Ethylendioxy-bis-(ethylennitrilo)-Tetraessigsäure \\
\hline EMSA & Elektrophoretischer Mobilitätsshift-Assay \\
\hline FCS & fetales Kälberserum \\
\hline$g$ & Erdbeschleunigung, auch: Gramm \\
\hline
\end{tabular}




\begin{tabular}{|c|c|}
\hline GAPDH & Glycerinaldehyd-3-Phosphat-Dehydrogenase \\
\hline GAS & Gamma-aktivierte Sequenz \\
\hline GBP & Guanylat-bindendes Protein \\
\hline GDP & Guanosindiphosphat \\
\hline GFP & grün-fluoreszierendes Protein \\
\hline GM-CSF & Granulozyten-Makrophagen-Kolonie-stimulierender Faktor \\
\hline GTP & Guanosintriphosphat \\
\hline $\mathrm{h}$ & Stunde(n) \\
\hline Hepes & $\mathrm{N}$-(2-Hydroxyethyl)-1-Piperazino-Ethansulfonsäure \\
\hline $\mathrm{H}_{2} \mathrm{O}$ & Wasser \\
\hline $\mathrm{H}_{2} \mathrm{O}_{2}$ & Wasserstoffperoxid \\
\hline ICAM-1 & intrazelluläres Adhäsions-Molekül-1 \\
\hline IFN & Interferon \\
\hline IFNAR & Interferon- $\alpha / \beta$-Rezeptor \\
\hline IFNGR & Interferon- $\gamma$-Rezeptor \\
\hline IL & Interleukin \\
\hline IRF1 & IFN-regulierender Faktor 1 \\
\hline ISGF3 & IFN-stimulierender Genfaktor 3 \\
\hline ISRE & engl.: interferon-stimulated response element \\
\hline JAK & Janus-Kinase \\
\hline k & Kilo \\
\hline $\mathrm{kb}$ & Kilobase \\
\hline $\mathrm{KCl}$ & Kaliumchlorid \\
\hline L & Liter \\
\hline LB & Luria-Broth \\
\hline LD & Linker-Domäne \\
\hline $\mathrm{m}$ & Milli \\
\hline M & Molar \\
\hline MAP & Mitogen-aktiviertes Protein \\
\hline $\mathrm{MgCl}_{2}$ & Magnesiumchlorid \\
\hline $\mathrm{MgSO}_{4}$ & Magnesiumsulfat \\
\hline $\mathrm{MHC}$ & Haupthistokompatibilitätskomplex \\
\hline MIG & engl.: monokine-induced by IFN $\gamma$ \\
\hline $\min$ & Minute(n) \\
\hline
\end{tabular}




\begin{tabular}{|c|c|}
\hline mRNA & Boten-RNA \\
\hline $\mathrm{n}$ & nano \\
\hline $\mathrm{N}$-Terminus & Amino-Terminus \\
\hline $\mathrm{NaCl}$ & Natriumchlorid \\
\hline $\mathrm{NaOH}$ & Natriumhydroxid \\
\hline $\mathrm{Na}_{3} \mathrm{VO}_{4}$ & Natrium-Ortho-Vanadat \\
\hline ND & Aminoterminale Domäne \\
\hline NES & Nukleäres Exportsignal \\
\hline NK-Zelle & Natürliche Killerzelle \\
\hline NLS & Nukleäres Lokalisationssignal \\
\hline NPC & Nukleärer Porenkomplex \\
\hline ONPG & ortho-Nitrophenyl- $\beta-D-G a l a c t o p y r a n o s i d$ \\
\hline $\mathrm{p}$ & pico \\
\hline PAGE & Polyacrylamid-Gelelektrophorese \\
\hline PBS & Phosphat-gepufferte Salzlösung \\
\hline PCR & Polymerase-Kettenreaktion \\
\hline PIAS & Protein-Inhibitor von aktiviertem STAT \\
\hline Poly-dldC & Poly-Desoxyinosin-Desoxycytidin-Säure \\
\hline PTP1B & Protein-Tyrosin-Phosphatase 1B \\
\hline pTyr & Phosphotyrosin \\
\hline PVDF & Polyvinylidenfluorid \\
\hline $\mathrm{RCC} 1$ & engl.: guanine nucleotide exchange factor \\
\hline RNA & Ribonukleinsäure \\
\hline rpm & Umdrehungen pro Minute \\
\hline RT & Raumtemperatur \\
\hline RT-PCR & Real-time-PCR \\
\hline SDS & Natriumlaurylsulfat \\
\hline sec & Sekunde(n) \\
\hline $\mathrm{SH} 1$ & Src-Homologie 1 \\
\hline $\mathrm{SH} 2$ & Src-Homologie 2 \\
\hline $\mathrm{SH} 3$ & Src-Homologie 3 \\
\hline SHP-1 & Protein-Tyrosin-Phosphatase-1 mit SH2-Domänen \\
\hline SHP-2 & Protein-Tyrosin-Phosphatase-2 mit SH2-Domänen \\
\hline SOCS & Suppressor des Zytokin-Signalwegs \\
\hline
\end{tabular}


(engl.: suppressor of the cytokine signalling)

STAT

$\mathrm{T}$

T-Zelle

TAD

TBE

TBS-T

TC-PTP

TEMED

$\mathrm{T}_{\mathrm{H}}$ 1-Zelle

$\mathrm{T}_{\mathrm{H}}$ 2-Zelle

TKL

Tris

U

UV

$\mathrm{V}$

v-fps

V-src

WT
Signaltransduktor und Aktivator der Transkription

tera

T-Lymphozyt

Transaktivierungsdomäne

Tris-Borsäure-EDTA

Tris-gepufferte Salzlösung mit 0,05\% Tween

T-Zell-Protein-Tyrosin-Phosphatase

$\mathrm{N}, \mathrm{N}, \mathrm{N}^{\prime}, \mathrm{N}^{\mathrm{c}},-$-Tetramethylethylendiamin

T-Helferzelle Typ 1

T-Helferzelle Typ 2

Tyrosinkinase-ähnliche Kinase

Tris-(Hydroxylmethyl)-Aminomethan

Einheiten

ultraviolett

Volt

virales Onkogen des Fujinami-Sarkoma-Virus

virales Onkogen des Rous-Sarkoma-Virus

Wildtyp 


\section{Proteinogene Aminosäuren}

\begin{tabular}{|l|l|l|}
\hline Aminosäure & 3-Buchstaben-Code & 1-Buchstaben-Code \\
\hline Alanin & Ala & A \\
\hline Cystein & Cys & C \\
\hline Asparaginsäure & Asp & D \\
\hline Glutaminsäure & Glu & E \\
\hline Phenylalanin & Phe & F \\
\hline Glycin & Gly & G \\
\hline Histidin & His & H \\
\hline Isoleucin & Ile & I \\
\hline Lysin & Lys & K \\
\hline Leucin & Leu & L \\
\hline Methionin & Met & M \\
\hline Asparagin & Asn & N \\
\hline Prolin & Pro & P \\
\hline Glutamin & Gln & Q \\
\hline Arginin & Arg & R \\
\hline Serin & Ser & S \\
\hline Threonin & Thr & T \\
\hline Valin & Val & V \\
\hline Tryptophan & Trp & W \\
\hline Tyrosin & Tyr & Y \\
\hline
\end{tabular}




\section{Einleitung}

In mehrzelligen Organismen dienen extrazelluläre Botenstoffe der Zell-ZellKommunikation und der Aufrechterhaltung physiologischer Funktionen. Auf einen externen Reiz hin werden beispielsweise Zytokine sezerniert und lösen zelluläre Antworten aus. Der von Zytokinen ausgehende JAK-STAT-Signalweg ist wohl einer der am besten untersuchten Signalwege dieser Art (Levy und Darnell 2002). Die Bindung eines Zytokins an seinen spezifischen Rezeptor führt zu einer Konformationsänderung im carboxyterminalen Rezeptormolekül. Diese Änderung löst eine intrazelluläre Signaltransduktionskaskade aus, die innerhalb weniger Minuten zur Aktivierung bzw. Phosphorylierung von Transkriptionsfaktoren aus der Familie der Signaltransduktoren und Aktivatoren (STATs) und damit verbunden zu einer veränderten Genexpression führt. Nach der Bindung des spezifischen Zytokins an seinen entsprechenden Rezeptor werden durch nicht-kovalent Rezeptor-gebundene Janus-Kinasen zytoplasmatisch lokalisierte STAT-Proteine an Tyrosinresten phosphoryliert. Diese vermitteln die direkte Weiterleitung des Signals von den Rezeptoren der Zelloberfläche in den Nukleus (Darnell et al. 1994; Levy und Darnell 2002). Alterationen im JAK-STAT-Signalweg können sich an unterschiedlichen Stellen innerhalb der Signalkaskade manifestieren und beim Menschen bestimmte Defekte des Immunsystems auslösen. Beispiele für eine Störung dieses Signalwegs können Punktmutationen innerhalb des STAT1-Gens sein, die die Funktion des Proteins bei Immunantworten beeinträchtigen (Dupuis et al. 2001, 2003; Chapgier et al. 2006; Liu et al. 2011; Sampaio et al. 2012; Smeekens et al. 2011; van de Veerdonk et al. 2011; Takezaki et al. 2012; Tsumura et al. 2012).

\section{Zytokine und ihre Bedeutung für die STAT-Proteine}

Die Aktivierung von STAT-Proteinen erfolgt durch eine Kaskade von Tyrosinphosphorylierungen, welche wiederum durch die Stimulation der Zellen mit Zytokinen hervorgerufen werden. Bei diesen Zytokinen handelt es sich um kleine Glykoproteine, die ein Molekulargewicht von ca. $20 \mathrm{kDa}$ und eine Aminosäurelänge von 100-200 aufweisen (Schooltink und Rose-John 2002). Sie sind eine bedeutende Botengruppe für die Kommunikation zwischen einzelnen Zellen und Organen (Kelker et al. 1983, 1984; Farrar und Schreiber 1993). Zu ihren wichtigsten Aufgaben gehören die Steuerung der Immunantwort und damit verbunden die Kontrolle des 
Aktivitätszustandes von immunkompetenten Zellen. Desweiteren übernehmen die Zytokine eine zentrale Rolle bei Entwicklungs-, Wachstums- und Differenzierungsprozessen. Bis dato sind weit über 100 verschiedene Zytokine beschrieben worden, ohne das eine einheitliche Nomenklatur dieser großen Gruppe existiert (Schooltink und Rose-John 2002). Zu der Superfamilie der Zytokine zählen eine große Anzahl unterschiedlicher Wachstumsfaktoren, Interleukine (IL), Chemokine sowie Interferone (IFN), die sich in ihren strukturellen Merkmalen voneinander unterscheiden (Thomson 1998; Nicola 1994). Ein besonderes Augenmerk dieser Dissertation liegt auf den zuletzt genannten Interferonen, da sie einen essentiellen Beitrag zur Aktivierung des STAT1-Proteins leisten. 1957 wurde im Rahmen der Behandlung von Hühner-Embryos mit lebenden und Hitze-inaktivierten Influenza-Viren erstmalig eine Interferon-Induktion festgestellt (Isaacs und Lindemann 1987). Man fand heraus, dass es sich dabei um mehrfach exprimierte Zytokine handelt, die immunmodulatorische, antiproliferative sowie antivirale Eigenschaften besitzen. Ihre große biologische Wirksamkeit wird vor allem in der Regulation des Immunsystems deutlich. Sie bilden die erste Achse bei der Immunabwehr gegenüber viralen Erregen und tragen zur Immunkontrolle maligner Zellen bei (Kaplan et al. 1998). Die Bezeichnung Interferon verweist auf ihre Fähigkeit zur Interferenz mit Virusinfektionen (Isaacs und Lindenmann 1987). Anhand ihrer kristallographischen Darstellung stellte man fest, dass sie eine Vier-Helix-Struktur besitzen, die bei über 50 weiteren Zytokinen identifiziert werden konnte (Ealick et al. 1991; Senda et al. 1992; Schindler und Plumlee 2008).

Die Familie der Interferone untergliedert sich in die Typ-I-Interferone $\alpha / \beta, \omega$ und $\tau$, das Typ-II-Interferon y und das Typ III-Interferon $\lambda$ (Platanias 2005). Die Gruppe der TypI-Interferone schließt acht weitere Unterklassen mit ein (IFN $\alpha, \operatorname{IFN} \beta, \operatorname{IFN} \varepsilon, \operatorname{IFN} \kappa$, $\operatorname{IFN} \omega$, IFN $\delta$, IFN $\tau$, IFN $\zeta$ ). Der Nachweis von IFN $\alpha, \operatorname{IFN} \beta$, IFN $\varepsilon$, IFN $\kappa$ und IFN $\omega$ aus dieser Unterklasse war auch in humanem Gewebe möglich (Roberts et al. 1991; Lefèvre und Boulay 1993; Lefèvre et al. 1998; Oritani und Tomiyama 2004; Pestka et al. 2004). Die Typ-I-Interferone besitzen antiproliferative, proapoptotische sowie antivirale Eigenschaften und werden als Reaktion auf eine Virusinfektion in Fibroblasten und Leukozyten produziert. Desweiteren übernehmen sie eine wichtige Rolle bei der Induktion der Zytotoxizität von Natürlichen Killerzellen, T-Zellen und Monozyten (Gidlund et al. 1978; Djeu et al. 1979; Evinger et al. 1981; Herberman 
et al. 1982; Ortaldo et al. 1983; Pestka 1983; Novick et al. 1994; Clemens 2003; Pestka et al. 2004). Sie binden an ihren spezifischen Rezeptor, den Interferon- $\alpha$ Rezeptor (IFNAR), der sich aus den zwei Untereinheiten IFNAR1 und IFNAR2 zusammensetzt (Novick et al. 1994). Das IFNY-Gen wird hingegen nach Aktivierung durch Antigen-präsentierende Zellen nur in T-Zellen und zytotoxischen Lymphozyten gebildet und aktiviert andere immunkompetente Zellen. In Makrophagen führt IFN $\gamma$ Stimulation beispielsweise zur Bildung von Stickstoffmonoxid und einigen reaktiven, zytotoxischen Sauerstoffspezies (Farrer und Schreiber 1993; Stark et al. 1998), die bei der Abtötung phagozytierter pathogener Erreger unabkömmlich sind. IFN $\gamma$ übernimmt zudem auch im Rahmen des Antiköperwechsels in B-Zellen sowie der T-Zell-Differenzierung eine wichtige Rolle (Snapper und Paul 1987; Stark et al. 1998). Hier erfolgt die Bindung an einen spezifischen Klasse-II Zytokin-Rezeptor (Interferon-Gamma-Rezeptor), der die Aktivierung des JAK-STAT-Signalweges zur Folge hat. Sämtliche kernhaltige Zellen, Erythrozyten damit ausgenommen, exprimieren IFNGR auf ihrer Oberfläche (Langer und Pestka 1988).

Das dritte Mitglied der Interferon-Familie wurde erst vor kurzem identifiziert. Sowohl der Nachweis der Typ-III-Interferone als auch der von IFN $\gamma$ war in humanem Gewebe möglich (Pestka et al. 1987; Kotenko et al. 2003; Sheppard et al. 2003). Die TypIII-Interferone umfassen die Unterklassen IFN $\lambda 1$, IFN $\lambda 2$ und IFN $\lambda 3$, die ehemals unter den Bezeichnungen IL-29, IL-28A und IL-28B bekannt waren und deren Signalweiterleitung ebenfalls über den JAK-STAT-Signalweg erfolgt. Neben der Aktivierung des JAK-STAT-Signalweges sind Interferone auch in der Lage, andere Signaltransduktionswege zu aktivieren. Einer dieser Signalwege ist zum Beispiel die MAPKinase-Kaskade, die unter anderem für das Zellwachstum und die Zelldifferenzierung bedeutsam ist (Seger und Krebs 1995; Stancato et al. 1997; Sakatsume et al. 1998; Pestka et al. 2004). Alle Interferone können die Bildung von MHC-I-Molekülen über einen von IRF-1- (Interferon-regulatory factor 1) abhängigen Weg herbeiführen (Chang et al. 1992), während die Expression von MHC II nur durch IFN $\gamma$ über CIITA (MHC class II transactivator) möglich ist (Mach et al. 1996; Boehm et al. 1997; Loppnow 2001). 


\section{Die Familie der STAT-Proteine}

STAT-Proteine kommen in Vertebraten (Oates et al. 1999; Pascal et al. 2001; Sung et al. 2003) und Insekten sowie im Schleimpilz Dictyostelium vor (Yan et al. 1996; Kawata et al. 1997; Barillas-Mury et al. 1999; Liu et al. 1999). Auch bei Nematoden wie Caenorhabditis elegans konnte man das Vorhandensein von STATMolekülen beweisen, welche strukturell mit der Domänenstruktur der humanen STAT-Moleküle übereinstimmen (Liu et al. 1999). Zudem konnte die Entdeckung von JAK- und STAT-Proteinen in Drosophila melanogaster als Beweis eines STAT-regulierten Signalwegs bei Wirbellosen dienen (Yan et al. 1996; Hou und Perrimon 1997). Somit konnte bestätigt werden, dass STAT-Proteine in sämtlichen tierischen mehrzelligen Organismen evolutionär konserviert sind, wobei Pflanzen und Pilze hier die Ausnahme bilden (Darnell 1997). Ihre Existenz wurde erstmalig bei Untersuchungen der IFN $\alpha$ - und IFN $\gamma$-abhängigen Genaktivierung entdeckt. Nach Isolation und Sequenzanalyse zweier Proteine, die bis dahin unbekannt waren und ein Molekulargewicht von $91 \mathrm{kDa}$ und $113 \mathrm{kDa}$ besaßen, wurden sie zu den Mitgliedern einer neuen Proteinfamilie, der STAT-Familie, ernannt (Fu et al. 1990; Fu et al. 1992; Schindler et al.1992; Shuai et al. 1992).

Die Familie der humanen STAT-Proteine zählt aktuell sieben Mitglieder: STAT1, STAT2, STAT3, STAT4, STAT5a, STAT5b und STAT6. Inre genetische Information befindet sich im menschlichen Genom auf drei verschiedenen Chromosomen. STAT1 und STAT4 befinden sich auf Chromosom 2, STAT3, STAT5a und 5b auf Chromosom 12 und STAT2 sowie STAT6 auf dem Chromosom 17 (Copeland et al. 1995; Darnell 1997). Alle Mitglieder der STAT-Familie besitzen eine Länge von ca. 750850 Aminosäureresten und verfügen über eine Sequenzhomologie von $28-40 \%$ innerhalb der ersten 700 AS (Schindler und Darnell 1995; Levy und Darnell 2002). Sie gleichen sich in ihrem Molekulargewicht, das etwa 80-113 kDa beträgt, und verfügen über dieselbe charakteristische Struktur von sechs funktionellen Domänen, wie sie in der Abb. 1 demonstriert wird. 


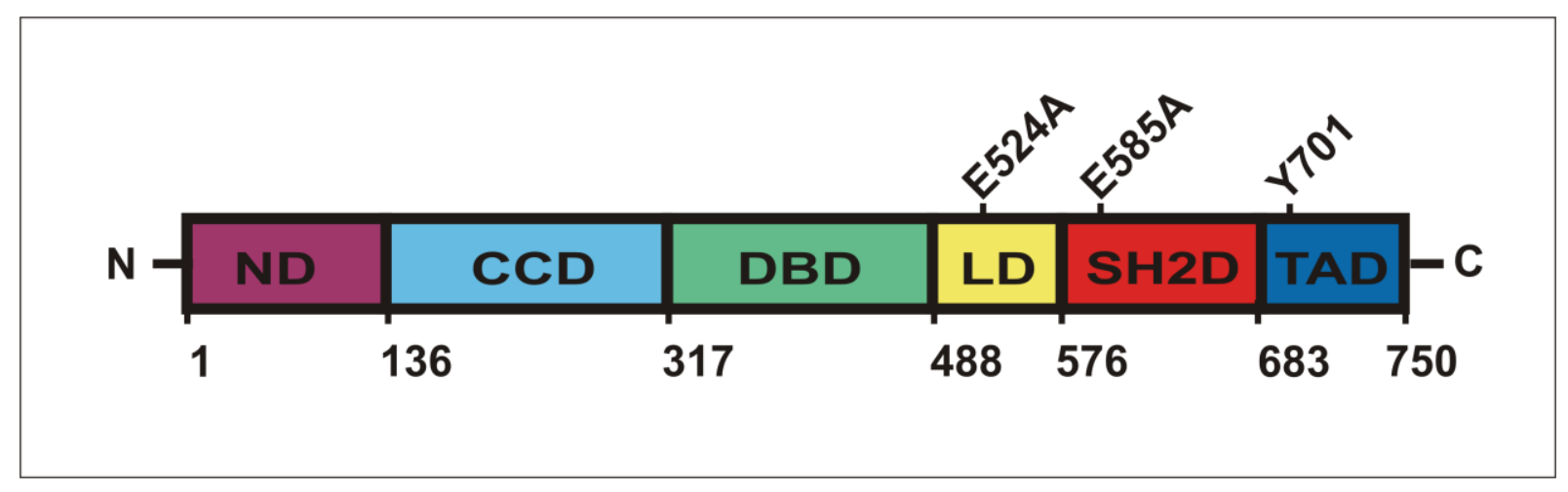

Abb. 1: Domänenstruktur der STAT-Proteine mit Darstellung der beiden in dieser Arbeit behandelten Punktmutanten. NH2: aminoterminale Domäne, CCD: Coiled-coil-Domäne, DBD: DNA-Bindedomäne, LD: Linker-Domäne, SH2: SrcHomologie-2-Domäne; TAD: Transaktivierungsdomäne, Y701: Phosphotyrosinrest.

Auf die aminoterminale Domäne folgen die Coiled-coil- (CCD), die DNA-Binde(DBD), die Linker- (LD), die Src-Homologie-2- (SH2-), und die carboxyterminale Transaktivierungsdomäne (TAD) (Darnell 1997; Chen et al. 1998; Horvath 2000; Levy und Darnell 2002; Lim und Cao 2006). Jede dieser Domänen besitzt unterschiedliche Funktionen. Die größte Sequenzhomologie liegt hierbei zwischen den AS-Resten 600-700 im Bereich der SH2-Domäne (Fu et al. 1992; Schindler und Darnell 1995). Bei den STAT-Proteinen findet sich ein kritischer hochkonservierter Tyrosinrest, der von JAK-Kinasen erkannt und phosphoryliert wird und für die transkriptionelle Aktivität der STAT-Proteine essentiell ist (Schindler et al. 1992; Shuai et al. 1993; Vinkemeier et al. 1998). STAT1, -3, -5a und -5b besitzen zudem noch einen konservierten Serinrest im carboxyterminalen Bereich, in dem eine Phosphorylierung durch Serin-Threonin-Kinasen stattfindet (Zhang et al. 1995). Innerhalb der STAT-Familie kommt es zudem zu einer Steigerung der Komplexität, da STAT1, STAT3, STAT4, STAT5 und STAT6 durch proteolytischen Abbau bzw. durch differentielles Spleißen verändert werden können (Schindler et al. 1992; Schaefer et al. 1995; Wang et al. 1996). Daraus resultiert beispielsweise, dass STAT1 und STAT3 jeweils in zwei unterschiedlichen Isoformen, $\alpha$ und $\beta$, vorkommen. Beide sind Spleißvarianten desselben Gens, mit dem Unterschied, dass die $\beta$ Isoform am carboxyterminalen Ende eine Trunkierung aufweist und deshalb nicht transkriptionell aktiv ist (Horvath 2000; Decker und Kovarik 2000; Lödige et al. 2005). 
Im Rahmen von Mäuseexperimenten konnte bewiesen werden, dass die einzelnen Mitglieder der STAT-Familie bei zahlreichen zellulären Prozessen, wie der Immunantwort, Zelldifferenzierung, dem Zellwachstum und der Apoptose, unterschiedliche Aufgaben übernehmen. STAT1 beispielsweise ist nach Aktivierung durch den Tumor-Nekrose-Faktor a (TNFa) in der Lage, Apoptose über einen Fas-abhängigen Weg oder über die Regulation der basalen Expression von Caspasen auszulösen (Chin et al. 1997; Kumar et al. 1997; Lee et al. 2000; Ouchi et al. 2000). Durch Mausmodelle mit STAT1-defizienten Mäusen wurde gezeigt, dass die fehlende STAT1-Expression insbesondere zu einer Beeinträchtigung der IFN $\alpha$ - und IFN $\gamma$ vermittelten Immunantwort gegenüber viralen und bakteriellen Erregern führt, während Störungen in anderen Signalwegen bisher nicht beobachtet werden konnten. Kommen die STAT1-Knockout-Mäuse hingegen mit keinem Pathogen in Berührung, steht ihrer normalen Entwicklung nichts im Wege. Somit konnte ein Einfluss von STAT1 auf die Entwicklung der Mäuse nicht nachgewiesen werden (Durbin et al. 1996; Horvath und Darnell 1996; Meraz et al. 1996). In anderen Experimenten konnte bei STAT1-defizienten Mäusen eine erhöhte Anfälligkeit für Tumorbildung beobachtet werden (Shankaran et al. 2001). Zudem kommt den durch Interferon oder epidermalen Wachstumsfaktor (EGF) stimulierten STAT1- und STAT2-Proteinen eine zentrale Rolle in der Immunantwort auf virale und bakterielle Infektionen zu, indem sie das Zellwachstum über IRF1 oder p21 inhibieren (Chin et al. 1996; Bromberg et al. 1998; Park et al. 2000; Zimmermann et al. 2005; Zhao et al. 2007). Eine defiziente Expression von STAT2-Protein, dessen Aktivierung allein durch Typ-I-Interferone möglich ist (Schindler et al. 1992; Schindler und Darnell 1995), führt ebenfalls zu einem Immundefekt gegenüber viralen Erregern (Park et al. 2000; Levy und Darnell 2002).

Ein weiteres Beispiel für die Rolle der STAT-Proteine ist die Bedeutung von STAT3 im Rahmen der embryonalen Entwicklung. Mäuse mit fehlender STAT3-Expression sterben schon in der Embryonalphase (Duncan et al. 1997; Takeda et al. 1997). Erfolgt die Ausschaltung des STAT3-Gens hingegen in adulten Tieren, werden weitere pathologische Defekte, wie zum Beispiel eine Störung der IL-6-getriggerten T-Zell-Proliferation (Takeda et al. 1998) oder eine Beeinträchtigung der entzündungsbedingten Induktion von Akut-Phase-Proteinen in der Leber (Alonzi et al. 2001), beobachtet. Die Aktivierung von STAT4 kann sowohl durch IFNa als auch 
durch IL-12 hervorgerufen werden (Kaplan et al. 1996; Nguyen et al. 2002). Wird die IL-12-Antwort inhibiert, resultiert eine Störung der STAT4-Aktivierung. STAT4defiziente Mäuse haben eine gestörte Zytotoxizität natürlicher Killerzellen, einen Defekt der IFN $\gamma$-Synthese und eine fehlerhafte Differenzierung naiver T-Helferzellen zu Ungunsten der TH1-Entwicklung (Kaplan et al. 1996; Thierfelder et al. 1996).

Trotz 96\% identischer muriner Aminosäuresequenz von STAT5a und STAT5b (Mui et al. 1995) wurden bei STAT5a- bzw. STAT5b-Knockout-Mäusen unterschiedliche Phänotypen nachgewiesen. Weibliche STAT5a-defiziente Mäuse zeigen eine abnorme Mammogenese und Laktationsauffälligkeiten. STAT5b ist hierbei trotz ähnlicher Sequenzhomologie nicht dazu in der Lage, das STAT5a-Defizit zu kompensieren (Liu et al. 1997). Als weiteres Beispiel für die Wichtigkeit der STAT-Proteine sollen STAT6-defiziente Mäusen dienen, bei denen eine Störung der Lymphozytenfunktion nachgewiesen werden konnte. Im Mausmodell wurde eine Störung des Immunglobulin-Klassenwechsels in Plasmazellen und eine Entwicklungsstörung reifer TH2-Zellen festgestellt (Kaplan et al. 1996; Takeda et al. 1996).

\section{Struktureller Aufbau der STAT-Proteine}

Alle Mitglieder der STAT-Proteinfamilie besitzen den gleichen Aufbau aus sechs funktionell und strukturell konservierten Domänen, welcher im Folgenden anhand der Architektur des STAT1-Moleküls erläutert wird. Mithilfe von kristallographischen Analysen von phosphorylierten DNA-gebundenen STAT1- und 3-Homodimeren (Becker et al. 1998; Chen et al. 1998) konnte bewiesen werden, dass dimere STATProteine, die über ihre SH2-Domänen untereinander in Verbindung stehen, mit der DNA interagieren. Allerdings wurden die Strukturdaten lediglich von trunkiertem STAT erhalten, dem die N-terminale und die Transaktivierungsdomäne fehlten, da eine Kristallisation des Volle-Länge-Moleküls an DNA nicht gelang. Da jedoch die Kristallstruktur der isolierten N-terminalen Domäne von STAT4 bekannt ist, konnte mithilfe dieser Struktur ein Modell entwickelt werden, das auch zum Verständnis der Interaktion der N-Termini von STAT1-Dimeren verwendet werden konnte (Baden et al. 1998; Chen et al. 1998; Vinkemeier et al. 1998; Chen et al. 2003).

Zusätzlich konnte in weiteren Versuchen bewiesen werden, dass STAT1-Dimere in zwei unterschiedlichen Konformationen vorliegen können: eine parallele und eine 
antiparallele Form. Der Unterschied zwischen diesen beiden Formen liegt in der Ausrichtung der SH2-Domänen. Bei der antiparallelen Konformation zeigen die SH2Domänen beider Monomere in entgegengesetzte Richtungen, während sie bei der parallelen Konformation in dieselbe Richtung gerichtet sind (Mao et al. 2005; Mertens et al. 2006). Für die Konformationsänderung von der einen in die andere Form ist eine flexible Region zwischen dem N-Terminus und der Coiled-coil-Domäne notwendig. Hierbei spielt maßgeblich deren Länge, nicht aber die Aminosäuresequenz dieses Bereiches eine entscheidende Rolle (Mertens et al. 2006). Die Stabilisierung der antiparallelen Form erfolgt über Interaktionen der Coiled-coilDomäne mit der DNA-Bindedomäne sowie möglicherweise durch reziproke aminoterminale Wechselwirkungen. Die parallele Form hingegen wird allein durch gegenseitige Wechselwirkung der SH2-Domänen stabilisiert. Während die antiparallele Konformation des Proteins für die Dephosphorylierung durch die TC45-Phosphatase essentiell ist, kommt der parallelen Konformation des Proteins bei der DNA-Bindung eine entscheidende Aufgabe zu (Mao et al. 2005; Mertens et al. 2006; Wenta et al. 2008; Zhong et al. 2005).

\section{Der JAK-STAT-Signalweg und seine Regulation}

Die Gemeinsamkeit aller Zytokin-Rezeptoren besteht darin, dass sie sich aus einer extrazellulären Liganden-bindenden Domäne, einer die Zellmembran einmal durchquerenden Transmembran-Domäne sowie einer intrazellulären carboxyterminalen Domäne zusammensetzen. Durch die Bindung von Interferon an seinen spezifischen Rezeptor kommt es zu einer Oligomerisierung der weiter oben genannten Rezeptor-Untereinheiten IFNGR1 und IFNGR2 sowie einer Dimerisierung der Rezeptor-Untereinheiten IFNAR1 und IFNAR2. Beide, IFNAR und IFNGR, gehören zu den Klasse-II-Zytokin-Rezeptoren (Bach et al. 1997). Da sie selbst über keine intrinsische Kinase-Aktivität verfügen, sind zur Auto- bzw. Transphosphorylierung des Rezeptors sowie zur Aktvierung der STAT-Proteine die Janus-Kinasen unentbehrlich. Diese befinden sich auf der zytoplasmatischen Seite der Plasmamembran und sind dort nicht-kovalent an den Rezeptor gebunden (Velazquez et al. 1992; Müller et al. 1993; Novick et al. 1994; Schindler und Darnell 1995, Darnell 1997). Diese JAKKinasen sind Mitglieder einer vierköpfigen Proteinfamilie, die sich aus den Kinasen JAK1, JAK2, JAK3 und TYK2 zusammensetzt. Allen gemeinsam ist, dass sie eine Pseudo-Kinase-Domäne und eine Kinase-Domäne besitzen, jedoch nicht mit $\mathrm{SH} 2$ - 
oder SH3-Domänen ausgestattet sind (Wilks et al. 1991; Darnell et al. 1994; Rane und Reddy 2000).

Beim IFN $\alpha / \beta$-vermittelten Signalweg erfolgt durch die Bindung des Liganden an den Rezeptor eine Homo- oder Heterodimerisierung des Rezeptors mit der Folge einer Kaskade von JAK-katalysierten Tyrosinphosphorylierungen. Diese bewirkt letztlich eine Heterodimerisierung von STAT1 und STAT2, die über eine Wechselwirkung des Phosphotyrosins des einen Monomers mit einem Argininrest in der SH2-Tasche des anderen Monomers die Dissoziation vom Rezeptor einleitet (Shuai et al. 1994; Greenlund et al. 1995; Becker et al. 1998; Chen et al. 1998). Danach bilden die tyrosinphosphorylierten STAT-Heterodimere einen trimeren Komplex mit p48 und werden daraufhin in den Nukleus transportiert. Der trimere Komplex aus den STATProteinen und dem p48 ist als IFN-stimulierter Genfaktor 3 (ISGF3) bekannt, der im Zellkern palindromische ISRE-Sequenzen (interferon-stimulated response element) erkennt und an sie bindet, wodurch die Transkription IFN $\alpha / \beta$-spezifischer Zielgene eingeleitet wird (Levy et al. 1988, 1989; Fu et al. 1990, 1992; Shuai et al. 1992; Darnell et al. 1994; Stark et al. 1998).

Die IFN $\gamma$-Stimulation hingegen löst eine Signalweiterleitung über die Ausbildung von STAT1/STAT1-Homodimeren aus. Nachdem IFN $\gamma$ an seinen spezifischen Rezeptor gebunden hat, werden die Rezeptor-assoziierten Janus-Kinasen JAK1 und JAK2 aktiviert, die die Auto- bzw. Transphosphorylierung durchführen (Müller et al. 1993; Watling et al. 1993; Darnell et al. 1994; Stark et al. 1998). Danach folgt die Phosphorylierung eines kritischen Tyrosinrestes in Position 440 des IFNGR1 durch die Janus-Kinasen. An diesen Tyrosinrest können nun STAT1-Proteine über ihre SH2-Domäne binden und ebenfalls phosphoryliert werden (Greenlund et al. 1993, 1994, 1995). Nach der Tyrosinphosphorylierung lösen sich die STAT-Moleküle vom Rezeptor und akkumulieren nun als Homodimere binnen weniger Minuten im Nukleus (Shuai et al. 1994; Stark und Darnell 2012). Im Zellkern erkennen die STAT1-Homodimere spezifische Gamma-aktivierte-Sequenzen (GAS) und führen so zur Transkription IFN $\gamma$-induzierter Zielgene (Darnell et al. 1994; Decker et al. 1991). Zusammenfassend ermöglicht also die Bindung des Liganden an seinen spezifischen Rezeptor und die damit verbundene Aktivierung des Rezeptor-Komplexes eine 
direkte Weitervermittlung des Signals in den Nukleus und löst dadurch eine Änderung der Genexpression in der stimulierten Zelle aus (Darnell et al. 1994).

Der Regulation dieses Signalweges, vor allem der Negativregulation, wird eine große Bedeutung zugeschrieben, da eine Fehlregulation oder anhaltende Aktivierung zu Krebs oder Immunerkrankungen führen kann. Die Inaktivierung kann sowohl durch zytoplasmatische als auch durch nukleäre Proteine erfolgen, die an unterschiedlichen Stellen des Signalweges eingreifen. Alle im Folgenden beschriebenen Negativ-Regulatoren bzw. Inhibitoren werden abhängig von der Stärke des Zytokinsignals von den STAT-Proteinen selbst induziert (Starr und Hilton 1999; Levy und Darnell 2002). Eine Gruppe solcher negativ-regulierender Proteine des Signalweges sind die zytoplasmatischen SOCS-Proteine (suppressor of cytokine signaling), bestehend aus den Mitgliedern SOCS1, SOCS7 sowie CIS (cytokine-inducible SH2-domaincontaining protein). SOCS1 und SOCS7 binden an die katalytische Region der JAKKinasen, wodurch ihre Autophosphorylierung gehemmt und folglich die Phosphorylierung der STAT-Proteine am konservierten Tyrosinrest verhindert werden kann. CIS kompetitiert hingegen mit dem STAT-Protein um die Bindungsregion am Rezeptor selbst und führt so zu dessen Inaktivierung (Starr und Hilton 1999; Rawlings et al. 2004). Eine weitere Kontrollfunktion der SOCS-Proteine umfasst die Degradierung von Signalproteinen (Krebs und Hilton 2001). Eine weitere Gruppe zytoplasmatischer Negativregulatoren sind die Phosphatasen SHP-1 und SHP-2 sowie PTP1B (Protein-Tyrosin-Phosphatase 1B), die entweder an die phosphorylierten Kinasen oder an den aktivierten Rezeptor binden und somit die Signalweiterleitung durch Dephosphorylierung inhibieren (Levy und Darnell 2002; Rawlings et al. 2004). Die STAT-Aktivierung kann jedoch auch im Nukleus inhibiert werden. Eine Möglichkeit zur Regulation der Zytokin-induzierten Genaktivierung im Nukleus sind die PIASProteine (protein inhibitors of activated STATS). PIAS1 interagiert hierbei mit STAT1, wohingegen PIAS3 als spezifischer Inhibitor von STAT3 identifiziert wurde (Chung et al. 1997; Liu et al. 1998, Starr und Hilton 1999). Durch die Interaktion von PIAS mit den STAT-Dimeren soll die für die Transkription wichtige DNA-Bindung erschwert sein (Rawlings et al. 2004). Phosphorylierte STAT-Moleküle können auch mithilfe von nukleären Phosphatasen wieder dephosphoryliert werden. Die Dephosphorylierung von STAT1-Dimeren geschieht hierbei mit mithilfe der nukleären Phosphatase TC45 (ten Hoeve et al. 2002; Levy und Darnell 2002; Simoncic et al. 2002). Eine 
Dephosphorylierung der im Zytoplasma befindlichen aktiven STAT-Proteine geschieht durch die Bindung der Phosphatase an phosphorylierte Kinasen bzw. an den aktivierten Rezeptor. Zu den Phosphatasen, die hauptsächlich für die Dephosphorylierung im Zytoplasma verantwortlich sind, gehören die PTP1B (protein tyrosine phosphatase 1B), SHP-1 (SH2-containing phosphatase 1) und SHP-2 (Levy und Darnell 2002; Rawlings et al. 2004). Des Weiteren wurde nachgewiesen, dass SHP-2 in den Zellkern transloziert und dort auch STAT1-Proteine dephosphorylieren kann (Wu et al. 2002). Inaktivierte bzw. dephosphorylierte STAT1-Moleküle werden aus dem Nukleus in das Zytoplasma zurück transportiert, wo in Abhängigkeit vom Rezeptorzustand ein erneuter Aktivierungszyklus beginnen kann. Zusätzlich wurde eine Zytokin-unabhängige fortwährende Translokation der STAT-Proteine zwischen Zellkern und Zytoplasma beschrieben (Meyer et al. 2004).

\section{Der Transport der STAT-Proteine zwischen Zytoplasma und Nukleus}

Die Liganden-vermittelte Dimerisierung des Rezeptors führt, wie oben bereits beschrieben, zum Auslösen einer Kaskade von Tyrosin-Phosphorylierungen, die die Rekrutierung der zytoplasmatischen STAT-Moleküle zum Rezeptor und deren nachfolgende Phosphorylierung zur Folge hat. Die auf diese Weise entstandenen phosphorylierten STAT-Dimere (Größe 180 kDa) müssen nun durch die Kern-membran in den Zellkern gelangen (Levy und Darnell 2002). Man nahm zunächst an, dass STAT-Proteine erst nach ihrer Aktivierung in den Zellkern gelangen, um die Transkription bestimmter Zielgene zu beeinflussen. Nach heutigem Kenntnisstand existiert jedoch ein nukleozytoplasmatischer Transport, welcher auch in Abwesenheit von Zytokinen unphosphorylierte STAT-Moleküle in den bzw. aus dem Zellkern transportiert (Meyer et al. 2004). Die Kernmembran besitzt zum Molekültransfer nukleäre Porenkomplexe (NPC), die als Filter für den Transport höhermolekularer Proteine fungieren (Mattaj und Englmeier 1998; Weis 1998). Da es sich bei den STAT-Molekülen um Makromoleküle handelt, die eine Größe von 40-60 kDa weit überschreiten, sind sie nicht dazu in der Lage, als phosphorylierte Dimere den NPC mittels freier Diffusion zu durchqueren, um in den Zellkern zu gelangen, sondern sind daher auf die Hilfe eines aktiven Transportmechanismus angewiesen (Paine und Feldherr 1972; Weis 1998). 
Die auf diese Weise transportierten Moleküle interagieren über Rezeptoren, die je nach Funktion als Importine (Importrezeptoren) oder Exportine (Exportrezeptoren) bezeichnet werden und in die Familie der Karyopherine gehören (Macara 2001; Rout et al. 2003). Importine benötigen für die Interaktion mit den Cargo-Proteinen eine spezielle Abfolge basischer Aminosäurereste, die sogenannte NLS-Sequenz (nukleäres Lokalisationssignal) (Weis 1998; Macara 2001; Körner et al. 2003; Fahrenkrog et al. 2004). In den letzten Jahren konnte man nachweisen, dass die DNA-Bindedomäne von STAT1, STAT2 und STAT3 ein konserviertes NLS besitzt, welches allerdings nicht einem klassischen NLS entspricht und nur im Dimer funktionsfähig ist (Melen et al. 2001; Fagerlund et al. 2002; McBride et al. 2002; Meyer et al. 2002). Weiterhin wurde anhand von Untersuchungen mit aminoterminalen Deletionsmutanten demonstriert, dass die Anwesenheit des Aminoterminus für die Kernakkumulation unabdingbar ist. Die betroffenen Mutanten zeigten nach Zytokin-Stimulation nicht die typische Kernakkumulation der STAT-Proteine, wie sie beim WT beobachtet wurde (Strehlow und Schindler 1998; Meyer und Vinkemeier 2004).

Man fand heraus, dass STAT1 im Zytoplasma als antiparalleles Dimer und als Monomer vorliegt, bei dem das NLS maskiert ist und erst durch TyrosinPhosphorylierung und reziproke SH2-Wechselwirkung der beiden STAT1-Monomere frei zugänglich wird (Zhong et al. 2005). Das bedeutet, dass Importine weder mit unphosphorylierten STAT-Dimeren noch mit STAT-Monomeren interagieren können, da das NLS nur in paralleler Konformation phosphorylierter Dimere funktional ist (Fagerlund et al. 2002; Melen et al. 2001; Meyer et al. 2002). Phospho-STAT1Dimere sind in der Lage, mithilfe ihrer frei zugänglichen NLS-Sequenz an Importin $\alpha 5$ zu binden (Sekimoto et al. 1997; Nardozzi et al. 2010). Dieses bildet mit Importin $\beta$ ein Cargo-Importin $\alpha / \beta$-Komplex, wobei Importin $\beta$ mit RanGTPase interagiert und den Durchtritt durch die Kernpore einleitet (Mattaj und EngImeier 1998; Weis 1998; Görlich und Kutay 1999). Die Interaktion mit der GTPase Ran ist deshalb notwendig, weil es sich hierbei um einen aktiven Transport handelt, wodurch die nötige Energie für den Transportprozess geliefert wird. Die Aktivität der GTPase wird hierbei durch einen Ran-GDP-/RanGTP-Gradienten gewährleistet. Durch die Funktion der GTPase herrscht im Zytoplasma ein Überschuss an Ran in Form von Ran-GDP, während im Zellkern die Ran-GTP-Form dominiert. Da Ran-GTP im Zyto- 
plasma durch RanBP-1 (Ran-binding protein) und RanGAP (Ran-GTPase-activating protein) hydrolysiert wird, ist die Konzentration von Ran-GTP deshalb im Zytosol niedriger als im Kern. Das im Zytosol befindliche Ran-GDP bindet an NTF-2 (nuclear transport factor) und bildet somit einen Dimer-Komplex, der alsdann in den Zellkern transportiert wird. Dort bindet Ran-GDP an RanGEF (guanine nucleotide exchange factor), der für die Synthese des Ran-GTP zuständig ist und zudem zu der hohen Ran-GTP Konzentration im Zellkern beiträgt (Görlich und Kutay 1999; Kalab et al. 2002). Ran-GTP wiederum ist für die Bindung des Cargo-Proteins an Exportin und für die Auflösung des Importin-Cargo-Komplexes verantwortlich (Weis 1998). Mit steigender Konzentration des Ran-GTP im Zellkern zerfällt der Importin-Cargo-Komplex und die ungeladenen Importine können nun wieder durch die Kernporen in das Zytoplasma gelangen (Mattaj und EngImeier 1998; Meyer und Vinkemeier 2004; Ribbeck und Görlich 2001; Weis 1998). In der gleichen Zeit werden, bedingt durch die hohe Ran-GTP-Konzentration, Exportine wie das CRM1 (chromosome region maintenance 1) mit ihren Cargo-Molekülen beladen und schleusen diese durch die Kernporen ins Zytosol zurück.

Auch beim Export der STAT1-Proteine aus dem Nukleus spielt eine spezifische Sequenz eine Rolle, die sich beim STAT1-Molekül in der Coiled-coil-Domäne befindet und als nukleäres Exportsignal (NES) bezeichnet wird (Begitt et al. 2000; Meyer und Vinkemeier 2004). Nach heutigem Kenntnisstand weiß man, dass nur unphosphorylierte STAT-Proteine den Kern verlassen können (Meyer et al. 2003, 2004). Somit hängt die Dauer der Kernakkumulation maßgeblich von der Dephosphorylierungskinetik der Proteine und somit von der Beteiligung bzw. Aktivität nukleärer Tyrosin-Phosphatasen ab (Haspel et al. 1996; Haspel und Darnell 1999; Meyer et al. 2003). Solange die Dimere an DNA gebunden vorliegen, sind sie vor Dephosphorylierung geschützt. Nur im ungebunden Zustand werden sie von der Phosphatase erkannt und dephosphoryliert (Meyer et al. 2003). Allerdings konnte man durch die Hemmung sämtlicher energieabhängiger Transportmechanismen der Zelle bzw. durch die Inhibition von CRM1 mit Leptomycin B keinen vollständigen Export-Stopp der STAT1-Moleküle beobachten. Diese Tatsache lässt darauf schließen, dass weitere energieunabhängige Transportwege existieren, mit deren Hilfe dephosphorylierte STAT-Proteine die Kernmembran überwinden können (Begitt et al. 2000; Marg et al. 2004). 
Ziel der vorliegenden Dissertation war es, mit Hilfe von eigens generierten STAT1Mutanten die Rolle der SH2-Domäne im Interferon-abhängigen JAK-STAT-Signalweg besser zu verstehen. Bei der Charakterisierung dieser Mutanten diente die Menge der IFN $\gamma$-induzierten Tyrosin-Phosphorylierung dieser Mutanten im Vergleich zum Wildtyp-Molekül als Referenz für phänotypische Unterschiede. Ausgehend von diesen Punktmutanten erwies sich die Suche nach molekularen und strukturellen Unterschieden zum Wildtyp-Molekül als hilfreich für ein vertieftes Verständnis der physiologischen Bedeutung der SH2-Domäne von STAT1.

\section{Material und Methoden}

\subsection{Materialien}

\subsubsection{Humane Zelllinien}

Bei den in dieser Arbeit verwendeten Zellen handelt es sich um eine Epithelzelllinie eines Zervix-Karzinoms, die als HeLa-S3 bezeichnet wird. Zudem kamen U3A-Zellen zum Einsatz, bei denen es sich um eine STAT1-defiziente Zelllinie handelt, die aus der Fibrosarkom-Zelllinie 2fTGH entstanden ist. Beide Zelllinien wurden von Prof. Dr. Uwe Vinkemeier (University of Nottingham, UK) zur Verfügung gestellt.

\subsubsection{Liste der Chemikalien}

\begin{tabular}{l|l}
\hline Agar & Carl Roth, Karlsruhe \\
\hline Ammoniumperoxodisulfat (APS) & Carl Roth \\
\hline Ampicillin & Sigma Aldrich, Taufkirchen \\
\hline Borsäure & $\begin{array}{l}\text { Amersham Pharmacia } \\
\text { Biotech, Freiburg }\end{array}$ \\
\hline Bromphenol-Blau & Sigma Aldrich \\
\hline Dimethylsulfoxid (DMSO) & Carl Roth \\
\hline Dithiothreitol (DTT) & AppliChem, Darmstadt \\
\hline Ethanol & Carl Roth \\
\hline Ethylendiamin-N,N,N',N'-Tetraessigsäure (EDTA) & Acros Organics, Geel, \\
& Belgien \\
\hline Ethylendioxy-bis-(Ethylennitrilo)-Tetraessigsäure & Carl Roth \\
(EGTA) & \\
\hline
\end{tabular}




\begin{tabular}{|c|c|}
\hline Ficoll-Paque Plus & $\begin{array}{l}\text { Amersham Bioscience, } \\
\text { Freiburg }\end{array}$ \\
\hline Formaldehyd $37 \%$ in $\mathrm{H}_{2} \mathrm{O}$ & Sigma Aldrich \\
\hline Glucose & Carl Roth \\
\hline Glycin & Carl Roth \\
\hline Glycerin & Carl Roth \\
\hline Glycylglycin & Sigma Aldrich \\
\hline $\begin{array}{l}\text { N-(2-Hydroxyethyl)-1-Piperazino-Ethansulfonsäure } \\
\text { (Hepes) }\end{array}$ & Carl Roth \\
\hline Hefeextrakt & Carl Roth \\
\hline IGEPAL-CA-360 & Sigma Aldrich \\
\hline Kaliumchlorid & Carl Roth \\
\hline Kaliumdihydrogenphosphat & Merck \\
\hline Kaliumhydroxid & Carl Roth \\
\hline Kanamycin & Sigma Aldrich \\
\hline Magnesiumchlorid-6-Hydrat & Sigma Aldrich \\
\hline Magnesiumsulfat & Carl Roth \\
\hline$\beta$-Mercaptoethanol & Sigma Aldrich \\
\hline Methanol & Carl Roth \\
\hline Natriumcarbonat & Carl Roth \\
\hline Natriumchlorid & Sigma Aldrich \\
\hline Natriumhydrogenphosphat & Merck \\
\hline Natriumlaurylsulfat (SDS) & Carl Roth \\
\hline Natrium-ortho-Vanadat & Sigma Aldrich \\
\hline ortho-Nitrophenyl- $\beta$-D-Galactopyranosid (ONPG) & Sigma Aldrich \\
\hline Pefabloc & Carl Roth \\
\hline 2-Propanol & Carl Roth \\
\hline Rinder-Serumalbumin (BSA) & Carl Roth \\
\hline Rotiphorese-Gel & Carl Roth \\
\hline Salzsäure & Carl Roth \\
\hline Staurosporin & Sigma Aldrich \\
\hline $\mathrm{N}, \mathrm{N}, \mathrm{N}^{*}, \mathrm{~N}^{*},-$ Tetramethylethylendiamin (TEMED) & Carl Roth \\
\hline Tris-Hydrochlorid (Tris-HCl) & Carl Roth \\
\hline
\end{tabular}




\begin{tabular}{l|l}
\hline Tris-(Hydroxymethyl)-Aminomethan (Tris-Base) & Carl Roth \\
\hline Triton X-100 & Sigma Aldrich \\
\hline Trypton & Carl Roth \\
\hline Tween-20 & Sigma Aldrich \\
\hline Wasserstoffperoxid $\left(\mathrm{H}_{2} \mathrm{O}_{2}\right)$ & Carl Roth \\
\hline
\end{tabular}

\subsubsection{Medien, Puffer und Lösungen}

Für die Herstellung von Medien, Puffern und Lösungen wurde entionisiertes Wasser aus der Millipore-Anlage PURELAB Plus (ELGA, Celle) verwendet, welches einen Molekülfilter mit der Porengröße 0,22 $\mu \mathrm{m}$ besaß. Falls möglich erfolgte zum einen die Filtration der Lösungen unter sterilen Umständen, zum anderen eine Einstellung der pH-Wert-Messung mit einem pH-Meter (Sartorius, Göttingen).

\subsubsection{Radiochemikalien}

Die Firma Hartmann Analytic (Braunschweig) stellte $\alpha-\left[{ }^{33} \mathrm{P}\right]$-markierte Desoxynukleotide (ATP) zur Verfügung, die eine spezifische Aktivität von $111 \mathrm{TBq} / \mathrm{mmol}$ aufwiesen und vor Ablauf ihrer Halbwertszeit zum Einsatz kamen.

\subsubsection{Antikörper und Reaktionskits}

\section{Antikörper}

\begin{tabular}{l|l}
\hline STAT1 $\alpha-p 91$ (C-24) & $\begin{array}{l}\text { Santa Cruz Biotechnology, Santa Cruz, } \\
\text { CA, USA }\end{array}$ \\
\hline Phospho-STAT1 (Tyr 701) & Cell Signaling, Danvers, Ma, USA \\
\hline STAT3 (H-190) & Santa Cruz Biotechnology \\
\hline IRDye 800CW Anti-Kaninchen-IgG & $\begin{array}{l}\text { LI-COR Biosciences, Bad Homburg, } \\
\text { Deutschland }\end{array}$ \\
\hline
\end{tabular}

Bei Western-Blot-Experimenten fanden die polyklonalen Antikörper STAT1 $\alpha$-p91 (C24) und Phospho-STAT1 (Tyr 701) in Form von Primärantikörpern Verwendung. Für den Gebrauch erfolgte ihre Verdünnung (1:1000) in 4\% BSA in TBS-T (137 mM $\mathrm{NaCl}, 10 \mathrm{mM}$ Tris- $\mathrm{HCl}, 0,05 \%)$. Das polyklonale IRDye 800CW Anti-Kaninchen-IgG aus Ziege wurde in diesen Experimenten jeweils als Sekundärantikörper in einer Verdünnung von 1:10.000, ebenfalls in $4 \%$ BSA in TBS-T, verwendet. Zudem kamen 
die STAT1 $\alpha$-p91- (C-24) und STAT3-Antikorper (H190) auch in Rahmen von EMSA Experimenten bei Supershift-Reaktionen zum Einsatz, dort jedoch mit einer Verdünnung von 1:10 in PBS (Gibco, Karlsruhe).

\section{Reaktionskits}

\begin{tabular}{l|l}
\hline $\begin{array}{l}\text { Absolute-Blue-QPCR-SYBR-Green } \\
\text { Mix }\end{array}$ & Thermo Scientific, Dreieich \\
\hline Luciferase-Assay-System & Promega, Mannheim \\
\hline peqGold Plasmid Miniprep Kit I & PEQLAB Biotechnologie, Erlangen \\
\hline peqGold Total RNA Kit & PEQLAB Biotechnologie \\
\hline QIAGEN Plasmid Maxi Kit & QIAGEN, Hilden \\
\hline $\begin{array}{l}\text { QuikChange II Site-Directed } \\
\text { Mutagenesis Kit }\end{array}$ & Stratagene, La Jolla, USA \\
\hline Verso cDNA Kit & Thermo Scientific \\
\hline
\end{tabular}

\subsubsection{Zytokine}

Die Stimulation der Zellen erfolgte alleinig mit humanem Interferon-y (IFNy) der Firma Biomol (Hamburg). Die Verdünnung des IFNy erfolgte, wenn nicht anders angegeben, 1:2000 im jeweiligen Zellmedium, um danach direkt auf die Zellen pipettiert zu werden.

\subsubsection{Enzyme}

In dieser Arbeit wurden der Complete Mini Protease Inhibitor (Roche, Grenzach) im Rahmen der Herstellung von Gesamtzellextrakten und beim Reportergen-Assay bzw. Dephosphorylierungs-Assay zur Herstellung bestimmter Pufferlösungen verwendet.

Die Dpnl-Endonuklease ist ein aus einem E. coli-Stamm hergestelltes Restriktionsenzym, welches vom dpnl-Gen des Diplococcus pneumoniae G41 exprimiert wird. Dieses Enzym wurde von New England Biolabs (Schwalbach) bezogen und für Mutagenese-Experimente verwendet.

Die DNA-Polymerase I, auch Klenow-Enzym genannt, ist das größere der beiden Proteinfragmente der DNA-Polymerase I aus Escherichia coli. Sie entsteht nach enzymatischer Spaltung mit Subtilisin und verfügt noch über die $5^{\prime} \rightarrow 3^{\prime}$ PolymeraseAktivität und $3^{\prime} \rightarrow 5^{\prime}$ Exonuklease-Aktivität (proof reading). Allerdings besitzt sie nicht 
mehr die 5' $\rightarrow$ 3' Exonuklease-Aktivität. Für diese Arbeit wurde sie von New England Biolabs bezogen und zur Markierung von doppelsträngigen DNA-Sonden verwendet.

PfuTurbo-DNA-Polymerase ist die verbesserte Version der Pfu-DNA-Polymerase. Sie diente in dieser Arbeit der Amplifikation der DNA und wurde von der Firma Stratagene bezogen. TC-PTP, auch bekannt als PTPN2 (Protein-Tyrosin-Phosphatase N2), ist ein Enzym mit einer katalytischen Domäne und N-terminaler GST-Markierung. Für diese Arbeit wurde sie von der Firma Biomol International (Plymouth, USA) bezogen.

Bei Trypsin handelt es sich um eine Serinprotease, die zu den Endopeptidasen gehört und Proteine an bestimmten Stellen spalten kann. Da sie ein pH-WertOptimum von 7-8 besitzt, ist ihre Leistung bei basischen Bedingungen am effektivsten. In dieser Arbeit wurde sie zur Lösung adhärenter Zellen vom Boden der Kulturschalen benutzt und von PAA (Pasching, Österreich) bezogen.

\subsubsection{Plasmide}

Bei dem Plasmid pEGFP-N1 handelt es sich um einen 4,7 kb langen, optimierten Vektor mit verbesserten Fluoreszenzeigenschaften, der in seiner Multi-Cloning-Site eine Neomycinresistenz-Kassette besitzt. Die humane STAT1-DNA wurde in die Multi-Cloning-Site inseriert. Das pSTAT1 $\alpha$-GFP-Konstrukt wurde bei Begitt et al. (2000) beschrieben und diente der Expression von N-terminalen GFP-Fusionsplasmiden von STAT1 in Säugerzellen. Der Vektor enthält eine SV40-Polyadenylierungssequenz für das Fusionsgen sowie eine Polyadenylierungssequenz aus dem Thymidinkinase-Gen des Herpes-Simplex-Virus für das Neomycin-Gen. Der Vektor wurde von der Firma Clontech (Mountain View, USA) bezogen.

Die beiden Plasmide pSTAT1 $\alpha($ E524A)-GFP und pSTAT1 $\alpha($ E585A)-GFP wurden im Rahmen dieser Arbeit sequenzspezifisch mutiert. Zum Einfügen der Mutation wurde für das Konstrukt pSTAT1 $\alpha(E 524 A)-G F P$ das Primerpaar E425AF/E425AR und für pSTAT1 $\alpha(K 585 A)$-GFP das Paar K585AF/K585AR verwendet. Sämtliche Primer wurden von Sigma zur Verfügung gestellt.

Bei dem Plasmid pcDNA3.1 handelt es sich um einen 5,4 kb langen eukaryontischen Expressionsvektor, der eine Ampicilinresistenz-Kassette besitzt. Die humane STAT1$\alpha$-cDNA wurde in pcDNA3.1 kloniert (Dr. James E. Darnell, New York, USA). In 
dieser Arbeit wird die Bezeichnung pSTAT1 $\alpha$-GFP durch die die oben erwähnte Bezeichnung pSTAT1-GFP ersetzt, da im Rahmen dieses Projekts nur die für STAT1 $\alpha$ kodierenden Plasmide untersucht werden. Im Weiteren wird die Bezeichnung pSTAT1 als Abkürzung für pcDNA3.1-STAT1 $\alpha$-Plasmide benutzt.

Die beiden Plasmide pcDNA3.1-STAT1 $\alpha$ (E524A) und pcDNA3.1-STAT1 $\alpha$ (E585A) wurden im Rahmen dieser Arbeit sequenzspezifisch mutiert. Zum Einfügen der Mutation wurde bei pcDNA3.1-STAT1 $\alpha(E 524 A)$ das Primerpaar E524AF/E524AR und pcDNA3.1-STAT1 $\alpha($ E585A) das Primerpaar E5855AF/E585AR verwendet. Beide Primerpaare wurden von Sigma zur Verfügung gestellt.

Beim $p \beta G$ al-Plasmid handelt es sich um einen 7,4 kb langen Expressionsvektor der B-Galactosidase, der im Rahmen von Reportergen-Assays zum Einsatz kam. Die in dieser Arbeit verwendeten Plasmide wurden von Stratagene (La Jolla, USA) bezogen.

Die Plasmide pGAS3xLy6E und pIC-339 sind Reportergen-Konstrukte. Das Konstrukt pGAS3xLy6E besitzt drei GAS-Bindestellen und wurde von Wen et al. (1995) beschrieben; pIC339 dagegen beinhaltet einen trunkierten Promotor des humanen ICAM-1-Gens und wurde von Prof. Dr. P. T. van der Saag (Utrecht, Niederlande) beschrieben.

\subsubsection{Oligonukleotide}

Primer für die sequenzspezifische Mutagenese

\begin{tabular}{|c|c|}
\hline E524A F & $5^{6}$-ctgaacatgttgggagcgaagcttcttggtcctaacgcc-3' \\
\hline E524A R & $5^{6}$-ggcgttaggaccaagaagcttcgctcccaacatgttcag-3' \\
\hline E585A F & $5^{\prime}$-gggcttcatcagcaaggcgcgagagcgtgccctgttg-3 \\
\hline K585A R & 5'-caacagggcacgctctcgcgccttgctgatgaagccc-3" \\
\hline
\end{tabular}

\section{Primer für die Sequenzierung}

\begin{tabular}{l|l}
\hline $484 \mathrm{f}$ & $5^{\prime}$-ccttcttcctgactccacca-3' \\
\hline $611 \mathrm{R}$ & $5^{\prime}$-ctccacccatgtgaatgtga-3' \\
\hline
\end{tabular}


Oligonukleotid-Sonden für den elektrophoretischen Mobilitätsshift-Assay

\begin{tabular}{l|l}
\hline M67 F & $5^{\prime}$-tttcgacatttcccgtaaatctg-3' \\
\hline M67 R & 5'-tttcagatttacgggaaatgtcg-3' $^{\prime}$ \\
\hline GASnonGAS F & 5'-tttcgtttccccgaaattgacggatttaccccaac-3' \\
\hline GASnonGAS R & $5^{\prime}$-ttttgttggggtaaatccgtcaatttcggggaaacg-3' \\
\hline 2xGAS F & $5^{\prime}$-tttttgtttccccgaaattgacggatttccccgaaac-3' \\
\hline 2xGAS R & 5'-ttttgtttcggggaaatccgtcaatttcggggaaac-3' \\
\hline 2xnonGAS F & 5'-tttcgtttaccccaaattgacggatttacccaac-3' \\
\hline 2xnonGAS R & 5'-tttgttggggtaaatccgtcaatttggggtaaacg-3' \\
\hline
\end{tabular}

Primer für die RT-PCR

\begin{tabular}{l|l}
\hline hGAPDH F & 5'-gaaggtgaaggtcggagtc-3' \\
\hline hGAPDH R & 5'-gaagatggtgatgggatttc-3‘ \\
\hline hIRF1 F & 5'-agctcagctgtgcgagtgta-3' \\
\hline hIRF1 R & 5'-tagctgctgtggtcatcagg-3' \\
\hline hGBP1 F & 5'-ggtccagttgctgaaagagc-3' \\
\hline hGBP1 R & 5'-tgacaggaaggctctggtct-3' \\
\hline hMIG1 F & 5'-ccaccgagatccttatcgaa-3' \\
\hline hMIG1 R & 5'-ctaaccgacttggctgcttc-3' \\
\hline hSTAT1 F & 5'-ccgtttcatgacctcctgt-3' \\
\hline hSTAT1 R & 5'-tgaatattccccgactgagc-3'
\end{tabular}

Alle aufgeführten Oligonukleotide wurden von der Firma Sigma Aldrich (Taufkirchen) bezogen.

\subsubsection{Bakterienstämme und Medien}

Bei den Bakterienstämmen, die in dieser Arbeit verwendet wurden, handelt es sich um E.coli DH5a und E.coli XL1-Blue. Beide wurden von Stratagene (La Jolla, USA) bezogen. Je nach Art des Plasmids waren für die Entstehung von Bakterienkolonien verschiedene LB-Agarplatten, LB-Flüssigmedium oder SOC-Medium notwendig. Die LB-Agarplatten setzten sich aus 1\% Trypton, $0,5 \%$ Hefeextrakt, $1 \% \mathrm{NaCl}$ und 1,5\% Agar zusammen, während das LB-Flüssigmedium aus 1\% Trypton, 0,5\% Hefeextrakt und $1 \% \mathrm{NaCl}$ zusammengesetzt war. Bei beiden erfolgte unter Zugabe von $\mathrm{NaOH}$ die Einstellung des pH-Wertes von 7. Danach erfolgte eine 30-minütige Autokla- 
vierung bei $121^{\circ} \mathrm{C}$ und 1,5 bar und anschließend je nach verwendeter Plasmid-DNA die Zugabe des Antibiotikums Kanamycin (50 mg/mL) oder Ampicillin (100 mg/mL) als Selektionsmarker. SOC-Medium, welches für die Transformation eingesetzt wurde, setzte sich aus folgenden Komponenten zusammen: 2\% Trypton, 0,5\% Hefeextrakt, $10 \mathrm{mM} \mathrm{NaCl}, 2,5 \mathrm{mM} \mathrm{KCl}, 10 \mathrm{mM} \mathrm{MgCl}_{2}, 10 \mathrm{mM} \mathrm{MgSO}_{4}, \mathrm{pH}$ 7,4. Dieses wurde nach einer 20 -minütigen Autoklavierung bei $121^{\circ} \mathrm{C}$ mit $20 \mathrm{mM}$ steril gefilterter Glucose supplementiert.

\begin{tabular}{|c|c|}
\hline \multirow[t]{2}{*}{ E.coli DH5a } & Stratagene, La Jolla, USA \\
\hline & 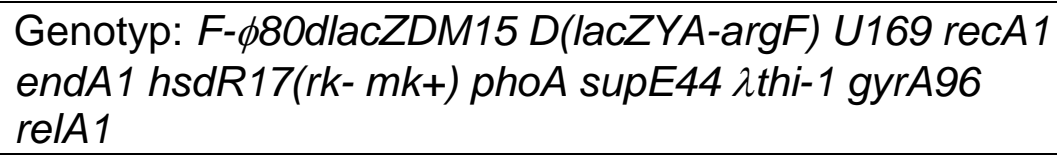 \\
\hline \multirow[t]{2}{*}{ E.coli XL1-Blue } & Stratagene \\
\hline & $\begin{array}{l}\text { Genotyp: recA1 endA1 gyrA96 thi-1 hsdR17 supE44 } \\
\text { relA1 lac [F'proAB } \lambda \alpha \chi I^{\theta} Z \Delta M 15 \text { Tn10 (Tet')] }\end{array}$ \\
\hline
\end{tabular}

\subsubsection{Geräte und Verbrauchsmaterialien}

In dieser Arbeit werden die Hersteller der verwendeten Geräte mit den jeweiligen Herstellerangaben in den betreffenden Kapiteln bzw. bei der Beschreibung der einzelnen Methoden angegeben. Falls nicht anders beschrieben, sind diese auf die folgenden Firmen zurückzuführen: B. Braun AG (Melsungen), Biometra (Gottingen), Carl Roth (Karlsruhe), Eppendorf (Hamburg), Greiner Bio-One (Frickenhausen), Nunc (Roskilde, Dänemark), PEQLAP (Erlangen), Sarstedt (Nümbrecht), ThermoFisher (Dreieich) und VWR (Darmstadt).

\subsection{Methoden}

\subsubsection{Zellkulturmethoden}

\section{Kultivierung der Säugerzellen}

Ausschließlich HeLa-S3- und U3A-Zellen kamen in den folgenden Experimenten zum Einsatz. Alle Arbeitsvorgänge erfolgten unter streng aseptischen Bedingungen und unter mikrobiologischen Sicherheitswerkbänken (Herasafe K2, Thermo Scientific, Dreieich). In einem Brutschrank (Heraeus, Thermo Scientific) mit einer Wasserdampf-gesättigten, $5 \%$ igen $\mathrm{CO}_{2}$-Atmosphäre und einer Temperatur von $37^{\circ} \mathrm{C}$ fand die Zellkultivierung in $75 \mathrm{~cm}^{2}$-Zellkulturflaschen (Greiner Bio-One, Frickenhausen) statt. Als Vollmedium für die U3A-Zellen kam Dulbecco's modifiziertes Eagle-Medium 
(DMEM, Biochrom, Berlin) zum Einsatz, welches mit 10\% fetalem Kälberserum (FCS) (Biochrom), 1\% Penicillin/Streptomycin (PAA, Pasching, Österreich) und 0,04 $\mu \mathrm{g} / \mathrm{mL}$ Puromycin (Sigma Aldrich, Taufkirchen) supplementiert wurde. Für die Kultivierung von HeLa-S3-Zellen wurde Quantum 101 HeLa-Medium (PAA) mit 1 $\%$ Penicillin/Streptomycin (PAA) verwendet.

\section{Passagierung der Zellen}

Für die Erhaltungskultur erfolgte die Passagierung der konfluenten Zellen alle 2-3 Tage. Die Zellen wurden einmalig mit Dulbecco's Phosphat-gepufferter Salzlösung (DPBS, Gibco, Karlsruhe) ohne $\mathrm{Ca}^{2+}$ und $\mathrm{Mg}^{2+}$ gewaschen und anschließend mit einer Trypsin/EDTA-Lösung (0,05\% Trypsin, 0,2 g/L EDTA, von Biochrom) vom Boden der Zellkulturflasche gelöst. Nach kurzer Inkubation bei $37^{\circ} \mathrm{C}$ im Brutschrank wurde die Trypsinreaktion durch die Zugabe von serumhaltigem Vollmedium gestoppt. Um die Zellkultur weiterführen zu können, fand die Ausplattierung in einem Verdünnungsverhältnis von 1:4 bis 1:6 statt.

\section{Einfrieren der Zellen}

Die Zellen wurden bei einer 70-prozentigen Konfluenz eingefroren. Hierbei erfolgte zunächst die Waschung der adhärenten Zellen mit DPBS, danach die Trypsinierung und anschließend ihre Aufnahme in PBS. Später wurden die Zellen bei $20^{\circ} \mathrm{C}$ und 1000 rpm für 10 min zentrifugiert (Centrifuge 5415 R, Eppendorf). Zu dem daraus entstandenem Pellet der $75 \mathrm{~cm}^{2}$-Zellkulturflasche wurden $1 \mathrm{ml}$ Einfriermedium $(20 \%$ FCS, 10\% Dimethylsulfoxid in DMEM) zugegeben. Diese Zellresuspension wurde bei $-80^{\circ} \mathrm{C}$ über Nacht in einem Gefrierkontainer eingefroren (Nalgene, Heidelberg), der mit Isopropanol (Carl Roth) gefüllt war. Da zum einen die Temperatur im Gefrierkontainer stündlich nur sehr langsam (um ca. $1-3^{\circ} \mathrm{C}$ ) gesenkt und zum anderen DMSO verwendet wurde, konnte die Bildung von intrazellularen Eiskristallen verhindert werden. Auch die weitere Lagerung fand bei $-80^{\circ} \mathrm{C}$ satt.

\section{Zellauftau}

Zum Wiederauftauen wurden die bei $-80^{\circ} \mathrm{C}$ eingefrorenen Zellen in ein Wasserbad mit einer Temperatur von $37^{\circ} \mathrm{C}$ gelagert. Daran anschließend fand eine Resuspension dieser Zellen in ihrem passenden Vollmedium statt. Nachdem sie dann für 5 min und bei $1000 \mathrm{rpm}$ und $20^{\circ} \mathrm{C}$ zentrifugiert wurden, konnte der Überstand ver- 
worfen werden. Das Pellet wurde daraufhin erneut in das jeweilige Vollmedium resuspendiert und konnte in Kultur genommen werden.

\subsubsection{Transfektion der Säugerzellen}

Bei den Experimenten dieser Arbeit erfolgte die Transfektion der humanen Zellen mit Plasmid-DNA unter Gebrauch des Transfektionsreagenzes MegaTran1.0 (Origen, Rockville, USA). Bei der Transfektion wurden die Herstellerangaben eingehalten, wobei man für eine 6-Lochplatte je Loch 1,6 $\mu$ g Plasmid-DNA, bei einer 48-Lochplatte je Loch 0,25 $\mu \mathrm{g}$ DNA und bei einem 8-Kammer-Objektträger je Kammer 0,1 $\mu \mathrm{g}$ Plasmid-DNA verwendete. Die Transfektion erfolgte in folgender Reihenfolge: zunächst verdünnte man die DNA in einer 150 mM NaCl-Lösung. Danach wurde sie mit dem Transfektionsreagenz MegaTran 1.0 komplementiert und das Gemisch für 10 sec gevortext. Der Ansatz wurde für $10 \mathrm{~min}$ bei Raumtemperatur inkubiert und danach direkt zu dem Vollmedium, in welchem sich die Zellen befanden, hinzugegeben. Etwa 16-20 h nach erfolgter Transfektion wurden die STAT1-exprimierenden Zellen weiter verarbeitet.

\subsubsection{Behandlung der Zellen mit Inhibitoren und Zytokinen}

Zytokine und Inhibitoren wurden in den Experimenten immer in einem, den jeweiligen Zellen entsprechendem Vollmedium verdünnt und danach in der benötigten Menge auf die Zellen, die sich ebenfalls im Vollmedium befanden, hinzugegeben. Für die Stimulation kam $10 \mathrm{ng} / \mathrm{mL}$ humanes, rekombinantes IFN $\gamma$ (Biomol) zum Einsatz und die Kinase-Inhibition erfolgte mit $1 \mu \mathrm{M}$ Staurosporin (Sigma Aldrich).

\subsubsection{Mutagenese}

Das Einfügen von Punktmutationen in STAT1-kodierenden Plasmiden geschah nach Herstellerangaben mit dem QuikChange II Site-Directed Mutagenesis Kit. Der Ansatz für die PCR setzte sich aus je 125 ng komplementäre Primer, $5 \mu \mathrm{L}$ 10x Reaktionspuffer, $50 \mathrm{ng}$ Matrizen-DNA, 5 Einheiten PfuTurbo-DNA-Polymerase sowie $1 \mu \mathrm{L}$ dNTP-Mix zusammen. Zusätzlich erfolgte die Zugabe von $\mathrm{H}_{2} \mathrm{O}$ zum Ansatz, um diesen auf $50 \mu \mathrm{L}$ aufzufüllen. Nach einer initialen Denaturierungsphase von $30 \mathrm{sec}$ bei $95^{\circ} \mathrm{C}$ erfolgten weitere 16 Zyklen, die aus einer Denaturierung für $30 \mathrm{sec}$ bei $95^{\circ} \mathrm{C}$, einem Annealing-Schritt für $1 \mathrm{~min}$ bei $55^{\circ} \mathrm{C}$ und der Elongation für $14 \mathrm{~min}$ bei $68^{\circ} \mathrm{C}$ bestanden. Der PCR folgte ein Dpnl-Verdau bei $37^{\circ} \mathrm{C}$ für eine Stunde. Hierfür 
wurden zum PCR-Amplifikat 10 Einheiten Dpnl-Restriktionsenzym hinzugegeben und der Ansatz auf einen pH-Wert von 10 eingestellt. Der Verdau diente der Entfernung der parentalen, methylierten DNA-Matrize.

\subsubsection{Transformation von Plasmid-DNA}

Die Transformation der Plasmid-DNA in kompetente E. coli DH5a-Bakterien bzw. in superkompetente XL1-Blue E. coli-Bakterien basierte auf der Hitzeschock-Methode (Cohen et al. 1972), indem $100 \mu \mathrm{L}$ der DH5a- bzw. $50 \mu \mathrm{L}$ der XL1-Blue-Bakterien auf Eis aufgetaut und mit $10 \mathrm{ng}$ Plasmid-DNA (entsprach $1 \mu \mathrm{L}$ des Mutageneseproduktes) versetzt wurden. Anschließend erfolgte für $30 \mathrm{~min}$ ihre Inkubation auf Eis, gefolgt von einem Hitzeschock im Wasserbad bei $42^{\circ} \mathrm{C}$ für jeweils $30 \mathrm{sec}(\mathrm{DH} 5 \mathrm{\alpha}-$ Bakterien) bzw. $45 \mathrm{sec}$ (XL1-blue-Bakterien). Anschließend fand eine erneute Inkubation der Zellen für 2 min auf Eis statt, um diese nachfolgend in 500-1000 $\mu \mathrm{L}$ vorgewärmtes SOC-Medium aufzunehmen. Nachdem dieser Ansatz bei $225 \mathrm{rpm}$ und $37^{\circ} \mathrm{C}$ für $1 \mathrm{~h}$ inkubiert wurde, wurden ihm $250 \mu \mathrm{L}$ der Bakterienkultur entnommen und auf LB-Agarplatten mit dem entsprechenden Selektionsmarker (Kanamycin bzw. Ampicilin) ausgestrichen. Die Lagerung dieser Agarplatten fand anschließend bei $37^{\circ} \mathrm{C}$ über Nacht im Schüttler statt.

\subsubsection{Plasmid-DNA-Gewinnung aus Bakterien}

Um eine analytische Präparation der Plasmid-DNA durchführen zu können, wurde eine einzelne transformierte Bakterienkolonie gepickt und in $2 \mathrm{ml}$ LB-Medium mit entsprechendem Selektionsmarker aufgenommen. Diese gepickte Kolonie wurde über Nacht bei $225 \mathrm{rpm}$ und $37^{\circ} \mathrm{C}$ inkubiert. Anschließend erfolgte die Zentrifugation des gesamten Inhaltes in einem $2 \mathrm{ml}$-Reaktionsgefäß für $5 \mathrm{~min}$ bei $13.000 \mathrm{rpm}$ und Raumtemperatur. Die Sequenzierung der mutierten Plasmid-DNA aus dem Zellpellet erfolgte mithilfe des QIAGEN Plasmid Mini-Kits (Qiagen, Hilden) nach Herstellerangaben. Für die Isolation großer Mengen reiner Plasmid-DNA wurde ein präparativer Ansatz verwendet, indem 150 mL LB-Medium mit entsprechendem Antibiotikum versetzt und mit einer einzelnen transformierten Bakterienkolonie angeimpft wurden. Auch hier wurde über Nacht bei $225 \mathrm{rpm}$ und $37^{\circ} \mathrm{C}$ inkubiert. Nachfolgend wurde die Bakteriensuspension für 15 min bei $6000 \mathrm{~g}$ und RT zentrifugiert und die PlasmidDNA mithilfe des QIAGEN Plasmid Maxi-Kits (Qiagen) isoliert. Schließlich fanden eine Eluierung der isolierten DNA mit $\mathrm{H}_{2} \mathrm{O}$, eine Konzentrationsbestimmung der DNA 
und eine Verdünnung mit $\mathrm{H}_{2} \mathrm{O}$ auf $1 \mu \mathrm{g} / \mu \mathrm{L}$ statt. Die verdünnte DNA wurde stets bei $20^{\circ} \mathrm{C}$ gelagert.

\subsubsection{Konzentrationsbestimmung isolierter Plasmid-DNA}

Die photometrische Konzentrationsbestimmung der DNA fand in einer $70 \mu \mathrm{L}-\mathrm{UV}$ Küvette (Brand, Wertheim) unter Zuhilfenahme des Photometers BioPhotometer Plus (Eppendorf) bei einer Wellenlange von $\lambda=260 \mathrm{~nm}$ statt. Zur Berechnung der Konzentration wurde die folgende Formel verwendet:

DNA-Konzentration $[\mu \mathrm{g} / \mathrm{mL}]=\mathrm{A}_{260} \times 50 \times$ Verdünnungsfaktor

Eine Verunreinigung der Probe konnte durch die Messung der Absorption bei $\lambda=280$ $\mathrm{nm}$ und durch die Bildung des Quotienten $\mathrm{A}_{260} / \mathrm{A}_{280}$ nachgewiesen bzw. ausgeschlossen werden. Bei einem Wert von 1,8 lag keine Verunreinigung vor.

\subsubsection{Sequenzierung}

Da die Sequenzierung der Plasmid-DNA essentiell war, um die eingefügten Punktmutationen bestätigen zu können, fand bei allen vorgenommenen Punktmutationen in dieser Arbeit eine Sequenzierung der Plasmid-DNA statt. Dafür wurden $700 \mathrm{ng}$ Plasmid-DNA und 20 pmol des entsprechenden Sequenzierprimers zu einem Ansatz vermischt und anschließend mit $\mathrm{H}_{2} \mathrm{O}$ auf ein Gesamtvolumen von $7 \mu$ aufgefüllt. Diese Proben wurden dann zur Sequenzierung zu SeqLab Sequence Laboratories (Göttingen) geschickt und dort weiter verarbeitet.

\subsubsection{Gewinnung von Gesamtzellextrakten}

Für Dephosphorylierungs-Assays, Western-Blot-Experimente und Gelshift-Versuche wurden Gesamtzellextrakte benötigt. Zu erwähnen ist, dass die komplette Zellaufarbeitung auf Eis erfolgte. Dafür wurden zunächst die Zellen, die auf 6-Lochplatten kultiviert vorlagen, entsprechend vorbehandelt und anschließend zweimal mit PBS (Gibco) gewaschen, um sie dann pro Loch für 5 min in $50 \mu \mathrm{L}$ eiskaltem zytosolischen Extraktionspuffer (20 mM Hepes, $\mathrm{pH}$ 7,4, $10 \mathrm{mM} \mathrm{KCl,} \mathrm{10 \%} \mathrm{(v/v)} \mathrm{Glycerin,} 1 \mathrm{mM}$ EDTA, 0,1 $\mathrm{mM} \mathrm{Na}_{3} \mathrm{VO}_{4}$ ) zu lysieren. Dieser Puffer wurde kurz vor der Verwendung mit 0,1\% IGEPAL-CA-360, 3 mM DTT, 0,4 mM Pefabloc und Complete-MiniProtease-Inhibitoren angesetzt. Nach der Inkubationszeit erfolgte die Lösung der Zellen mit einem Zellschaber, wobei der gesamte Inhalt der jeweiligen Löcher in 1,5 
$\mathrm{mL}$ Reaktionsgefäße pipettiert wurde, um weiterverarbeitet werden zu können. Alsdann wurden diese Ansätze für $15 \mathrm{sec}$ bei $13000 \mathrm{rpm}$ und $4^{\circ} \mathrm{C}$ zentrifugiert. Die Überstände wurden in neue Reaktionsgefäße überführt und erneut für $5 \mathrm{~min}$ bei $13.000 \mathrm{rpm}$ und $4^{\circ} \mathrm{C}$ zentrifugiert. Danach wurden je $40 \mu \mathrm{l}$ dieser neuen Überstände (zytosolische Zellextrakte) in eine neue Generation von 1,5 mL-Reaktionsgefäße pipettiert und auf Eis gelagert, um sie später weiterverarbeiten zu können. Die Zellpellets aus dem ersten Schritt befanden sich währenddessen auf Eis und wurden alsdann mit je $50 \mu \mathrm{L}$ des nukleären Extraktionspuffers (20 mM Hepes, pH 7,4, 420 $\mathrm{mM} \mathrm{KCl}, 20 \%$ (v/v) Glycerin, $1 \mathrm{mM}$ EDTA, 0,1 $\mathrm{mM} \mathrm{Na}_{3} \mathrm{VO}_{4}$ ), welcher ebenfalls erst kurz vor der Benutzung angesetzt wurde (3 mM DTT, 0,4 mM Pefabloc und Complete-Mini-Protease-Inhibitoren) resuspendiert und anschließend für $30 \mathrm{~min}$ auf Eis inkubiert. Nach den 30-minütigen Inkubationsphasen wurden die Ansätze für $15 \mathrm{~min}$ bei $13000 \mathrm{rpm}$ und $4^{\circ} \mathrm{C}$ zentrifugiert. Danach wurden $40 \mu \mathrm{l}$ dieser nukleären Extrakte zu den oben erwähnten zytosolischen Extrakten hinzugegeben. Im Falle der Weiterverarbeitung für Western-Blot-Experimente wurden diese Gesamtzellextrakte im Verhältnis 1:5 mit 350 mM Tris-HCl, pH 6,8, 8\% SDS, 30\% Glycerin, 10\% $\beta$-Mercaptoethanol, $0,04 \%$ Bromphenolblau versetzt, bei $95^{\circ} \mathrm{C}$ denaturiert und anschließend bei $-20^{\circ} \mathrm{C}$ gelagert. Für Gelshift-Experimente erfolgte die Lagerung der Proben bei einer Temperatur von $-80^{\circ} \mathrm{C}$; es wurde kein $6 x$ SDS-Probenpuffer hinzugegeben.

\subsubsection{SDS-Polyacrylamid-Gelelektrophorese}

Die Auftrennung der STAT-Proteine erfolgte mithilfe SDS-Polyacrylamid-Gelelektrophorese. Dazu wurden die oben gewonnenen Gesamtzellextrakte für 3 min bei $95^{\circ} \mathrm{C}$ aufgeheizt, um anschließend auf Polyacrylamidgelen aufgetragen zu werden. Diese Gele bestanden aus zwei Anteilen, dem Trenngel und dem Sammelgel. Das Trenngel setzte sich aus $4 x$ Trenngelpuffer bestehend aus 1,5 M Tris-HCl, 0,4\% SDS, pH 8,8 und $0,03 \%$ APS, $0,16 \%$ TEMED und 10\% (v/v) Rotiphorese 30 (Acrylamid/Bisacrylamid $37 \mathrm{im}$ Verhältnis 5:1) zusammen. Das Sammelgel hatte die folgende Zusammensetzung aus $4 x$ Sammelgelpuffer $(0,5 \mathrm{M}$ Tris-HCl, 0,4\% SDS, pH 6,8), 0,06\% APS, 0,2\% TEMED, 5\% Rotiphorese Gel 30. Für die Herstellung des Polyacrylamidgels wurden zunächst zwei Glasplatten mithilfe eines Gummibandes und zwei Klemmen dicht zusammengebaut. Das Trenngel wurde angemischt und in die Aussparung zwischen diesen beiden Glasplatten gegossen. Um einen blasenfreien Übergang zwischen dem Trenn- und Sammelgel zu bekommen, wurde das Trenngel 
mit Isopropanol beschichtet und der etwa 20-minütige Polymerisations-vorgang abgewartet. Danach wurde das Sammelgel angemischt und, nachdem das Isopropanol abgegossen wurde, auf das polymerisierte Trenngel gegeben. Um die Bildung der Geltaschen, die die Extrakte enthalten sollten, zu gewährleisten, wurde ein Sammelkamm in das Sammelgel eingelegt und die Polymerisation abgewartet. Danach wurden die nun fertigen Gele in einem vertikalen Elektrophoresesystem (Minigel-Twin, Biometra, Göttingen) eingespannt. Wie oben erwähnt, wurden schließlich die eingefrorenen Proben für 3 min bei $95^{\circ} \mathrm{C}$ denaturiert, bevor ihre Auftragung in einer Menge zwischen 10 und $20 \mu \mathrm{L}$ in die Geltaschen stattfand. Im SDS-Laufpuffer (25 mM Tris-Base, $192 \mathrm{mM}$ Glycin, 0,1\% SDS, pH 8,6) und bei einer konstanten Spannung von $11 \mathrm{~mA}$ pro Gel erfolgte schließlich für 2 bis 2,5 Stunden die Auftrennung der STAT-Proteine.

\subsubsection{Analyse mittels Western-Blot}

Nach dem Elektrophoreselauf wurden die nach ihrem Molekulargewicht aufgetrennten Proteine auf eine Polyvinylidenfluorid-Membran (PVDF-Membran, Millipore, Schwalbach/Ts.) übertragen. Alle Western-Blots dieser Arbeit wurden nach dem elektrischen Transferverfahren der Semi-Dry-Methode mit dem Fastblot B44 (Biometra, Göttingen) durchgeführt. Da die PVDF-Membran hydrophob ist, musste sie zunächst 5 min in Methanol (Carl Roth) aktiviert werden. Daran schloss sich eine Inkubation der Membran unter Schütteln für $30 \mathrm{~min}$ in Transferpuffer $(25 \mathrm{mM}$ TrisBase, $150 \mathrm{mM}$ Glycin, 10\% Methanol, pH 8) an. Die Transferdauer betrug 90 min und erfolgte bei $80 \mathrm{~mA}$ pro Blot. Danach wurde die Membran für $1 \mathrm{~h}$ in $4 \%$ BSA (Albumin Fraktion V, Carl Roth) in TBS-T blockiert. Das Blockierungsreagenz hatte die Aufgabe, freie, unspezifische Bindungsstellen abzusättigen. Nach dem Blocken wurde die Membran mit $5 \mathrm{ml}$ des Primärantikörpers bedeckt und unter Schütteln bei $4^{\circ} \mathrm{C}$ über Nacht inkubiert. Am nachfolgenden Tag wurde der Primärantikörper entfernt und die Membran jeweils fünfmal 5 min mit $5 \mathrm{ml}$ TBS-T gewaschen. Anschließend wurde die Membran mit $5 \mathrm{ml}$ des 1:10000 in 4\% BSA/TBS-T-verdünnten IRDye-gekoppelten Sekundärantikörpers bedeckt und für eine Stunde auf dem Schüttler inkubiert. Der nächste Schritt bestand aus der Detektion der STAT-Proteine. Dies erfolgte im LICOR Odyssey Sa Imaging System (Biosciences, Bad Homburg). Nach dem Einlesen der Membranen erfolgte ihre Weiterverarbeitung mit dem Ablösepuffer (2\% SDS, $0,7 \%$ B-Mercaptoethanol, $62,5 \mathrm{mM}$ Tris- $\mathrm{HCl}, \mathrm{pH} 6,8)$ für $1 \mathrm{~h}$ im $60^{\circ} \mathrm{C}$ warmen 
Wasserbad, um sie für eine weitere Behandlung mit einem Erstantikörper vorzubereiten. Der Ablösepuffer diente hierbei dazu, gebundene Immunglobulinkomplexe von der Membran zu entfernen. Nach einstündiger Inkubationszeit wurde die Membran viermal 15 min in TBS-T gewaschen und wie am ersten Tag erneut für $1 \mathrm{~h}$ mit 4\% BSA in TBS-T blockiert, um sie anschließend mit $5 \mathrm{ml}$ einer ZweitAntikörper-enthaltenden Lösung zu bedecken. Die Inkubation fand ebenfalls über Nacht bei $4^{\circ} \mathrm{C}$ und unter Schütteln statt. Am dritten und letzten Tag wurde der Erstantikörper entfernt und die Membran wieder fünfmal jeweils 5 min mit TBS-T gewaschen, bevor sie zum letzten Mal im LI-COR Odyssey-Sa-Imaging-System eingelesen wurde.

\subsubsection{Dephosphorylierungs-Assay}

Der In-vitro-Dephosphorylierungs-Assay erfolgte mit Gesamtzellextrakten aus rekonstituierten U3A-Zellen. Nachdem der Dephosphorylierungspuffer (25 mM Tris- $\mathrm{HCl}$, $\mathrm{pH} 7,5,0,5 \mathrm{mg} / \mathrm{mL}$ BSA, $50 \mathrm{mM} \mathrm{KCl,} 5$ mM EDTA) kurz vor dem Gebrauch mit 20 mM DTT, Complete-Mini-Protease-Inhibitoren und 2 Einheiten T-Zell-Protein-TyrosinPhosphatase (TC-PTP, Biomol International, Plymouth, USA) komplementiert wurde, wurden $10 \mu \mathrm{L}$ der Extrakte mit $10 \mu \mathrm{L}$ des Dephosphorylierungspuffers versetzt. Nachdem die Proben mit der angegebenen Reaktionszeit bei $30^{\circ} \mathrm{C}$ inkubiert worden waren, erfolgte ein Stoppen der Reaktion durch die Zugabe von 6x SDS-Probenpuffer. Die Proben wurden alsdann für 3 min bei $95^{\circ} \mathrm{C}$ denaturiert und zur Ermittlung der Dephosphorylierung mittels Western-Blot weiterverarbeitet.

\subsubsection{Fluoreszenzmikroskopische Analyse}

Zur fluoreszenzmikroskopischen Untersuchung von STAT1-GFP-exprimierenden Zellen wurden HeLa-Zellen in 8-Kammer-Objektträgern (Lab-Tek Chamber Slides, Thermo Fisher Scientific, Langenselbold) kultiviert und am Folgetag mit pSTAT1GFP-Derivaten transfiziert. Anschließend erfolgte ihre Stimulation für die angegebenen Zeiten mit $10 \mathrm{ng} / \mathrm{mL}$ IFN $\gamma$ bzw. nachfolgend mit $1 \mu \mathrm{M}$ Staurosporin. Nach der Stimulation wurden die Zellen mit 4\% Formaldehyd in PBS für 15 min bei RT fixiert und anschließend die Zellkerne mit $5 \mu \mathrm{g} / \mathrm{mL}$ Hoechst 33258 (Sigma Aldrich) in PBS für 10 min unter Schütteln und bei RT gefärbt. Nach zweimaligem Waschen mit PBS und einmaligem Waschen mit destilliertem Wasser wurden die Zellen mit Fluoromount-G (Southern Biotech, Birmingham, USA) eingedeckt. Die Lagerung der 
Objektträger erfolgte lichtgeschützt bei $4^{\circ} \mathrm{C}$. Mithilfe des Mikroskops Axiovert 200M (Carl Zeiss Lichtmikroskopie, Göttingen) konnten die Zellen fluoreszenzmikroskopisch analysiert werden. Dazu wurden sie mit einer CCD-Kamera (Intas, Science Imaging Instruments, Göttingen) unter Verwendung verschiedener Fluoreszenzfilter fotografiert. Dabei wurden die GFP-Fusionsproteine bei einer Wellenlänge von $\lambda=$ $480 \mathrm{~nm}$ und die mit Hoechst 33258 angefärbten Zellkerne bei einer Wellenlänge von $\lambda=280 \mathrm{~nm}$ aufgenommen. Die Aufnahmen wurden mit Corel Draw (Corel Cooperation, Unterschleißheim) und dem Softwareprogrammen Image-Pro MDA 5.1 (Media Cybernetics, Bethesda, USA) bearbeitet.

\subsubsection{Reportergen-Assay}

Der Reportergen-Assay diente der Bestimmung der transkriptionellen Aktivität der beiden STAT1-Mutanten. Bei der Untersuchung der Genaktivierung standen unterschiedliche IFN $\gamma$-sensitive Luciferase-Reportergenkonstrukte, wie z.B. das 3xLy6EGen mit einer dreifachen GAS-Bindestelle im Promotorbereich (Wen et al. 1995), zur Verfügung. Die Methode basiert auf der Tatsache, dass bei der Promotoraktivierung durch Phospho-STAT1 das Enzym Luciferase transkribiert wird, das die Umsetzung von $\alpha$-Luciferin zu Oxyluciferin katalysiert. Bei dieser Reaktion werden Lichtquanten emittiert, deren Anzahl proportional zur gebildeten Luciferasemenge und damit indirekt zu der Menge an phosphorylierten STAT1-Proteinen ist. Ein weiteres Konstrukt für die Anwendung im Reportergen-Assay war pIC-339, welches ein natives Promotorfragment mit singulärer GAS-Bindestelle aus dem humanen icam1-Gen enthielt. Zur Normierung der Transfektionseffizienz wurde ein konstitutiv exprimierter $\beta$-Galaktosidase-Reporter benutzt. Im Rahmen des Experiments wurden U3A-Zellen verwendet, die in einer 48-Lochplatte kultiviert wurden. Die Transfektion dieser Zellen erfolgte pro Well mit $250 \mathrm{ng}$ STAT1-Plasmid, $200 \mathrm{ng} \beta$-Gal-Reportergen und $70 \mathrm{ng}$ des 3xLy6E- bzw. plC-339-Plasmids. Es wurde eine Sechsfach-Bestimmung je Konstrukt und Behandlungsmodus vorgenommen. Am Folgetag fand die Stimulation einiger Zellen für $6 \mathrm{~h}$ mit $10 \mathrm{ng} / \mathrm{mL}$ IFN $\gamma$ statt, während die restlichen Zellen zum Vergleich unstimuliert gelassen wurden. Nach Ablauf der Stimulationszeit erfolgte das Waschen der Zellen mit PBS, um sie anschließend für 15 min bei RT mit $100 \mu \mathrm{L}$ eines komplementierten Triton-Glycylglycin-Lysepuffers (25 mM Glycylglycin, pH 7,8, 1\% Triton X-100, $15 \mathrm{mM} \mathrm{MgSO}_{4}, 4 \mathrm{mM}$ EGTA, $3 \mathrm{mM}$ DTT, 0,4 mM Pefabloc und Complete-Mini-Protease-Inhibitoren) zu inkubieren. Danach wurden diese Lysate in 
1,5 mL-Reaktionsgefäße überführt und für $15 \mathrm{~min}$ bei $13.000 \mathrm{rpm}$ und $4^{\circ} \mathrm{C}$ zentrifugiert. Nach der Zentrifugation wurden $20 \mu \mathrm{L}$ des Überstandes in eine weiße 96-Lochplatte (Nunclon Surface, Taufkirchen) pipettiert und unter Zuhilfenahme des Luminometers Centro XS3 LB960 (Berthold Technologies, Bad Wildbad) pro Loch mit $50 \mu \mathrm{L}$ des Luciferase-Reagenzgemisches injiziert. Nach der Messung fand die Auswertung der Ergebnisse mit dem Softwareprogramm MikroWin in der Version 4.41 statt.

\subsubsection{Elektrophoretischer Mobilitätsshift-Assay (EMSA)}

Der elektrophoretische Mobilitätsshift-Assay (EMSA) diente in dieser Arbeit dem Nachweis spezifischer DNA-Bindung von STAT1 (Begitt et al. 2000). Es ist bekannt, dass STAT1-Proteine mit GAS-enthaltenden Doppelstrang-Oligonukleotid-Sonden eine nicht-kovalente, transiente Verbindung eingehen. Diese Eigenschaft verursacht eine Retardierung ihrer elektrophoretischen Mobilität im Gel. Zur autoradiographischen Detektion der Banden dienten radioaktiv markierte DoppelstrangOligonukleotide mit degenerierten oder kanonischen GAS-Sequenzen. Für solche Experimente wurden U3A-Zellen in 6-Lochplatten in Vollmedium kultiviert und von diesen nach entsprechender Vorbehandlung, wie oben beschrieben, Gesamtzellextrakte hergestellt. Um die Interaktion zwischen STAT-Proteinen und der DNA zu analysieren, verwendete man Sonden aus hydridisierten Doppelstrang-Oligonukleotiden, die jeweils eine singuläre (M67), zwei degenerierte (2xnonGAS), eine zweifache (2xGAS) oder eine degenerierte und eine kanonische GAS-Bindestelle (GASnonGAS) aufwiesen. Die radioaktive Markierung erfolgte an ihren überhängenden Enden. Für die Herstellung der Sonden wurden zunächst 50 pmol/mL komplementäre Oligonukleotide $5 \mathrm{~min}$ bei $95^{\circ} \mathrm{C}$ in Oligo-Puffer $\left(10 \mathrm{mM} \mathrm{MgCl}_{2}, 50 \mathrm{mM}\right.$ $\mathrm{KCl}, 20 \mathrm{mM}$ Tris-HCl, $\mathrm{pH}$ 7,5) inkubiert. Danach wurde dieser Ansatz langsam auf Raumtemperatur abgekühlt. Die Lagerung der Nukleotide erfolgte bei $-20^{\circ} \mathrm{C}$. Anschließend fand die radioaktive Markierung der DNA-Sonden mit $\alpha\left[{ }^{33} \mathrm{P}\right]$-markierten Desoxynukleotiden an ihren nicht komplementären 5'-überhängenden Enden statt. Hierzu diente ein Ansatz, der sich aus $8 \mu \mathrm{L}$ der radioaktiv markierten dNTPs, 0,1 ng der Oligonukleotide, 5 Einheiten des Klenow-Enzyms (ein Fragment der E.coli-DNAPolymerase I) und $5 \mu \mathrm{L}$ 10x Eco-Pol-Puffer (New England Biolabs) zusammensetzte. Dieser wurde 25 min bei RT inkubiert und anschließend für 5 minn mit einem Überschuss an unmarkierten dNTPs versetzt. Nach Ablaufen der Inkubationszeit 
konnte die Reaktion mit $1 \mu \mathrm{L}$ einer 0,5 mM EDTA-Lösung beendet werden. Zuletzt wurde dieser Ansatz für $3 \mathrm{~min}$ und bei $700 \mathrm{~g}$ zentrifugiert und die freien Nukleotide mittels Ilustra-MicroSpin-G-25-Säulen (GE Healthcare, München) chromatographisch entfernt. Zur Untersuchung der STAT1-DNA-Interaktion wurden STAT1-DNA-Komplexe hergestellt, indem 4,5 $\mu \mathrm{L}$ Gesamtzellextrakte mit 0,2 $\mu \mathrm{L}$ radioaktiv markierter DNA-Sonde, $1 \mu \mathrm{L}$ einer Poly-dldC-Lösung ( $2 \mathrm{mg} / \mathrm{mL}$ ), 1,3 $\mu \mathrm{L}$ DTT (100 mM), 3,5 $\mu \mathrm{L}$ $\mathrm{H}_{2} \mathrm{O}$ und 2,5 $\mu \mathrm{L} 5 x$ Gelshift-Puffer (100 mM Hepes, pH 7,9, $200 \mathrm{mM} \mathrm{KCl,} 5 \mathrm{mM}$ $\mathrm{MgCl}_{2}, 2,5 \mathrm{mM}$ EDTA, 0,5 mM EGTA, 20\% FiColl) für $15 \mathrm{~min}$ bei RT inkubiert wurden. Im Falle, dass weniger als 4,5 $\mu \mathrm{L}$ Extrakte eingesetzt wurden, ergänzte man das fehlende Volumen durch die Zugabe von 1xPBS. Die Identifikation der DNAgebundenen STAT1-Proteine erfolgte im Rahmen einer Supershift-Reaktion durch Inkubation mit 1,3 $\mu \mathrm{L}$ polyklonalem STAT1a-p91-Antikörper bzw. als Kontrolle STAT3-Antikörper (beide von Santa Cruz, Santa Cruz, Kalifornien). Die 4,8\%-igen TBE-Polyacrylamidgele setzten sich aus 2,4 mL 10x TBE, $84 \mathrm{~mL} \mathrm{H}_{2} \mathrm{O}, 12 \mathrm{~mL}$ Rotiphorese (Acrylamid/Bisacrylamid 29:1), $2 \mathrm{~mL}$ 10\% APS und $100 \mu \mathrm{L}$ TEMED zusammen und wurden nach der Anmischung zur Polymerisierung in die Aussparung zwischen zwei zusammengebauten Glasplatten gegossen. Die Gele mussten vor Gebrauch für $2 \mathrm{~h}$ bei 400 Volt prääquilibriert werden. Anschließend wurden die Proben für ca. $2,5 \mathrm{~h}$ in 0,25-fachem TBE-Laufpuffer bei $4^{\circ} \mathrm{C}$ und $400 \mathrm{~V}$ elektrophoretisch aufgetrennt. Nach der elektrophoretischen Auftrennung wurden die Gele auf Whatman-Papier (Albet Lab Science, Dassel) übertragen und vakuumgetrocknet. Zuletzt erfolgte ihre Exponierung auf eine Phospho-Imager-Folie. Am nächsten Tag wurden die Platten mithilfe eines Fujifilm FLA-5100 Scanner (Fuji, Düsseldorf) eingescannt und mit der Software Aida Image Analyzer v. 4.06 (Raytest) und Corel Draw weiter bearbeitet.

\subsubsection{Isolation von RNA}

Für die Extraktion von mRNA wurden U3A-Zellen benötigt, die auf 6-Lochplatten in Vollmedium kultiviert wurden. Nach 24 h fand ein Mediumwechsel auf Dulbecco'smodifiziertem Eagle-Medium (DMEM), supplementiert mit 1\% fetalem Kälberserum (FCS) und 1\% Penicillin/Streptomycin, statt. Sofort im Anschluss wurden die Zellen mit pcDNA3.1-Konstrukten transfiziert. Am Folgetag wurden einige dieser Zellen für 6 $\mathrm{h}$ mit $10 \mathrm{ng} / \mathrm{mL}$ IFN $\gamma$ stimuliert, Kontrollen hingegen wurden unstimuliert gelassen. 
Nach Ablauf der Stimulationszeit erfolgte die RNA-Isolierung mithilfe des peqGoldTotal-RNA-Kits (PEQLAB) nach Herstellerangaben und ihre Eluierung mit $50 \mu \mathrm{L}$ RNase-freiem $\mathrm{H}_{2} \mathrm{O}$. Die fertiggestellten Proben konnten nun entweder sofort zu cDNA weiterverarbeitet oder bei $-80^{\circ} \mathrm{C}$ gelagert werden.

\subsubsection{Herstellung der cDNA}

Mithilfe des Verso-cDNA-Kits (Thermo Fisher Scientific) erfolgte die Herstellung der komplementären DNA (cDNA) aus der isolierten mRNA. Es wurde ein Ansatz von 20 $\mu \mathrm{L}$ nach den Angaben des Herstellers pipetiert, welcher $8 \mu \mathrm{L}$ RNA enthielt. Das Protokoll der reversen Transkription beinhaltete zwei Zyklen: nach einem ersten Zyklus, indem eine 30-minütige cDNA-Synthese bei $42^{\circ} \mathrm{C}$ stattfand, wurden die Proben in einem zweiten Zyklus für 2 min auf $95^{\circ} \mathrm{C}$ erhitzt. Anschließend konnte die cDNA bei $-20^{\circ} \mathrm{C}$ gelagert werden.

\subsubsection{Real-time-PCR}

Die Real-time-PCR dient der Analyse der Genexpression von STAT1-WT und den generierten Punktmutanten. Die Herstellung des $19 \mu \mathrm{L}$ Reaktionsansatzes erfolgte nach Herstellerangaben mit dem Absolute-Blue-QPCR-SYBR-Green Mix (Thermo Scientific). Für den Ansatz wurden komplementäre Primer (Tib MolBiol, Berlin) verwendet. Zu diesem Ansatz wurde $1 \mu \mathrm{L}$ cDNA hinzugefügt. Für die Untersuchung der Genexpression wurden literaturbekannte endogene Zielgene von STAT1 in Betracht gezogen.

\subsubsection{Statistik}

Die statistische Auswertung aller Genexpressionsanalysen wurde im Rahmen eines $t$-Tests, in manchen Fällen auch mithilfe eines Rang-Summen-Tests vorgenommen. Die Bestimmung der Mittelwerte und Standardabweichungen erfolgte aus den Ergebnissen von mindestens drei unabhängigen Versuchen. Für die Analyse wurden die Programme SigmaPlot und Microsoft Office-Excel verwendet. Ein p-Wert $<0,05$ wurde als statistisch signifikant gewertet. 


\section{Ergebnisse}

Im Rahmen dieser Arbeit wurden durch Einführung von Punktmutationen in der Linker- bzw. SH2-Domäne von STAT1 zwei Mutanten generiert und im Weiteren hinsichtlich ihrer phänotypischen Eigenschaften im Interferon-abhängigen Signalweg charakterisiert. Hierbei wurde ein besonderes Augenmerk auf eventuelle Veränderungen der Tyrosinphosphorylierung und der transkriptionellen Aktivierung gelegt. Hergestellt wurden die beiden Punktmutanten durch Austausche zweier konservierter Aminosäurereste in der Linker- bzw. SH2-Domäne, welche zuvor durch Sequenzvergleiche innerhalb der sieben Mitglieder der humanen STAT-Familie als vergleichsweise konserviert identifiziert worden waren. Untersuchungen der Kristallstruktur stellten sicher, dass sich diese beiden Aminosäurereste an der Proteinoberfläche befinden.

\subsection{Sequenzhomologie von STAT1-E524}

Bei dem ersten hier untersuchten Aminosäurerest handelt es sich um einen Glutaminsäurerest in Position 524 von STAT1, der durch Sequenzvergleich aller humanen STAT-Proteine als relativ konserviert eingestuft wurde (Abb. 2). Die humanen Familienmitglieder STAT1, STAT3 und STAT4 sowie STAT92E aus Drosophila melanogaster besitzen an homologer Stelle einen entsprechenden Glutaminsäurerest, der carboxyterminal bei allen aufgeführten STAT-Mitgliedern von einem Lysinrest gefolgt wird. Der Glutaminsäurerest 524 im STAT1-Molekül wurde im Rahmen einer sequenzspezifischen Mutagenese durch Alanin ausgetauscht und die erhaltene Punktmutante STAT1-E524A in späteren Experimenten eingehend charakterisiert.

\begin{tabular}{|l|c|c|c|c|c|c|c|c|c|c|c|c|c|c|}
\hline STAT1 & D & Q & L & N & M & L & G & E & K & L & L & G & P & N \\
\hline STAT2 & D & Q & L & S & M & L & R & N & K & L & F & G & Q & N \\
\hline STAT3 & E & Q & L & T & T & L & A & E & K & L & L & G & P & G \\
\hline STAT4 & D & Q & L & H & M & L & A & E & K & L & T & V & Q & S \\
\hline STAT5a & E & N & L & V & F & L & A & Q & K & L & F & N & N & S \\
\hline STAT5b & E & N & L & V & F & L & A & Q & K & L & F & N & N & S \\
\hline STAT6 & E & H & F & L & F & L & A & Q & K & I & F & N & D & N \\
\hline 92E & D & N & L & D & F & L & Y & E & K & L & Q & R & E & E \\
\hline Dicty & R & P & L & S & S & Y & D & L & K & Y & I & Q & T & H \\
\hline
\end{tabular}


Abb. 2: Sequenzvergleich einer Region aus der Linker-Domäne verschiedener STATProteine. Im Sequenzvergleich zwischen den angegebenen STAT-Proteinen wird deutlich, dass der Glutaminsäurerest in Position 524 von STAT1 (rot) vergleichsweise gut in der Familie der STAT-Proteine konserviert ist.

\subsection{Homologie von STAT1-E585}

Ein zweiter Glutaminsäurerest, der in Position 585 in der SH2-Domäne des STAT1Moleküls lokalisiert ist, wurde ebenfalls unter Zuhilfenahme der Kristallstruktur und durch Sequenzvergleich aller humanen STAT-Proteine bestimmt; er ist bei den ersten vier humanen Familienmitgliedern in gleicher Weise vorhanden (Abb. 3). Im Rahmen einer sequenzspezifischen Mutagenese erfolgte auch hier der Austausch dieses Glutaminsäurerestes gegen Alanin; die Mutante STAT1-E585A wurde ebenfalls nach Expression in humanen Zellen charakterisiert und hinsichtlich ihrer Eigenschaften mit STAT1-WT verglichen.

\begin{tabular}{|l|c|c|c|c|c|c|c|c|c|c|c|c|c|c|}
\hline STAT1 & G & F & I & S & K & E & R & E & R & A & L & L & K & D \\
\hline STAT2 & G & F & V & S & R & S & Q & E & R & R & L & L & K & K \\
\hline STAT3 & G & F & I & S & K & E & R & E & R & A & I & L & S & T \\
\hline STAT4 & G & F & V & S & K & E & K & E & R & L & L & L & K & D \\
\hline STAT5a & G & F & V & N & K & Q & Q & A & H & D & L & L & I & N \\
\hline STAT5b & G & F & V & N & K & Q & Q & A & H & D & L & L & I & N \\
\hline STAT6 & G & F & I & S & K & Q & Y & V & T & S & L & L & L & N \\
\hline 92E & G & F & I & N & K & T & K & A & Q & T & D & L & L & R \\
\hline Dicty & G & Y & M & G & R & Q & E & V & N & D & A & L & Q & N \\
\hline
\end{tabular}

Abb. 3: Sequenzvergleich humaner und nicht-humaner STAT-Proteine aus einem Bereich der SH2-Domäne unter Einschluss von E585. Der Sequenzvergleich zwischen den aufgeführten STAT-Proteinen macht deutlich, dass der Glutaminsäurerest in Position 585 von STAT1 (rot) in der Familie der STAT-Proteine relativ konserviert ist.

\subsection{STAT1-E585A zeigt ein erhöhtes Phosphorylierungsniveau}

Da Tyrosinphosphorylierung, Dimerisierung und DNA-Bindung notwendige Voraussetzungen der Zytokin-induzierten Kernakkumulation der STATs darstellen (Shuai et al. 1992; Darnell et al. 1994; Mowen und David 1998; Herrington et al. 1999), wurde zunächst untersucht, ob die Alaninsubstitutionen an den Positionen 524 und 
585 die Kinetik der Tyrosinphosphorylierung beeinflussen. Das Phosphorylierungsniveau der beiden Mutanten STAT1-E524A und -E585A wurde im Rahmen von Western-Blot-Analysen überprüft. Dazu erfolgte zunächst die transiente Transfektion der HeLa-S3-Zellen mit den Vektoren pSTAT1-WT-GFP, pSTAT-E524A bzw. pSTAT-E585A und am Folgetag die Stimulation der Zellen mit IFN $\gamma$. Zusätzlich konnte durch die Zugabe von Staurosporin, einem Proteinkinase-Inhibitor, die zeitabhängige Abnahme der Phosphorylierung dargestellt werden. Dazu wurden die Zellen nach einer 45-minütigen Stimulation mit IFN- $\gamma$ unterschiedlich lang mit $1 \mu \mathrm{M}$ Staurosporin inkubiert. Nach der Herstellung von Gesamtzellextrakten und ihrer gelelektrophoretischen Auftrennung konnten anschließend mithilfe eines PhosphoSTAT1-Antikörpers im Immunoblot die Phosphorylierungsbanden detektiert werden. Um die Gesamtmenge von STAT1 zu bestimmen, wurden die Blot-Membranen anschließend gestrippt, um sie nach mehrmaligem Waschen mit einem Pan-STAT1Antikörper ex-ponieren zu können.

Wie man der Abb. 4 entnehmen kann, ist nach 45-minütiger IFN $\gamma$-Stimulation in den Extrakten von STAT1-WT-exprimierenden Zellen und in STAT1-E524A-enthaltenden Extrakten eine vergleichbare Tyrosinphosphorylierung zu beobachten. Zusätzlich kann bei denjenigen Zellen, die einer Staurosporin-Inkubation unterzogen wurden, bereits nach 15 min eine abgeschwächte Phosphorylierungsbande beobachtet werden. Diese Abnahme des Phosphorylierungsniveaus wird bei Zellen, die für 30 min mit Staurosporin behandelt wurden, noch deutlicher, bis das Phosphorylierungssignal nach 45-minütiger Inkubation mit Staurosporin kaum noch detektiert werden kann. Die Abbildung demonstriert zudem, dass die STAT1-E585A-Mutante im Vergleich zum STAT1-WT nach 45-minütiger Stimulation mit IFN $\gamma$ eine signifikante Erhöhung des Phosphorylierungsniveaus aufweist. Während bei STAT1-WT mit zunehmender Dauer der Staurosporin-Behandlung die bereits beschriebene kontinuierliche Abnahme des Phosphorylierungssignals registriert wurde, wies diese Punktmutante im Vergleich dazu eine signifikant erhöhte Phosphorylierungsrate nach 30minütiger Staurosporin-Inkubation auf, erkennbar am stärkeren Phospho-STAT1Signal. Das Experiment legt nahe, dass sich die Mutante STAT-E524A weder in ihrer Kinetik der Dephosphorylierung nach Staurosporin-Behandlung noch im Phosphorylierungsniveau nach IFNy-Stimulation vom WT-STAT1 unterscheidet. Zum anderen konnte demonstriert werden, dass die Mutante STAT1-E585A im Vergleich zum STAT1-WT diskret, aber signifikant hyperphosphoryliert ist. 


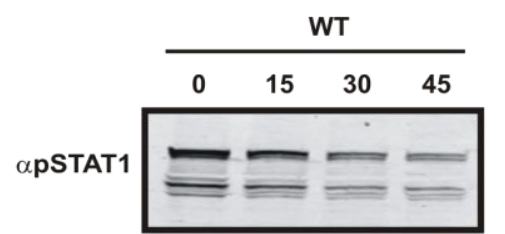

WT

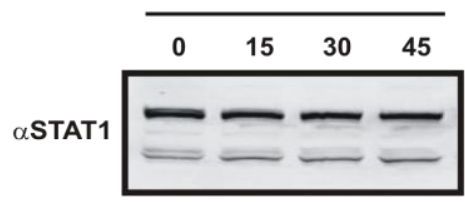

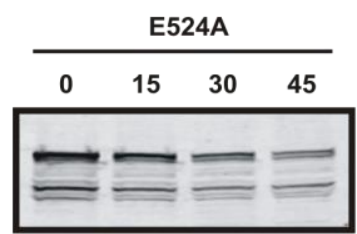

E524A

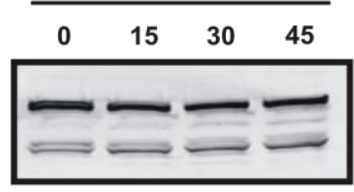

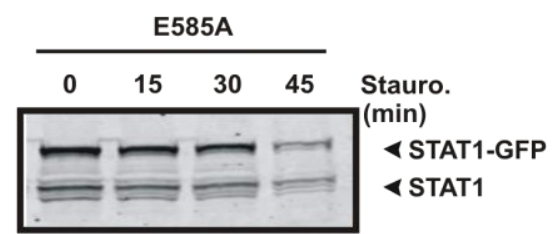

E585A

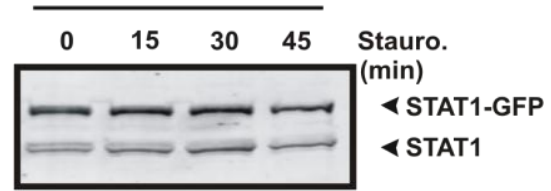

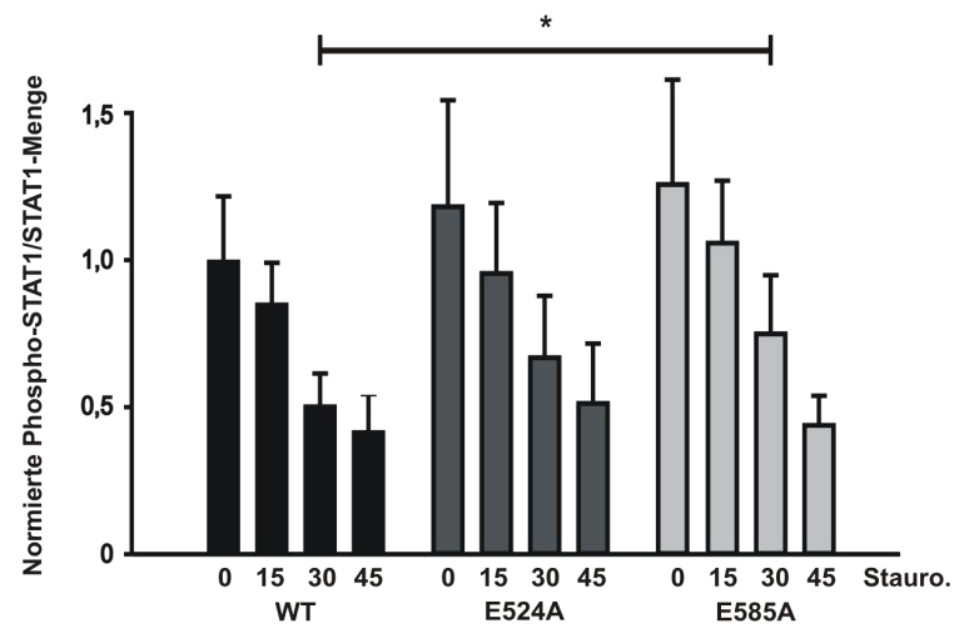

Abb. 4: STAT1-E524A und STAT1-WT haben nach IFN $\gamma$-Stimulation eine ähnliche Invivo-Phosphorylierungskinetik, während STAT1-E585A hyperphosphoryliert ist. Nach transienter Transfektion von HeLa-Zellen mit pSTAT1-WT-, pSTAT-E524A- bzw. pSTATE585A-GFP und ihrer 45-minütigen Stimulation mit $10 \mathrm{ng} / \mathrm{mL}$ IFN $\gamma$ am Folgetag erfolgte unmittelbar anschließend eine Inkubation mit $1 \mu \mathrm{M}$ Staurosporin für die angegebenen Zeiten. Das obere Bild der Abbildung stellt das Ergebnis repräsentativer Western-Blot-Analysen nach Inkubation mit einem Phospho-STAT1-Antikörper dar und unten eine Reinkubation der Membranen mit einem STAT1-spezifischen Antikörper. Um eine statistische Signifikanz berechnen zu können, wurden die Ergebnisse aus mindestens drei unterschiedlichen Versuchen quantifiziert und in der Graphik im positiven Fall mithilfe eines Balkens dargestellt (unteres Bild, $p=0,024$ ). 


\subsection{Normale Kinetik der IFN $\gamma$-induzierten Kernakkumulation von STAT1-}

E524A und -E585A

Mithilfe von STAT1-GFP-Fusionsproteinen wurde die Kinetik der IFN $\gamma$-induzierten Kernakkumulation fluoreszenzmikroskopisch bestimmt. Dazu wurden im Rahmen dieses Experiment zunächst HeLa-S3-Zellen transient mit pSTAT1-WT-GFP, STAT1E524A-GFP oder pSTAT1-E585A-GFP transfiziert und am Folgetag entweder unbehandelt belassen oder 45 min mit IFNy stimuliert bzw. alternativ nach IFNY-Stimulation zusätzlich mit $1 \mu \mathrm{M}$ Staurosporin inkubiert. Anschließend erfolgte die Fixierung der Zellen mit 3,7\% Formaldehyd/PBS und die Färbung der Kerne mit Hoechst 33258. Die entstandenen Objektträger wurden im Fluoreszenzmikroskop beurteilt und von den fixierten Zellen typische Aufnahmen angefertigt, wie sie in Abb. 5 dargestellt sind. Diese verdeutlichen, dass WT-STAT1 und beide Mutanten ohne IFN $\gamma$ Stimulation zunächst eine panzelluläre Verteilung des STAT-Proteins aufweisen, nach IFN $\gamma$-Stimulation jedoch eine komplette Translokation in den Zellkern beobachtet wird.

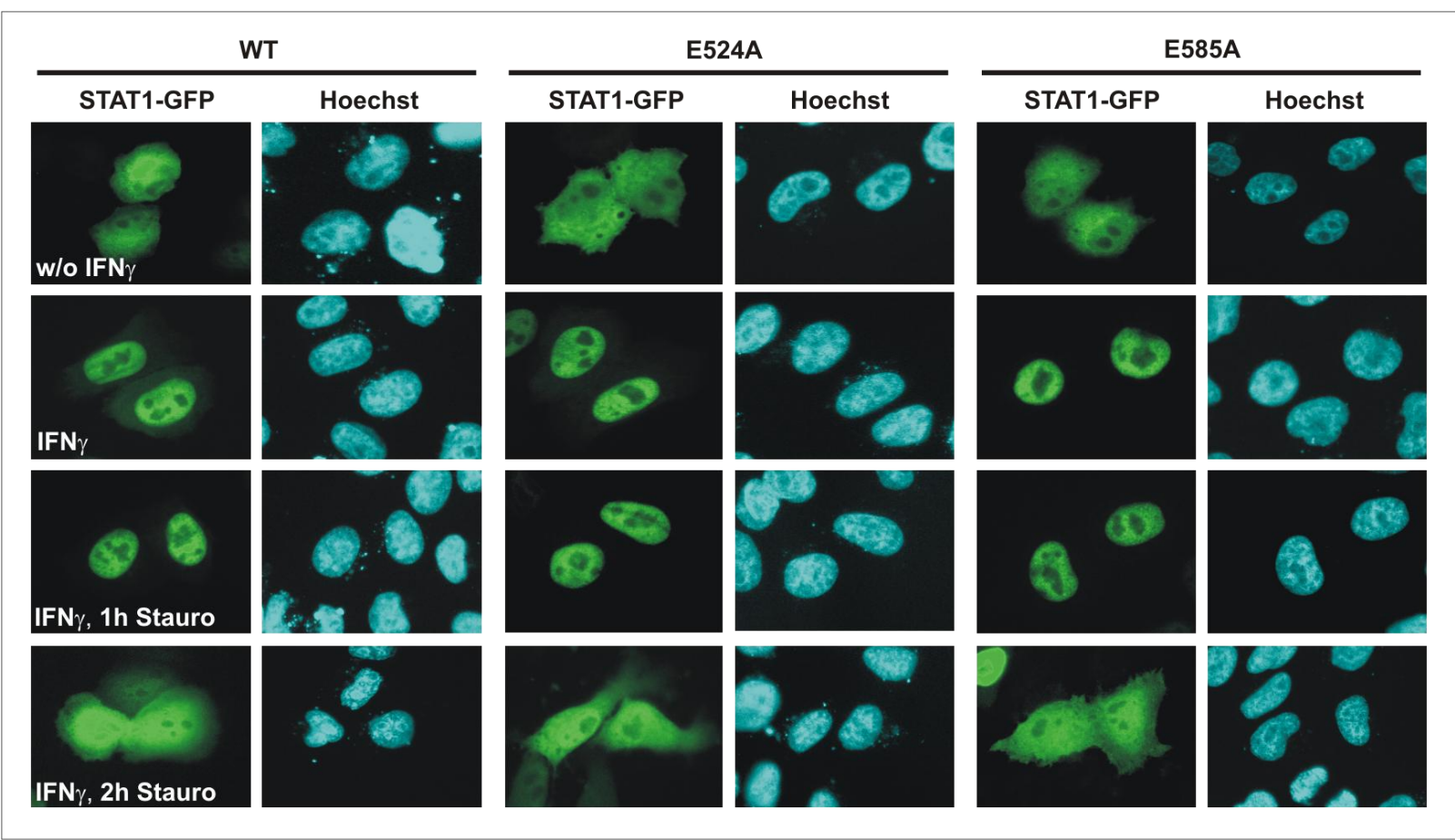

Abb. 5: Vergleichbare Kinetik der Kernakkumulation von STAT1-WT, -E585A und E524A. Nach Transfektion von HeLa-Zellen mit pSTAT1-WT-GFP, pSTAT1-E524A-GFP oder pSTAT1-E585A-GFP wurden die Zellen entweder unstimuliert belassen (obere Reihe) oder $45 \mathrm{~min}$ mit $10 \mathrm{ng} / \mathrm{mL}$ IFN $\gamma$ stimuliert (zweite Reihe) bzw. nach vorangegangener 45- 
minütiger IFN $\gamma$-Stimulation für $1 \mathrm{~h}$ (dritte Reihe) bzw. $2 \mathrm{~h}$ (vierte Reihe) mit $1 \mu \mathrm{M}$ Staurosporin inkubiert. Die Zellkerne der Formalin-fixierten Zellen wurden mit Hoechst 33258 angefärbt.

Bereits nach einer einstündigen Inkubation der Zellen mit Staurosporin konnte die anfänglich beobachtete panzelluläre Ruheverteilung der STAT-Proteine wiederhergestellt werden, da JAK-Kinasen durch Staurosporin inhibiert wurden und folglich keine Tyrosinphosphorylierung mehr stattfinden konnte. Ein zusätzliches Experiment wurde mit unmarkiertem STAT1 unter Einsatz von pcDNA3.1-STAT1-Plasmiden durchgeführt, um auszuschließen, dass die Präsenz des GFP-Fusionsproteins, welches im Vergleich zu endogenem STAT1 eine verringerte Exportrate besitzt (Köster und Hauser 1999; Begitt et al. 2000; Meyer et al. 2007), die subzelluläre Verteilung von STAT1 beeinflussen könnte. Hierfür erfolgte in gleicher Weise die Transfektion von U3A-Zellen mit den pcDNA3.1-Expressionsvektoren der jeweiligen STAT1-Moleküle. Im Anschluss daran fand die Stimulation der Zellen mit IFN $\gamma$ und inre zusätzliche Inkubation mit Staurosporin statt. Nach Immunfärbung mit STAT1spezifischem Antikörper wurden die Präparate fluoreszenzmikroskopisch analysiert. Wie man der Abb. 6 entnehmen kann, erfolgte nach 45-minütiger Stimulation mit IFN $\gamma$ eine Kernakkumulation sowohl beim STAT1-WT als auch bei beiden Punktmutanten. Die 60-minütige Inkubation der Zellen mit Staurosporin führte zu einer panzelluläre Verteilung der STAT1-Moleküle. Durch diese beiden Experimente konnte gezeigt werden, dass sich die beiden Punktmutanten in ihrer Kinetik der Kernakkumulation nicht von STAT1-WT unterscheiden. 


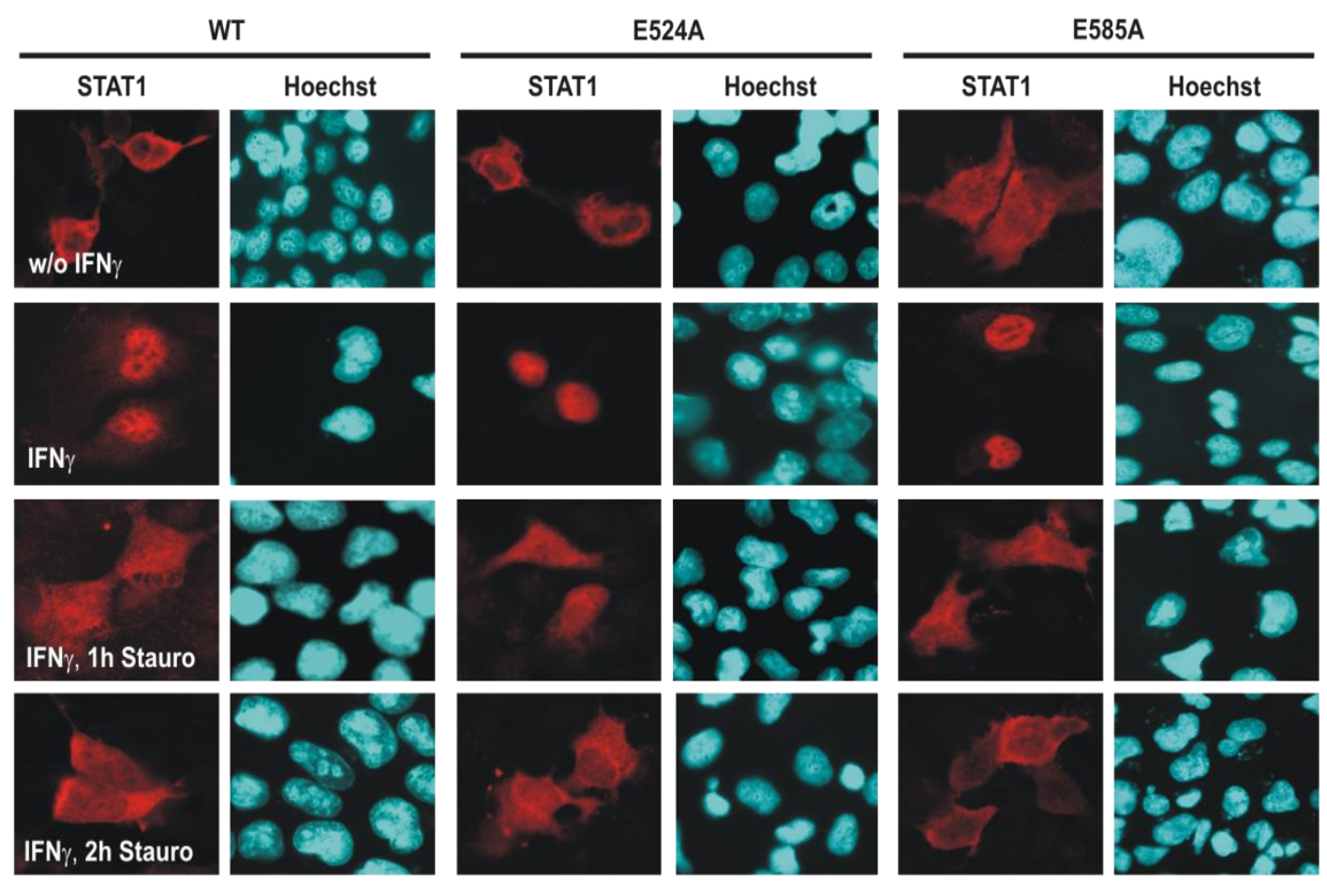

Abb. 6: Die immunzytochemische Untersuchung weist keinen Unterschied in der Kinetik der Kernakkumulation von STAT1-WT und den beiden Punktmutanten auf. STAT1-WT-, STAT1-E524A- und STAT1-E585A-exprimierende U3A-Zellen wurden für 45 min mit $10 \mathrm{ng} / \mathrm{mL}$ IFN $\gamma$ stimuliert und anschließend für die angegebenen Zeiten mit $1 \mu \mathrm{M}$ Staurosporin behandelt. Anschließend erfolgte die Fixierung der Zellen mit Methanol. Die STAT1-Lokalisation wurde immunzytochemisch mit einem STAT1-spezifischen Antikörper und Cy3-gekoppeltem Anti-Kaninchen-lgG aus Ziege detektiert und die Zellkerne mit Hoechst-Farbstoff angefärbt.

\subsection{Die Hyperphosphorylierung führt bei STAT1-E585A zu einer verstärkten DNA-Bindung}

Ein weiterer Nachweis für die verstärkte Phosphorylierung von STAT1-E585A geschah mittels Gelshift-Assays (EMSA). Dazu erfolgte nach transienter Transfektion von U3A-Zellen mit pSTAT1-WT-GFP, pSTAT1-E524A-GFP bzW. pSTAT1-E585AGFP eine 45-minütige Stimulation der Zellen mit $10 \mathrm{ng} / \mathrm{mL} \mathrm{IFN} \gamma$ und eine anschließende Inkubation mit $1 \mu \mathrm{M}$ Staurosporin für die angegebenen Zeiten. Nach Herstellung von nukleären Zellextrakten wurden diese für 15 min mit radioaktiver M67-Sonde inkubiert, die über eine einfache GAS-Bindestelle verfügte. In allen 
EMSA-Experimenten wurden gleiche Extraktmengen aufgetragen. Die Analyse der Bindung von phosphorylierten STAT1-Proteinen an die [ $\left.{ }^{33} \mathrm{P}\right]$-markierte Sonde erfolgte autoradiographisch (Abb. 7). Zusätzlich konnte im Rahmen einer Supershift-Reaktion durch den Einsatz von Anti-STAT1 $\alpha$-Antikörper $(\alpha S 1)$ und als Kontrolle Anti-STAT3Anti-köper ( $\alpha \mathrm{S} 3$ ) gezeigt werden, dass es sich bei den detektierten Banden um STAT1-DNA-Komplexe handelte. Die Zugabe von spezifischen $\alpha$ S1-Antikörpern, die gegen den STAT1-DNA-Komplex gerichtet waren, führte dazu, dass es zu einer Größenzunahme des Molekülkomplexes durch Bindung von Immunglobulin und folglich zu einer retardierten Laufgeschwindigkeit kommt. Dieses zeigte sich in einer Verschiebung bzw. einem partiellen Verlust der STAT1-DNA-Bande. Eine Negativkontrolle erfolgte durch die Zugabe von unspezifischem aS3-Antikörper zu den Zellextrakten, die bei einer vergleichbaren Extraktmenge keine Änderung der Laufgeschwindigkeit der Komplexe, wie sie bei einem positiven Supershift vorkommen würde, zur Folge hatte.

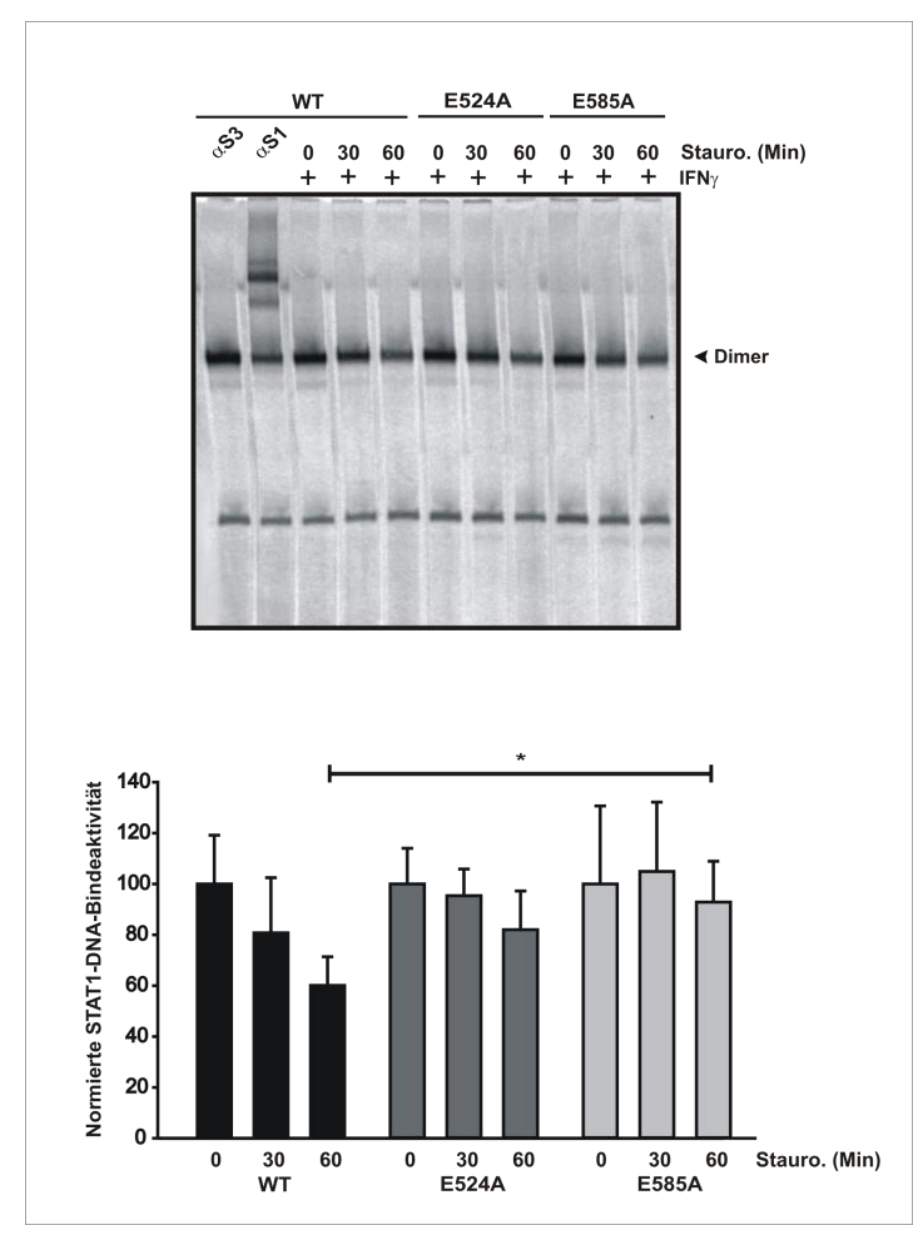

Abb. 7: Verbesserte Bindung von STAT1-E585A an M67-DNA. Die Abbildung zeigt das Ergebnis eines repräsentativen Gelshift-Assays. Nachdem U3A-Zellen mit pSTAT1-WT-GFP, 
pSTAT1-E524A-GFP bzw. pSTAT1-E585A-GFP transfiziert und am Folgetag zunächst mit $10 \mathrm{ng} / \mathrm{mL}$ IFN $\gamma$ und nachfolgend mit $1 \mu \mathrm{M}$ Staurosporin für die angegebenen Zeiten behandelt wurden, erfolgte die Herstellung nukleärer Extrakte, die zunächst 15 min lang mit einer $\left[{ }^{33} \mathrm{P}\right]$-markierten M67-Sonde inkubiert wurden. Daran schlossen sich eine gelelektrophoretische Auftrennung, die Geltrocknung im Vakuum und abschließend eine autoradiographische Detektion an. Im Rahmen der Supershift-Reaktion wurden Anti-STAT1 $\alpha$-Antikörper ( $\alpha S 1)$ und Anti-STAT3-Antiköper $(\alpha S 3)$ benutzt. Das obere Bild der Abbildung stellt das Ergebnis nach Inkubation mit markierter M67-Sonde dar. Die mit dem Pfeil markierten Banden zeigen detektierte STAT1-DNA-Komplexe. Für Signifikanzberechnungen wurden die Ergebnisse aus mindestens drei unterschiedlichen Versuchen quantifiziert (unteres Bild, $\mathrm{p}=0,044)$.

\subsection{STAT1-E5245A und -E585A besitzen eine normale Dissoziationsrate von DNA}

Kompetitions-Gelshifts sollten die Hypothese belegen, dass die Hyperphosphorylierung eine Folge einer verminderten Off-Rate von DNA darstellt. Dazu wurden erneut Gesamtzellextrakte aus IFN $\gamma$-stimulierten STAT1-WT-GFP-, -E524A-GFPbzw. -E585A-GFP-exprimierenden U3A-Zellen hergestellt, die anschließend für 15 min mit $\left[{ }^{33} \mathrm{P}\right]$-markierter M67-Sonde und danach für die angegebenen Zeiten mit einem 750-fachem molaren Überschuss an nicht-radioaktiv markierter M67-DNA inkubiert wurden. Nach Ablauf der Inkubationszeit wurden die Zellextrakte in gleicher Weise mittels Polyacrylamid-Gelelektrophorese aufgetragen. Wie in Abb. 8 demonstriert wird, konnte in Bezug auf die Dissoziationskinetik kein Unterschied zum STAT1-WT festgestellt werden. Das Experiment konnte beweisen, dass eine veränderte Dissoziationskinetik der Mutante STAT1-E585A nicht der Grund für deren in den früheren Experimenten dokumentierte Hyperphosphorylierung ist. 


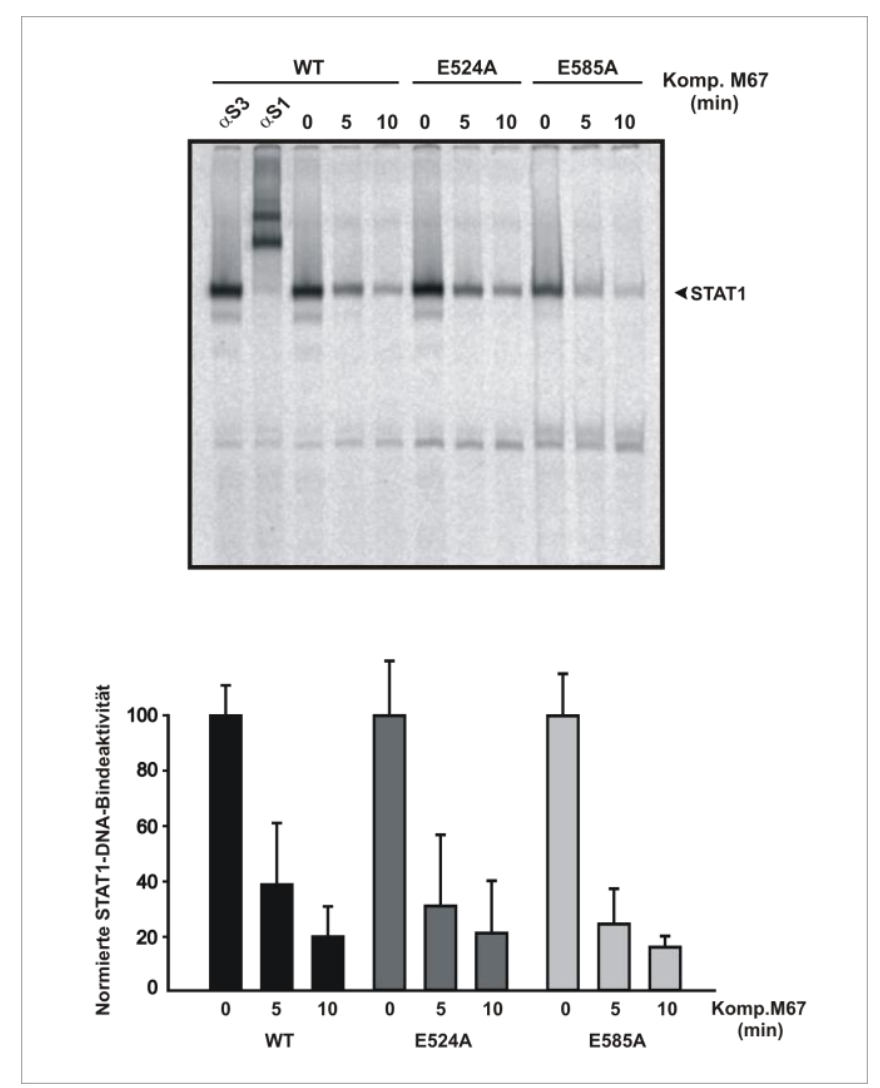

Abb. 8: Normale Dissoziationskinetik der STAT1-Varianten E585A und E524A von DNA. Nachdem U3A-Zellen mit pSTAT1-WT-GFP, pSTAT1-E585A bzw. pSTAT1-E524A transfiziert und am Folgetag mit IFN $\gamma$ stimuliert wurden, erfolgte die Herstellung von Zellextrakten und deren anschließende Inkubation für 15 min mit radioaktiv markierter M67Sonde, die eine einfache GAS-Bindestelle besitzt. Anschließend wurden die Reaktionen mit unmarkierter M67-DNA im 750-fachen molaren Überschuss für die angegebenen Zeiten inkubiert und sofort danach auf ein natives Polyacrylamid-Gel aufgetragen. Nach gelelektrophoretischer Auftrennung wurden die STAT1-DNA-Banden (Pfeil) autoradiographisch im Vakuum-getrockneten Gel detektiert. Das obere Bild der Abbildung stellt das autoradiographische Ergebnis der Kompetition mit der M67-DNA dar. Die mit dem Pfeil markierten Banden zeigen die detektierten STAT1-DNA-Komplexe. Für die Quantifizierung wurden die Ergebnisse aus mindestens drei verschiedenen Versuchen gemittelt und als Mittelwerte sowie Standardabweichungen graphisch dargestellt (unteres Bild).

\subsection{STAT1-E524A und -E585A haben eine normale Affinität zu DNA}

Um die Affinität der DNA-Bindung beider Punktmutanten genauer analysieren zu können, wurden weitere Gelshift-Versuche durchgeführt. Dazu wurden zunächst nach 45-minütiger IFN $\gamma$-Stimulation zelluläre Extrakten aus STAT1-WT-GFP-, STAT1-E524A-GFP-, und STAT-E585A-GFP-exprimierenden U3A-Zellen hergestellt 
und anschließend mit radioaktiv-markierten DNA-Sonden inkubiert. Als DNA-Proben kamen eine Sonde mit doppelter GAS-Bindestelle (2xGAS), eine Sonde mit einfacher, gefolgt von einer degenerierten GAS-Bindestelle (GASnonGAS) sowie eine zweifache Nicht-GAS-Sonde (2xnonGAS) zum Einsatz.

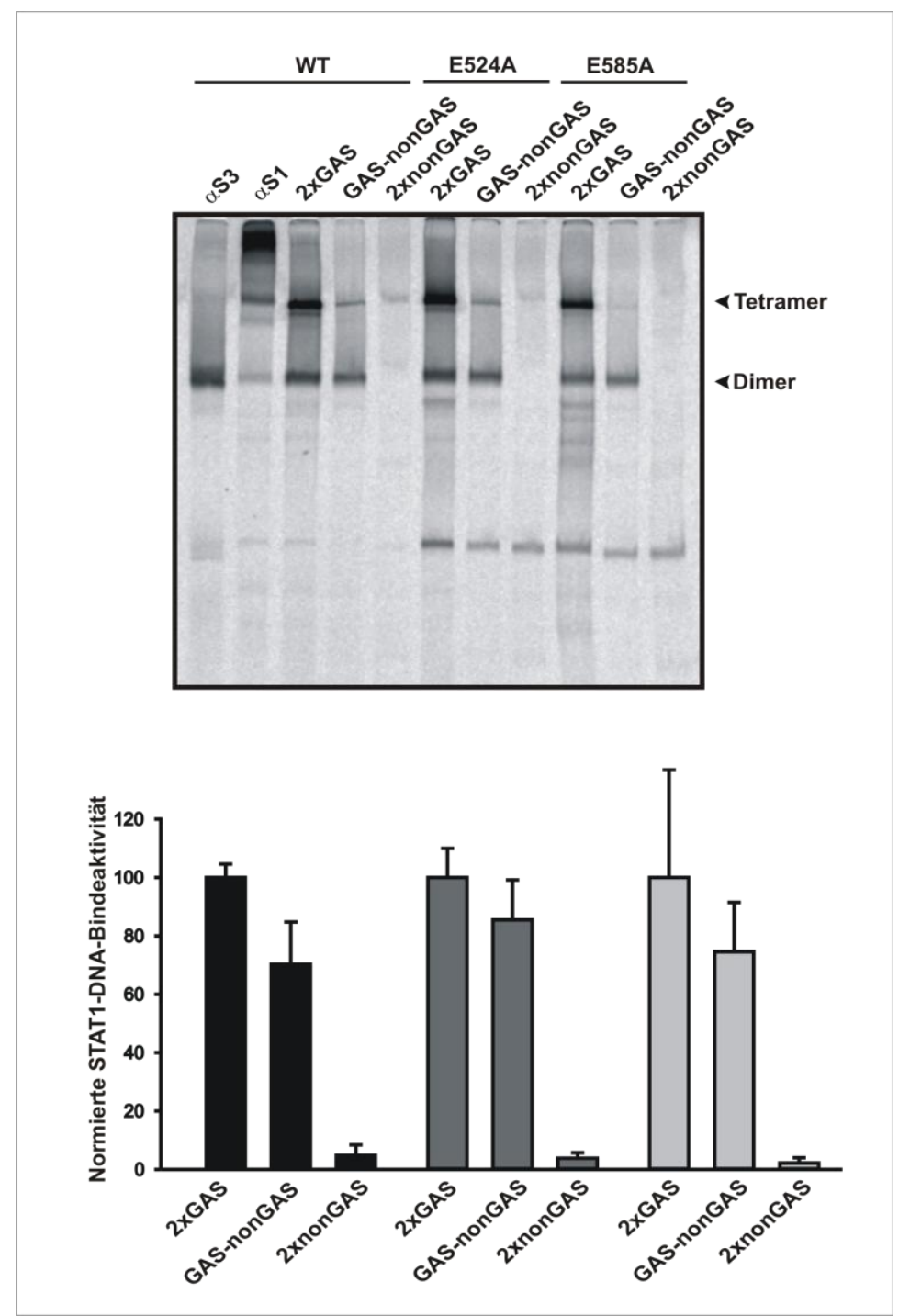

Abb. 9: Regelrechte DNA-Bindeaffinität von STAT1-E524A und STAT1-E585A im Vergleich zum Wildtyp-Molekül. Nachdem U3A-Zellen mit pSTAT1-WT-GFP, pSTAT1-E585AGFP bzw. pSTAT1-E524A-GFP transfiziert und für $45 \mathrm{~min}$ mit $10 \mathrm{ng} / \mathrm{mL}$ IFN $\gamma$ stimuliert wurden, erfolgte die Herstellung nukleärer Extrakte. In Gelshift-Assay wurden diese mit den angegebenen $\left[{ }^{33} \mathrm{P}\right]$-markierten Sonden inkubiert. Die autoradiographische Auswertung fand nach der Polyacrylamid-Gelelektrophorese in Vakuum-getrockneten Gelen statt. Der Pfeil verweist auf die detektierten dimeren und tetrameren STAT1-DNA-Komplexe. 
In Abb. 9 ist ein typisches Ergebnis der autoradiographischen Detektion mit quantitativer Auswertung dargestellt. Unter Verwendung aller Sonden kann man keinen signifikanten Unterschied der DNA-Bindeaffinität von STAT1-WT im Vergleich zu den beiden Punktmutanten beobachten.

\subsection{Kein Unterschied in der Dephosphorylierungskinetik zwischen STAT1-WT und STAT1-E585A}

In den bisherigen Versuchen wurde kein Unterschied zwischen STAT1-E524A und STAT1-WT festgestellt. Deshalb konzentrierte ich mich in den folgenden Experimenten nur noch auf STAT1-E585A. In den vorigen Western-Blot-Versuchen konnte demonstriert werden, dass die letztgenannte Mutante nach 45-minütiger IFN $\gamma$-Stimulation ein diskret, aber signifikant erhöhtes Phosphorylierungsniveau aufweist. Basierend auf der Hypothese, dass sich die beobachtete Hyperphosphorylierung (Abb. 4 und Abb. 7) auf eine verminderte Dephosphorylierung zurückzuführen lässt, erfolgte bei STAT1-E585A die Durchführung eines In-vitro-Dephosphorylierungs-Assays. Hierfür wurden von STAT1-WT-GFP- und STAT1-E585A-GFP-exprimierenden U3AZellen nach 45-minütiger Stimulation mit $10 \mathrm{ng} / \mathrm{mL}$ IFN $\gamma$ Gesamtzellextrakte hergestellt. Anschließend wurden diese Extrakte für die angegebenen Zeiten bei $30^{\circ} \mathrm{C}$ mit Tc45-Protein-Tyrosin-Phosphatase inkubiert, um eine Dephosphorylierung zu induzieren. Der elektrophoretischen Auftrennung der Proteine mittels PolyacrylamidGelelektrophorese schloss sich eine Western-Blot-Analyse an. Durch die Behandlung der Blot-Membranen mit einem Phopho-STAT1-Antikörper erfolgte im Immunoblot die Detektion der Tyrosin-Phosphorylierungsbanden. Zur Bestimmung der STAT1Menge wurden nach stringentem Waschen die Membranen mit einem pan-STAT1Antikörper reinkubiert. Abb. 10 demonstriert das Ergebnis der In-vitro-Dephosphorylierung. Das Phosphorylierungssignal der Punktmutante ist mit zunehmender Tc45PTP-Inkubationsdauer mit dem des STAT1-WT vergleichbar. Durch dieses Experiment konnte bewiesen werden, dass die Hyperphosphorylierung bei STAT1-E585A nicht auf eine kompromittierte Dephosphorylierungskinetik zurückzuführen ist. Somit ist STAT1-E585A keine Dephosphorylierungsmutante. 


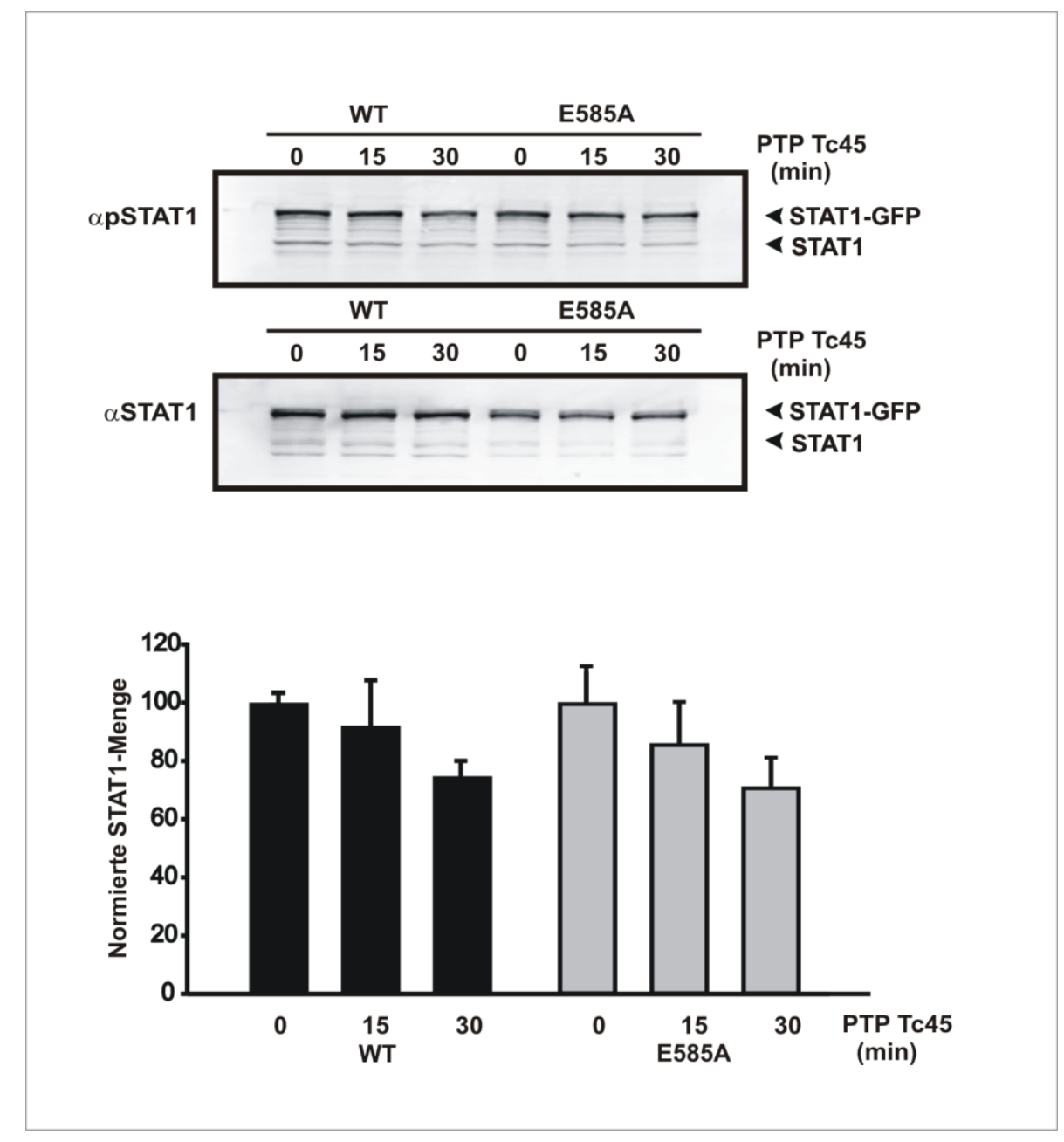

Abb. 10: Gleiche Dephosphorylierungskinetik der STAT1-Varianten E585A und -WT. Nach der Transfektion von U3A-Zellen mit pSTAT1-WT-GFP bzw. pSTAT1-E585A-GFP fand am Folgetag eine 45-minütige Stimulation mit $10 \mathrm{ng} / \mathrm{mL}$ IFN $\gamma$ statt, um Gesamtzellextrakte zu gewinnen. Nach erfolgter Inkubation mit der Tyrosin-Phosphatase Tc45-PTP bei $30^{\circ} \mathrm{C}$ für die angegebenen Zeiten wurden die Dephosphorylierungsreaktionen mittels Western-BlotAnalysen überprüft. Die obere Abbildung stellt das Ergebnis nach Inkubation mit einem Phospho-STAT1-Antikörper dar, die Mittlere eine Reinkubation derselben Membran mit einem STAT1-spezifischen Antikörper und die Untere die entsprechende Quantifizierung aus mindestens drei unterschiedlichen Versuchen nach gleichem Protokoll.

\subsection{Die Hyperphosphorylierung führt zu einer geänderten Reportergen- Aktivität von STAT1-E585A}

Um mögliche Folgen der Mutation auf die IFN $\gamma$-induzierte Genaktivierung feststellen zu können, erfolgte ein Reportergen-Assay. Hierzu fand zunächst die Transfektion von U3A-Zellen mit pSTAT1-WT-GFP bzw. pSTAT1-E585A-GFP, pGAS3xLy6E sowie $p \beta G$ al statt. Bei dem verwendeten Luciferase-Reportergenkonstrukt handelt es 
sich um einen synthetischen Promotor mit drei hintereinander liegenden GASBindestellen (3xLy6E) in einem Abstand von $10 \mathrm{bp}$. Die Zellen wurden am Folgetag entweder unstimuliert gelassen oder $6 \mathrm{~h}$ mit $5 \mathrm{ng} / \mathrm{mL}$ IFN $\gamma$ stimuliert. Anschließend fand eine spektrometrische Messung der Luciferase-Aktivität im Photometer statt und die gemessene Aktivität der Luciferase wurde auf die $\beta$-Galactosidaseaktivität normiert. Wie in Abb. 11 demonstriert wird, hat die Mutation an Position 585 einen signifikanten Einfluss auf die transkriptionelle Aktivität: STAT1-E585A zeigt im Vergleich zum STAT1-WT eine verbesserte transkriptionelle Aktivität. Anhand dieses Experiments kann somit ein zweiter phänotypischer Unterschied zum STAT1-WT nachgewiesen werden.

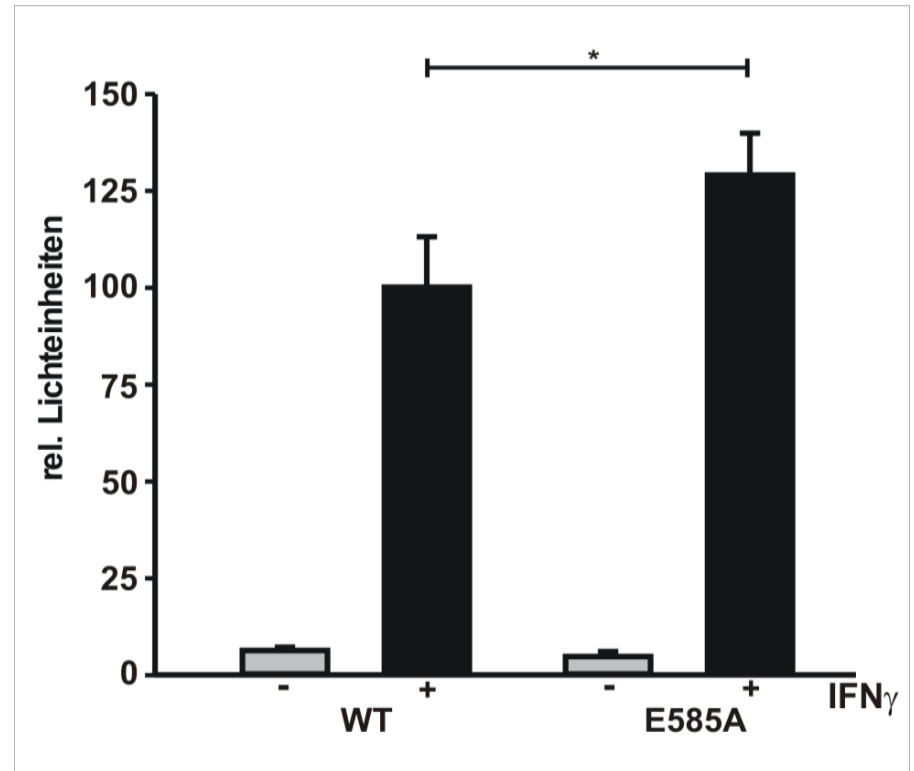

Abb. 11: Dargestellt ist das Ergebnis eines Reportergen-Assays mit verbesserter IFN $\gamma$ abhängiger Genaktivierung durch die STAT1-Mutation E585A. Nach der Transfektion von U3A-Zellen mit den Vektoren pSTAT1-WT bzw. PSTAT1-E585A sowie den ReportergenKonstrukten p3xLy6E und p $\beta G$ al wurden diese 16-24 $\mathrm{h}$ danach entweder unbehandelt belassen (graue Balken) oder für $6 \mathrm{~h}$ mit $5 \mathrm{ng} / \mathrm{mL} \mathrm{IFN} \gamma$ stimuliert (schwarze Balken). Nach der Herstellung von Zellextrakten erfolgte die Bestimmung der Luciferase-Aktivität in Proben von gleich großer Zellzahl. Dabei erfolgte die Normierung der Luciferase-Aktivität auf die spektrometrisch gemessene $\beta$-Galactosidase-Aktivität der jeweiligen Proben. Statistisch signifikante Abweichungen sind durch das Symbol $\left(^{*}\right)$ gekennzeichnet $(p=0,001)$.

Um die verbesserte transkriptionelle Aktivität zu bestätigen, erfolgte die Untersuchung von STAT1-E585A in weiteren Reportergen-Assays unter Verwendung eines nativen Promotors mit singulärer GAS-Bindestelle. Hierbei kam das Reporter- 
gen pIC-339 mit einem trunkierten Promotor des icam1-Gens zum Einsatz. Wie oben beschrieben, erfolgte die Transfektion von U3A-Zellen mit den Vektoren pSTAT1WT-GFP, pSTAT1-E585A-GFP, pIC-339 und p $\beta$ Gal. Es fand eine Sechsfach-Bestimmung statt, bei der die Zellen entweder für $6 \mathrm{~h}$ mit $10 \mathrm{ng} / \mathrm{mL}$ IFN $\gamma$ stimuliert oder unbehandelt gelassen wurden.

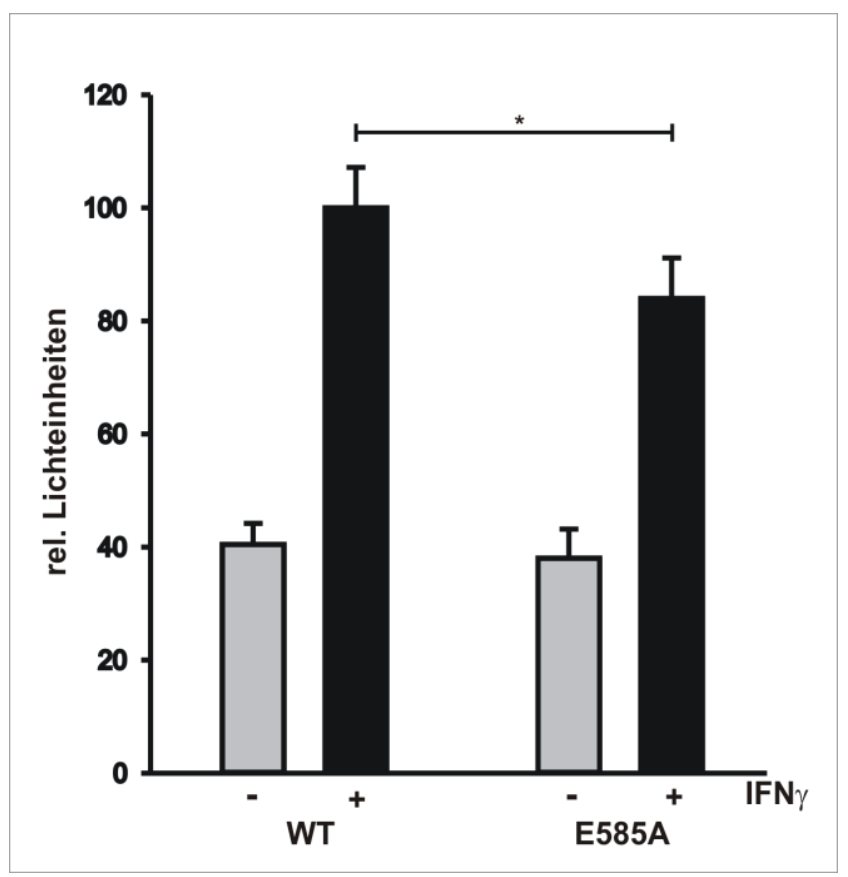

Abb. 12: Eine verbesserte transkriptionelle Aktivität der Mutante konnte unter Verwendung von nativen Promotorelementen nicht bestätigt werden. Nach der Transfektion von U3A-Zellen mit den Vektoren pSTAT1-WT und PSTAT1-E585A, dem Vektor pIC-339 und p $\beta$ Gal erfolgte 16-24 h danach die Stimulation der Zellen mit $10 \mathrm{ng} / \mathrm{mL}$ IFN $\gamma$ für $6 \mathrm{~h}$ (schwarzer Balken) oder sie blieben unbehandelt (grauer Balken). Nach Lyse der Zellen wurde die Luciferase-Induktion auf die $\beta$-Galaktosidase-Aktivität normiert. Es erfolgte eine Sechsfach-Bestimmung. Die dargestellten Mittelwerte und Standardabweichungen beziehen sich auf sechs unabhängige Transfektionen. Der Stern markiert statistisch signifikante Unterschiede.

Die $\beta$-Galaktosidase-Aktivität diente dabei der Normierung der spektrometrisch erfassten Luciferase-Aktivität der Zellextrakte. Abb. 12 demonstriert, dass nach IFN $\gamma$ Stimulation unter Verwendung von nativen Promotoren keine verbesserte Genaktivierung der Punktmutante STAT1-E585A beobachtet wird. Die transkriptionelle Aktivität von STAT1-E585A ist in diesem Fall mit dem STAT1-WT vergleichbar. 


\subsection{Erhöhte Expression des mcp1-Gens durch STAT1-E585A}

Um die Induktion von nativen STAT1-Zielgenen in vivo analysieren zu können, wurden Real-time-PCR-Experimente durchgeführt. Die Untersuchungen fanden dabei mithilfe einer Doppelbestimmung an sechs literaturbekannten endogenen Zielgenen von STAT1 statt, die durch IFN $\gamma$-Stimulation aktiviert werden. In den durchgeführten Experimenten gelang es, über die Messung der emittierten Fluoreszenzsignale eine direkte Aussage über die Menge an Transkript-mRNA zu treffen, da die Zunahme der Fluoreszenz proportional zur Genexpression verlaufen muss.

Für die Quantifizierung wurden die Expressionsdaten der jeweiligen STAT1-Zielgene auf das Expressionsniveau des Haushaltsgens gapdh normiert. Im Verlauf des Experiments erfolgte die transiente Transfektion von U3A-Zellen mit den pcDNAKonstrukten pSTAT1-WT oder pSTAT1-E585A. Anschließend wurden die transfizierten Zellen im serumarmen Kulturmedium mit 1\% FCS kultiviert, um sie am darauffolgenden Tag für $0 \mathrm{~h}$ oder $6 \mathrm{~h}$ mit $10 \mathrm{ng} / \mathrm{mL}$ IFN $\gamma$ zu stimulieren. Im nächsten Schritt erfolgte die Isolierung der RNA aus den STAT1-exprimierenden U3A-Zellen und ihre Umschreibung in cDNA, um aus ihr die Genexpression mittels RT-PCR quantitativ bestimmen zu können.

In der Abb. 13 wird der Vergleich zwischen STAT1-WT und STAT1-E585A dargestellt. Es wird deutlich, dass die Mutante im Vergleich zum STAT1-WT nach IFN $\gamma$ Stimulation vor allem eine signifikante Zunahme der Induktion der beiden STAT1Zielgene mcp1 und cxc/10 aufweist. 

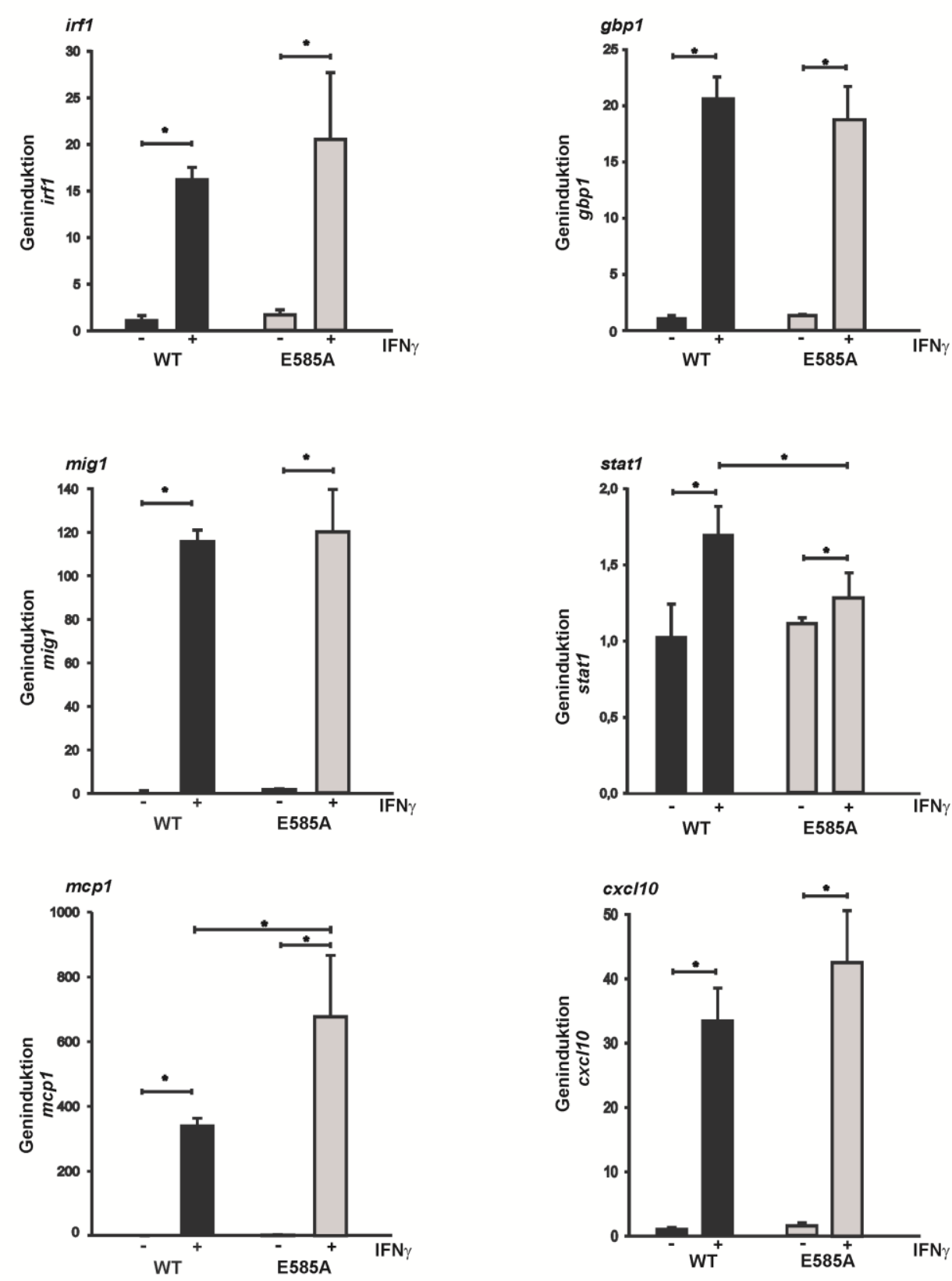

Abb. 13: Die Punktmutanten zeigen eine verminderte In-vivo-Genaktivierung. Nach der Transfektion der U3A-Zellen mit pSTAT1-WT oder pSTAT1-E585A erfolgte ihre Kultivierung im Nährmedium mit 1\% FCS. Am Folgetag wurden sie für $6 \mathrm{~h}$ mit $10 \mathrm{ng} / \mathrm{mL}$ Interferon- $\gamma$ (schwarzer Balken) stimuliert oder unstimuliert gelassen (grauer Balken). Anschließend wurde nach Extraktion der RNA aus den lysierten Zellen cDNA hergestellt. Im Zuge der Real-time-PCR wurde die Genexpression von STAT1-Zielgenen ermittelt. Ihre Normierung fand dabei auf die Induktion des Haushaltsgenes gapdh statt. Im Rahmen einer Doppelbestimmung wurden Mittelwerte und Standardabweichungen bestimmt. Der Stern markiert statistisch signifikante Unterschiede. 


\section{Diskussion}

Die STAT1-vermittelte Signalverarbeitung ist von allen STAT-Proteinen wohl am besten, obgleich immer noch lückenhaft verstanden. Gut belegt ist, dass nach IFN $\gamma$ Stimulation die intrazelluläre Signalweiterleitung über die Ausbildung von STAT1/STAT1-Homodimeren ausgelöst wird. Aktivierte Janus-Kinasen phosphorylieren daraufhin die STAT-Moleküle an einem kritischen Tyrosinrest, woraufhin diese mithilfe von Transportmechanismen in den Zellkern gelangen. Dort erfolgt ihre Bindung an die DNA, um die Transkription IFN $\gamma$-induzierter Gene herbeizuführen. Die Tyrosin-Phosphorylierung stellt somit die wichtigste Voraussetzung für die Akkumulation der Proteine im Nukleus, die Bindung an DNA sowie die Zytokin-abhängige Zielgenaktivierung dar.

Bevor sich der Linker- und SH2-Domäne bei der Steuerung der Interferon-Antwort zugewandt wird, soll hier zunächst ein kurzer Überblick über die verschiedenen Domänen des STAT1-Moleküls gegeben werden. Bei der aminoterminalen Domäne des Proteins handelt es sich um eine stark konservierte Sequenz, die bei STAT1 aus 135 AS besteht und in vitro proteolytisch vom sogenannten Kernfragment abspaltbar ist (Vinkemeier et al. 1996; Murphy et al. 2000). Die N-Domäne weist innerhalb der STAT-Familie einen ähnlichen strukturellen Aufbau auf; allerdings kann sie innerhalb der Mitglieder der STAT-Protein-Familie nicht beliebig ausgetauscht werden (Strehlow und Schindler 1998; Murphy et al. 2000). Wie Analysen der Kristallstruktur von STAT4 zeigen, bilden jeweils acht kurze $\alpha$-Helices einen hakenförmigen Ring aus (Schindler und Darnell 1995; Strehlow und Schindler 1998; Vinkemeier et al. 1998). Mutationsexperimente machten deutlich, dass der Aminoterminus an vielen bedeutenden Funktionen der STAT-Proteine teilnimmt. Eine zentrale Rolle kommt inm bei der Vermittlung von Protein-Protein-Interaktionen zwischen benachbarten Dimeren zu, die eine kooperative DNA-Bindung der Dimere an Gamma-aktivierten Sequenzen (GAS) ermöglicht. Durch diese Oligomerisierung bzw. Tetramerisierung kann eine Stabilisierung der DNA-Bindungsaktivität an schwachen Promotoren erfolgen (Vinkemeier et al. 1996; Xu et al. 1996; Stark et al. 1998; John et al. 1999). Zusätzlich ist die aminoterminale Domäne des STAT1Proteins für den Transport des phosphorylierten Proteins in den Nukleus notwendig (Meissner et al. 2004). Darüber hinaus wurden im Bereich des aminoterminalen 
Endes des STAT1-Proteins spezifische Oberflächen entdeckt, die mit dem CREBbindenden Protein (CBP/p300) (Liao et al. 2000), dem Protein-Inhibitor von aktiviertem STAT 1 (PIAS1) (Horvath 2000) und Zytokin-Rezeptoren (Leung 1996; Murphy 2000) interagieren. Zuletzt scheint der Aminoterminus bei der Dephosphorylierung einen bedeutsamen Part zu übernehmen. Hierfür wurde mithilfe von Mutationsexperimenten ein konservierter Phenylalaninrest in Position 77 von STAT1 (Position 81 von STAT5), der für die Oligomerisierung und Tyrosindephosphorylierung von STAT-Molekülen essentiell ist, zu Alanin mutiert. Dadurch war die Möglichkeit zur Bildung von Tetrameren und damit verbunden die Fähigkeit zur kooperativen DNA-Bindung erschwert (Meyer et al. 2004a). Die Vermutung lag darin, dass die erzeugten Mutanten nicht mehr dazu fähig waren, den Wechsel zwischen paralleler und antiparalleler Konformation durchzuführen, welcher jedoch für die Rekrutierung der TC45-Phosphatase unentbehrlich ist. Diese Mutanten zeigten im Versuch folglich kaum eine Abnahme des Phosphorylierungsniveaus (Shuai et al. 1996; Strehlow und Schindler 1998; Meyer et al. 2004; Mao et al. 2005; Mertens et al. 2006). Des Weiteren konnte anhand von Deletionsexperimenten mit STAT1und STAT4-Mutanten, die um 88 bzw. 44 Aminosäurereste am Aminoterminus trunkiert waren, gezeigt werden, dass der Aminoterminus die Fähigkeit zur kooperativen DNA-Bindung von STAT-Dimeren beeinflusst (Xu et al. 1996).

Auf den Aminoterminus folgt im STAT1-Molekül die Coiled-coil-Domäne, die mit diesem über eine flexible Region von 20 AS verbunden ist und die die Aminosäuren 136 bis 316 enthält (Mertens et al. 2006). Den strukturellen Aufbau der Coiled-coilDomäne bilden vier antiparallele $\alpha$-Helices (Chen et al. 1998; Levy und Darnell 2002). Ihre Funktion erfüllt die Coiled-coil-Domäne im Rahmen von Protein-ProteinInteraktionen, indem sie die zweite Interaktionsfläche für die Bindung des einen Monomers mit der DNA-Bindedomäne des zweiten Monomers herstellt. Somit trägt sie zur Stabilisierung der antiparallelen Konformation des Proteins bei. Durch Mutation der Reste, die an dieser Interaktion beteiligt sind (Q340, L383, G384, T385, H406, Q408 in der DBD und besonders F172 in der CCD), kam es zu einer Verringerung der Stabilität der antiparallelen Form, mit der Folge, dass das Molekül hyperphosphoryliert blieb (Mao et al. 2005; Mertens et al. 2006). Zusätzlich besitzt die Vier-Helix-Struktur eine leucinreiche helikale Region, die als nukleäres Exportsignal (NES) dient (Begitt et al. 2000). Zuletzt kann die Coiled-coil-Domäne 
als potentielle Kontaktstelle für andere Transkriptionsfaktoren dienen. So kann zum Beispiel die Mutation eines Lysinrestes zu Alanin an Stelle 161 der Coiled-coilDomäne dazu führen, dass das Protein nicht mehr an p48 binden kann. Diese Bindung ist jedoch für die Ausbildung des ISGF3-Transkriptionskomplexes essentiell (Bromberg und Darnell 2000; Shuai 2000).

Die DNA-Bindedomäne liegt carboxyterminal der Coiled-coil-Domäne und gehört wie diese zum Kerngerüst des STAT1-Proteins. Sie hat eine Länge von annähernd 170 Aminosäuren (317-487) und weist eine Immunglobulin-ähnliche Struktur auf, die sich aus $\beta$-Faltblattstrukturen und Schleifen zusammensetzt (Chen et al. 1998; Levy und Darnell 2002). Sie beinhaltet eine Region, die palindromische GAS-Sequenzen erkennt und über diese mit der DNA-Doppelhelix interagiert. Hierbei findet jeweils eine Wechselwirkung eines phosphorylierten STAT-Monomers mit einer halben palindromischen Sequenz statt (Chen et al. 1998; Decker et al. 1997). Dabei findet die Bindung an die DNA sowohl mit der kleinen als auch mit der großen Furche statt. Hierbei interagiert die Aminosäure E421 mit der kleinen, während die Aminosäuren N460 und K336 mit der großen Furche interagieren (Chen et al. 1998). Es konnte gezeigt werden, dass Mutationen in diesem Bereich eine Verringerung der Affinität des Proteins zur DNA zur Folge haben (Darnell 1997; Decker et al. 1997; Stark et al. 1998; Williams et al. 2000). Beispiele für solche Mutationen sind die DNA-MinusMutante (V426D, T427D) sowie die DNA-Plus-Mutante (T327R, V426H und T427H, Meyer et al. 2003). Bei der DNA-Minus-Mutante konnte weder eine Bindung an GAS-Stellen noch an Nicht-GAS-Stellen der DNA beobachtet werden; daraus folgend fand bei dieser Mutante auch keine Kernakkumulation statt. Im Vergleich dazu beobachtete man bei der DNA-Plus-Mutante eine verlängerte Protein-Tyrosin-Phosphorylierung sowie eine verlängerte Dauer der Kernakkumulation in den durch IFN $\gamma$ Stimulation behandelten Zellen. Außerdem zeigt sich bei dieser Mutante zusätzlich eine unspezifische Bindung an Nicht-GAS-Elemente im Vergleich zum WT. Trotz der Tatsache, dass diese Mutante im Vergleich zum WT eine höhere Affinität zu unspezifischen DNA-Sequenzen hatte, konnte keine transkriptionelle Aktivität der STAT1-Zielgene beobachtet werden (Meyer et al. 2003). Eine weitere Funktion der DBD ist die Vermittlung der Bindung an Importin- $\alpha 5$. Der Kernimport geschieht dabei mittels eines Dimer-spezifischen nukleären Lokalisationssignals (ds-NLS) (Fagerlund et al. 2002; McBride et al. 2002; Meyer et al. 2002). 
Die Linker-Domäne beinhaltet helikale Strukturen und verbindet die DBD mit der SH2-Domäne. Sie reicht beim STAT1-Protein von der Aminosäure 488 bis 575 und umfasst folglich 88 AS-Reste (Chen et al. 1998, Levy und Darnell 2002). Ihre Funktion ist noch weitestgehend unbekannt, doch scheint ihre Hauptaufgabe darin zu liegen, die DNA-Bindung durch Auslösung von strukturellen Änderungen in der SH2Domäne zu modulieren. Folglich hat sie auch einen Einfluss auf die Regulation der transkriptionellen Aktivität (Chen et al. 1998; Yang et al. 1999). Mutationen in diesem Bereich des Proteins haben oft eine Veränderung der transkriptionellen Aktivität sowie eine veränderte Dissoziationsrate von der DNA zur Folge (Yang et al. 1999; Yang et al. 2002). Die Linker-Domäne scheint auch bei der nukleozytoplasmatischen Translokation des STAT-Proteins eine Rolle zu spielen, da sie die Bindung des STAT1 an den Kernporen-Komplex beeinflusst (Marg et al. 2004).

Auf die Linker-Domäne folgt im STAT1-Protein die SH2-Domäne. Der namensgebende Domänentyp wurde ursprünglich als nichtkatalytische, konservierte Domäne mit einer Länge von ca. 100 Aminosäureresten in der zytoplasmatischen Tyrosinkinase des Fujinami-Sarkoma-Virus (v-fps) und später auch in der Sequenz der Tyrosinkinase Src aminoterminal der Kinase-Domäne (SH1-Domäne) identifiziert. Daher wird sie auch als Src-Homolgie-2-Domäne (SH2) bezeichnet (Sadowski et al. 1986; Pawson 1988; Koch et al. 1991). Sie liegt im STAT1-Protein carboxyterminal der Linker-Domäne und umfasst die Aminosäurereste 576 bis 682. In allen STATProteinen ist sie die am stärksten konservierte Domäne. Im Rahmen kristallographischer Analysen konnte ein struktureller Unterschied der SH2-Domäne von STATProteinen mit anderen Proteinen festgestellt werden (Gao et al. 2004). Die Grundstruktur der SH2-Domäne $(\alpha \beta \beta \beta \alpha)$ besteht aus zwei $\alpha$-Helices $(\alpha A$ und $\alpha B)$, die ein zentrales antiparalleles $\beta$-Faltblattmotiv $(\beta B-\beta D)$ einfassen (Waksman et al. 1992;

Chen et al. 1998, Gao et al. 2004). Im Unterschied zur Kristallstruktur der Src-SH2Domäne $(v$-src) besitzt die STAT-SH2-Domäne ein anderes $\beta$-Motiv und fünf $\alpha$ Helices, die der Linker-Domäne entsprechen (Gao et al. 2004). Bei der Signalweiterleitung kommt ihr im Rahmen der Homo- und Heterodimerisierung sowie der Rekrutierung von STAT1-Monomeren an die phosphorylierten Abschnitte von membranständigen Rezeptoren oder intrazellulären Tyrosinkinasen eine bedeutende Funktion zu (Shuai et al. 1994; Becker et al. 1998). Die SH2-Interaktion wird fast ausschließlich durch die Aminosäurereste 701-708 vermittelt (Shuai et al. 1994). 
Auch Sequenzen carboxyterminal des phosphorylierten Tyrosinrestes können von der SH2-Domäne erkannt werden, woraus ein unterschiedliches Bindeverhalten resultiert, das sich in der Spezifität der unterschiedlichen SH2-Domänen deutlich macht (Koch et al. 1991; Songyang et al. 1993; Pawson et al. 2001). Die Dimerisierung basiert auf der reziproken Interaktion eines invarianten phosphorylierten Tyrosinrestes des einen Monomers mit der SH2-Domäne des zweiten Monomers (Shuai et al. 1993; Chen et al. 1998). Dabei wird ein Phosphotyrosinrest in Position 701 des kontralateralen Monomers vom konservierten Argininrest in Position 602 erkannt. Die Interaktion wird durch einen Lysinrest in der SH2-Domäne an der Position 584 sowie von den Aminosäuren in der Nähe des Phosphotyrosins an den Positionen zwischen 701 und 708 vermittelt. Durch die Wechselwirkung der SH2Domänen beider Monomere mit dem Tyrosinphosphat kommt es zur Bildung stabiler Homodimere in paralleler Konfiguration (Wenta et al. 2008). STAT-1-Proteine, bei denen eine Mutation am Argininrest in Position 602 stattgefunden hat, verlieren die Fähigkeit zur Dimerisierung (Shuai et al. 1994; Chen et al. 1998). Eine weitere Funktion der SH2-Domäne liegt in der Regulierung katalytischer Domänen von Tyrosinkinasen. Ein Beispiel hierfür ist die Tyrosinkinase v-fps. Nachdem Phosphotyrosinpeptide an die Kinase gebunden haben, wirkt die SH2-Domäne als positiver Effektor der Reaktion, indem sie die enzymatische Aktivität der Kinase-Domäne steigert (Koch et al. 1989). Nicht nur Enzyme, sondern auch viele regulatorische Proteine verfügen über eine SH2-Domäne, mit deren Hilfe es dem Adapterprotein ermöglicht wird, tyrosinphosphorylierte Substrate zu erkennen und zu ubiquitilieren. Ein Beispiel für solch ein regulatorisch wirkendes Protein ist das c-Cbl (casitas blineage lymphoma proto-oncogene) (Joazeiro et al. 1999; Pawson et al. 2001). Im STAT-Molekül folgt auf die SH-2-Domäne die carboxyterminal liegende Transaktivierungsdomäne (TAD), die mit dieser flexibel in Verbindung steht und innerhalb des STAT-Moleküls die geringste Konservierung aufweist. Im Bezug auf ihre Länge, die sich auf 40-200 Aminosäuren beläuft, herrscht eine große Variabilität. Wahrscheinlich ist diese Tatsache mit verantwortlich für die Zielgenspezifität von STATProteinen (Paulson et al. 1999). Im STAT1 $\alpha$-Protein weist die TAD eine Länge von 68 Aminosäuren auf. In der Transaktivierungdomäne von STAT1 ist ein konservierter Serinrest in Position 727 lokalisiert, der nicht, wie früher angenommen, für die veränderte DNA-Bindeaffinität, sondern für eine maximale transkriptionelle Aktivität bedeutsam ist (Wen und Darnell 1997; Wen et al. 1995). Außerdem beinhaltet die 
TAD den kritischen Tyrosinrest in Position 701, der durch Rezeptor-Kinasen phosphoryliert wird und somit einen großen Einfluss auf die transkriptionelle Aktivität ausübt (Schindler et al. 1992; Shuai et al. 1992). Zu den weiteren Funktionen der TAD gehören zum einen die Regulierung des Stress-induzierten Zelltodes (Janjua et al. 2002; Stephanou und Latchman 2003), zum anderen die Protein-ProteinInteraktionen mit MCM5 (Zhang et al. 1998), NCoA1 (Litterst und Pfitzner 2001), CBP/p300 (Zhang et al. 1996) und BRCA1 (Ouchi et al. 2000).

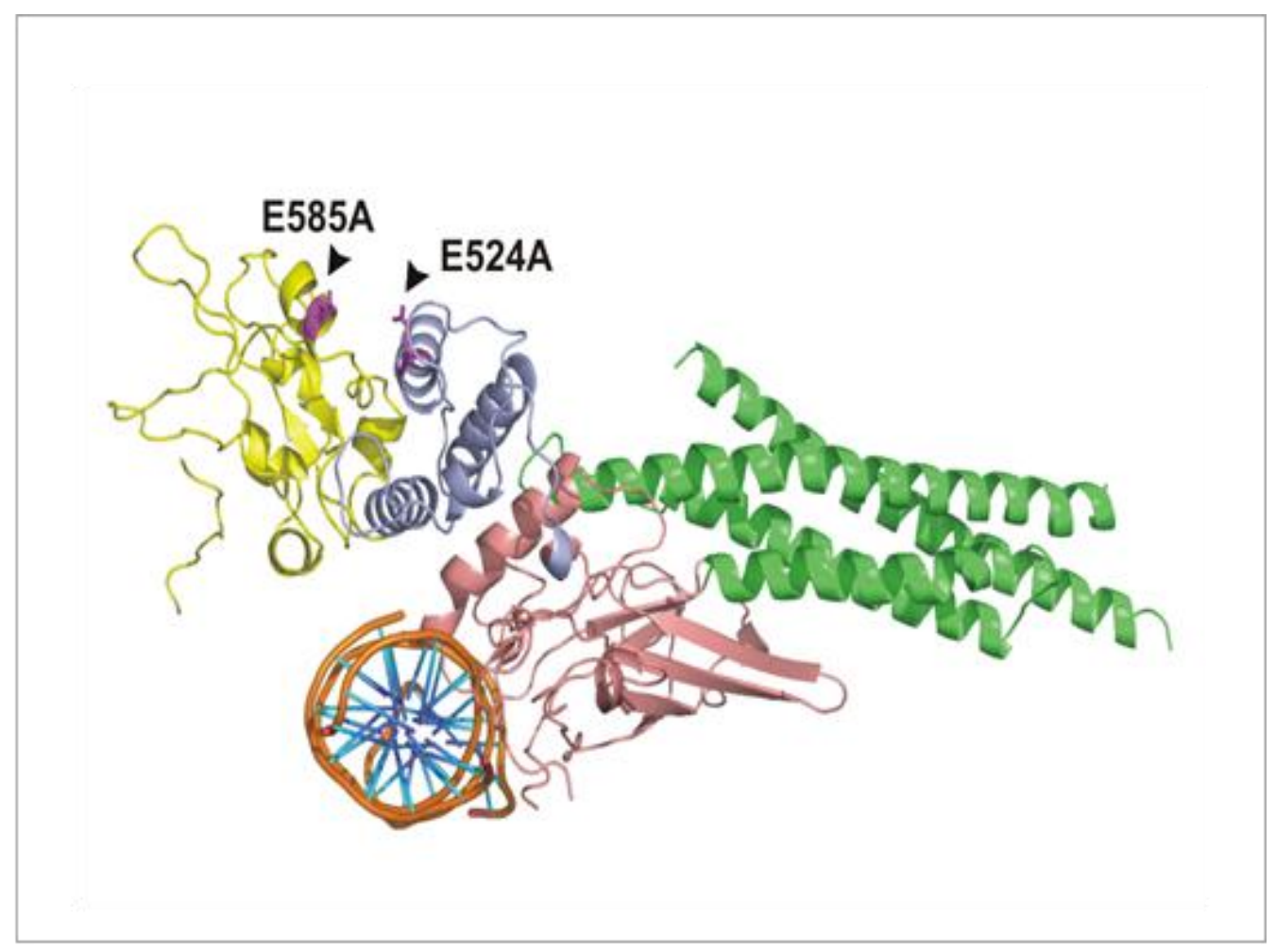

Abb. 14: Kristallstruktur eines DNA-gebundenen STAT1-Monomers mit den in dieser Arbeit eingeführten Punktmutationen. Es werden die vier Domänen des Kernfragments von STAT1 $\alpha$ dargestellt. Die Coiled-coil-Domäne ist in grün, die DNA-Bindedomäne in lachs, die Linker-Domäne in grau und die SH2-Domäne in gelb hervorgehoben.

In der vorliegenden Dissertationsschrift wurden durch Austausch zweier Glutaminsäurereste in Position 524 und 585 Punktmutanten generiert, von denen eine im Vergleich zum STAT1-WT ein erhöhtes Phosphorylierungsniveau aufweist. Um beide Mutanten bezüglich dieser Eigenschaften analysieren zu können, wurden in dieser Arbeit verschiedene Experimente durchgeführt. Die Seitenketten der mutierten Aminosäurereste sind in den krsitallographischen Darstellungen des DNA-gebundenen STAT1 in den Abb. 14-16 hervorgehoben. 


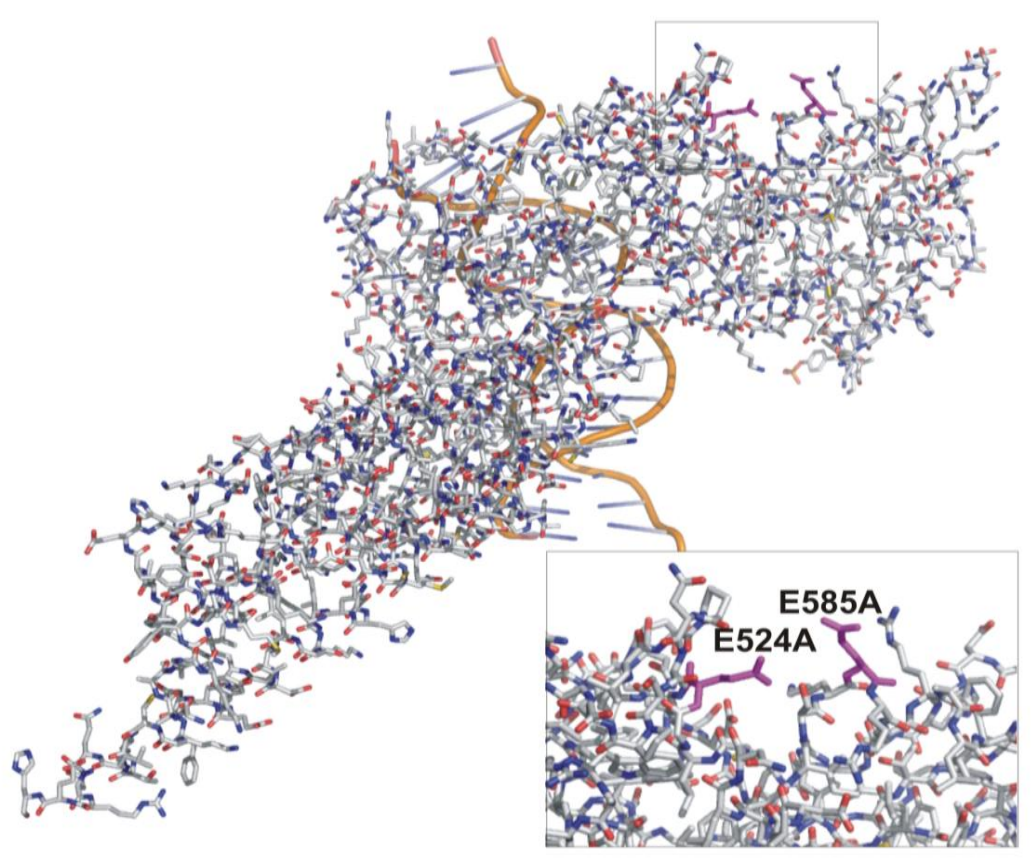

Abb. 15: Darstellung der Kristallstruktur eines STAT1-Monomers mit Seitenketten und den beiden in dieser Arbeit untersuchten Punktmutanten. Die beiden Glutamatreste sind in Magenta dargestellt.

Zunächst nahm man an, die Hyperphosphorylierung sei die Folge einer veränderten Kinetik der Kernakkumulation, hervorgerufen durch einen Import-Defekt im Rahmen des STAT1-Transports in den Nukleus. Wie in dieser Arbeit beschrieben wurde, ist STAT1 im in unstimulierten Zustand überwiegend panzellulär verteilt. Nach Zytokinstimulation jedoch kommt es zur Translokation des größten Teils des STAT1 in den Nukleus. Da STAT-Moleküle aufgrund ihrer Molekülgröße nicht dazu in der Lage sind, die Kernmembran mittels freier Diffusion zu durchqueren, werden zu diesem Zweck bestimmte Transportmechanismen benötigt (Paine und Feldherr 1972; Weis 1998). Die auf dieser Weise in den Zellkern transportierten Tyrosin-phosphorylierten STAT1-Dimere können dann über Rezeptoren, die als Importine (Importrezeptoren) bezeichnet werden, mit dem Porenkomplex interagieren und so in den Zellkern transportiert werden. Da die Mutante STAT1-E585A hyperphosphoryliert ist, liegt der Gedanke nahe, dass ein Import-Defekt dazu führen könnte, ihren Transport in den Zellkern im Vergleich zum Wildtyp-Molekül zu verringern bzw. ganz aufzuheben. Diese Annahme beruht auf der Kenntnis, dass sich der Aminosäurerest E425 in einer Region befindet, die das nukleäre Lokalisationssignal (dsNLS) enthält. Dieses Signal ermöglicht die Bindung von STAT1-Dimeren an Importin a5 und ist somit essentiell für die Kernakkumulation (Fagerlund et al. 2002; McBride et al. 2002; Meyer et al. 
2002; Nardozzi et al. 2010). STAT1-Mutanten, deren nukleärer Import beeinträchtigt ist, haben dementsprechend eine erhöhte zytosolische Anwesenheit und sind dort weniger der Phosphatase-Aktivität ausgesetzt. Folglich käme es in diesem Fall zu einer höheren Anzahl von STAT1-Dimeren im Zytoplasma, wo sie vermehrt zu einem Substrat der Kinasen werden. Die Phosphorylierung von STAT1-Dimeren schreitet immer weiter voran und führt letztendlich zu einer Hyperphosphorylierung der Punktmutante. Um dieser Hypothese auf den Grund zu gehen, wurden in dieser Forschungsprojekt Experimente mit GFP-Fusionsproteinen durchgeführt, die die Kinetik der Kernakkumulation analysieren.

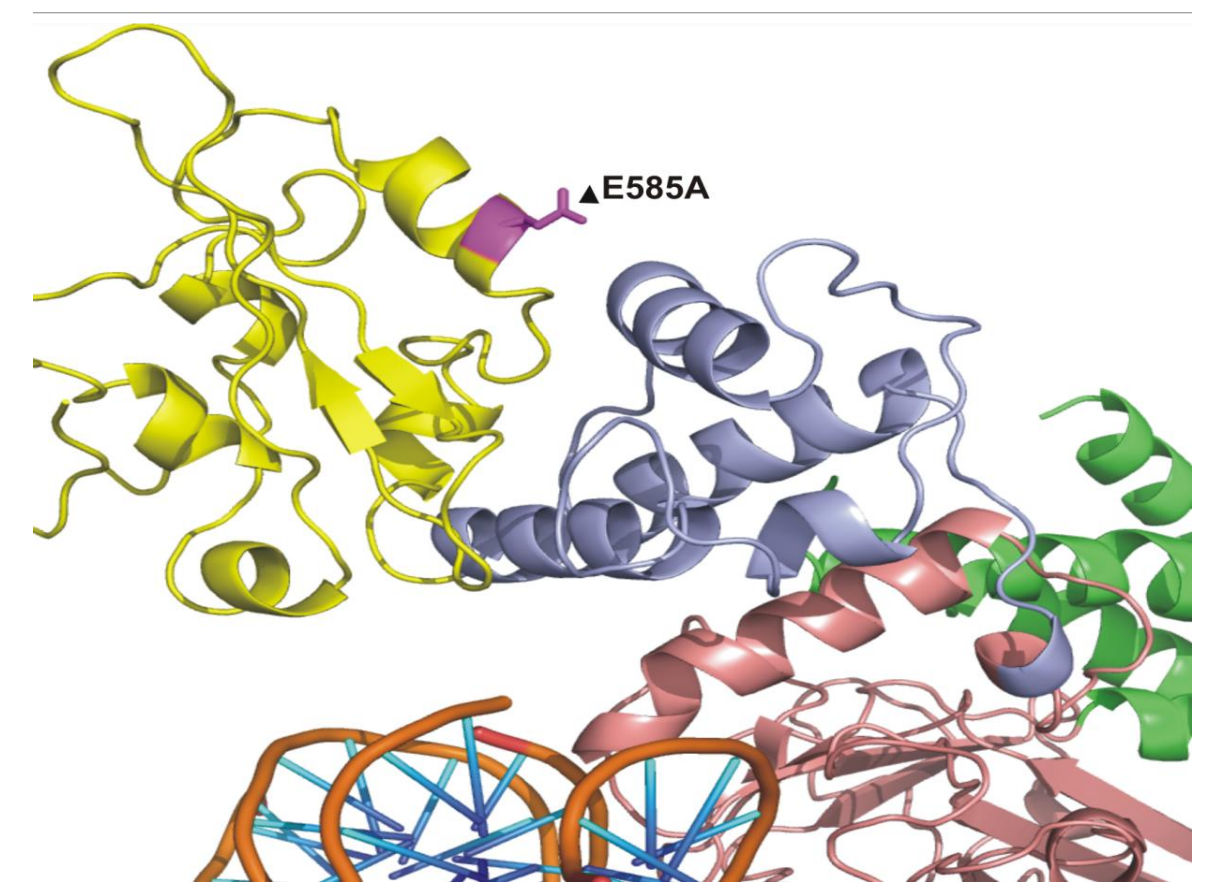

Abb. 16: Ausschnitt der STAT1-Kristallstruktur mit der in dieser Arbeit untersuchten Punktmutante STAT1-E585A. In der DNA-gebundenen Form mit Darstellung nur eines STAT1-Monomers sind der AS-Rest E585 (magenta), die SH2-Domäne (gelb), die LinkerDomäne (blaugrau), die Coiled-coil-Domäne (grün) und die DNA-Bindedomäne (lachs) farblich hervorgehoben.

Eine fluoreszenzmikroskopisch beobachtete verlängerte Kernakkumulation von STAT1 nach IFN $\gamma$-Stimulation konnte weder bei STAT1-E585A noch bei STAT1E524A detektiert werden (Abb. 5). Somit kann ein Import-Defekt beider Mutanten und eine damit verbundene Hyperphosphorylierung als Ursache einer erniedrigten Kernakkumulation bzw. einer Retention im Zytoplasma ausgeschlossen werden. 
Im STAT1-Molekül ist eine Änderung in der Dissoziationsrate von DNA mit einem abnormalen DNA-Bindeverhalten, einer geänderten Tyrosin-Dephosphorylierung sowie einer üblicherweise gestörten transkriptionellen Aktivität verbunden. In Anbetracht dieser Tatsache könnte eine weitere Erklärung für die beobachtete Hyperphosphorylierung bei STAT1-E585A die Möglichkeit einer veränderten Dissoziationskinetik im Sinne einer erniedrigten Dissoziationsrate von der DNA sein. Zudem bestand die Annahme, dass ein Austausch von einem negativ geladenen zu einem positiv geladenen Aminosäurerest, die elektrostatische Anziehungskraft des STATProteins zu der aufgrund des Phosphatrückgrats negativ geladenen DNA verstärken könnte. Um diese Behauptung auf ihrer Richtigkeit zu untersuchen, wurden weitere Gelshift-Experimente durchgeführt. Dort zeigte sich, dass STAT1-E585A und STAT1E524A weder eine Veränderung der Dissoziationskinetik von der DNA, noch eine erhöhte DNA-Bindungsaffinität aufweisen. Schon nach 5-minütiger Kompetition mit unmarkierter Sonde war in den Gelshift-Assays kaum noch eine Bindung an DNASonden vorhanden (Abb. 8 und 9). Somit kann ausgeschlossen werden, dass die Hyperphosphorylierung auf eine verlängerte DNA-Bindung bzw. eine erhöhte Affinität zur DNA-Bindung zurückzuführen ist, und dass es sich weder bei STAT1-E585A noch bei STAT1-E524A um DNA-Bindemutanten handelt.

Wie frühere Arbeiten unabhängig voneinander demonstrierten, schützt die DNABindung vor Dephosphorylierung (Meyer et al. 2003; Meyer et al. 2004). Generell unterscheidet man zwei verschiedene Konformationen der tyrosinphosphorylierten STAT-Dimere, die parallele und die antiparallele Konformation. In der parallelen Konfiguration zeigen die SH2-Domänen in dieselbe Richtung. Die antiparallele Form hat jedoch unterschiedlich ausgerichtete SH2-Domänen. Während die antiparallele Konformation bei der Dephosphorylierung eine Rolle spielt, ist die parallele Form essentiell für die Bindung an die DNA (Mao et al. 2005; Mertens et al. 2006). Nach Lösung tyrosinphosphorylierter STAT1-Dimere von der DNA wird das antiparallele Konformer von der TC45-Phosphatase erkannt und dephosphoryliert. Nur im Tyrosindephosphorylierten Zustand sind die STAT1-Proteine in der Lage, die Kernmembran zu überwinden (Meyer et al. 2003). Daraus resultiert eine weitere Hypothese für die Klärung der Hyperphosphorylierung von STAT1-E585A, nämlich dass die beobachtete Hyperphosphorylierung die Folge einer Erniedrigung des Dephosphorylierungsniveaus dieser Mutante sein könnte. Um beide Mutanten im Bezug auf ihr Dephos- 
phorylierungsverhalten zu charakterisieren, erfolgten in diesr Arbeit Dephosphorylierungsexperimente. Bei der Reaktion von Extrakten STAT1-E585A-exprimierender, IFNy-prästimulierter Zellen in vitro mit der aktiven Phosphatase TC-PTP wurde offensichtlich, dass die Dephosphorylierung von STAT1-E585A in gleicher Geschwindigkeit stattfindet wie beim STAT1-WT (Abb. 10). Somit bestätigt sich das Ergebnis aus den Gelshift-Experimenten: das WT-ähnliche DNA-Bindeverhalten äußert sich in einer WT-ähnlichen Dephosphorylierungskinetik. Daraus resultierend kann vermutet werden, dass STAT1-E585A wohl keine Dephosphorylierungsmutante ist.

Allerdings besteht für den Phänotyp der Mutante STAT1-E585A eine weitaus plausiblere Erklärung. Durch eine mutmaßliche Stabilisierung der parallelen Konformation, die mit der Einführung der Punktmutation an Position 585 verbunden sein könnte, käme es zu einer Verschiebung des Gleichgewichtes von der antiparallelen zur parallelen Dimer-Konformation. Dadurch wäre die Menge von STAT1-Dimeren, die für die Phosphatase zugänglich ist, erniedrigt, wodurch im Verhältnis eine geringere Dephosphorylierung dieser Moleküle stattfinden würde. Wie man in den durchgeführten Experimenten beobachten kann, würde diese Verschiebung bei der Dephosphorylierung nicht zum Tragen kommen, da sie kompensiert wird. Allerdings würde sie sich wahrscheinlich in einer Erhöhung des Phosphorylierungsniveaus widerspiegeln, wie man dies auch bei STAT1-E585A beobachten kann. Die Seitenkette von E585 wäre damit an der Stabilisierung der parallelen Dimer-Konformation oder umgekehrt an der Destabilisierung des antiparallelen Dimers beteiligt.

Wie oben bereits erwähnt, geht eine Änderung im Phosphorylierungsniveau von STAT1 mit einer Änderung der transkriptionellen Aktivität einher. Die erhöhte transkriptionelle Leistung der E585A-Mutante gegenüber STAT1-WT konnte in den in dieser Arbeit durchgeführten Experimenten durch In-vitro-Versuche partiell belegt werden. Mithilfe von Reportergen-Konstrukten konnte dargelegt werden, dass die Verwendung eines synthetischen Promoters (3xLy6E) nach 6-stündiger Stimulation transfizierter Zellen mit IFN $\gamma$ bei der Mutante STAT1-E585A eine erhöhte transkriptionelle Aktivität zur Folge hat. Diese Erhöhung der transkriptionellen Aktivität konnte allerdings bei Verwendung eines nativen Promoters nicht belegt werden (Abb. 11 und 12). Interessant war in diesem Zusammenhang die Beobachtung, dass im Rahmen von Genexpressionsuntersuchungen von endogenen Zielgenen in vivo 
ebenso eine veränderte transkriptionelle Aktivität durch STAT1-E585A nach Exposition der Zellen mit IFN $\gamma$ erfolgte (Abb. 13). Während die Expression der Zielgene irf1, gpb1, and mig1 mit einer klassischen singulären Gamma-aktivierten Stelle (GAS) durch die Mutation weitgehend unverändert blieb, wurden das Zielgen mcp1 signifikant vermehrt exprimiert. Insgesamt war die transkriptionelle Antwort auf IFN $\gamma$ bei der Mutante also differentiell unterschiedlich zum Wildtyp-Molekül, wenn auch nicht für alle Gene gleichartig, sondern in einem Gen-spezifischen Muster.

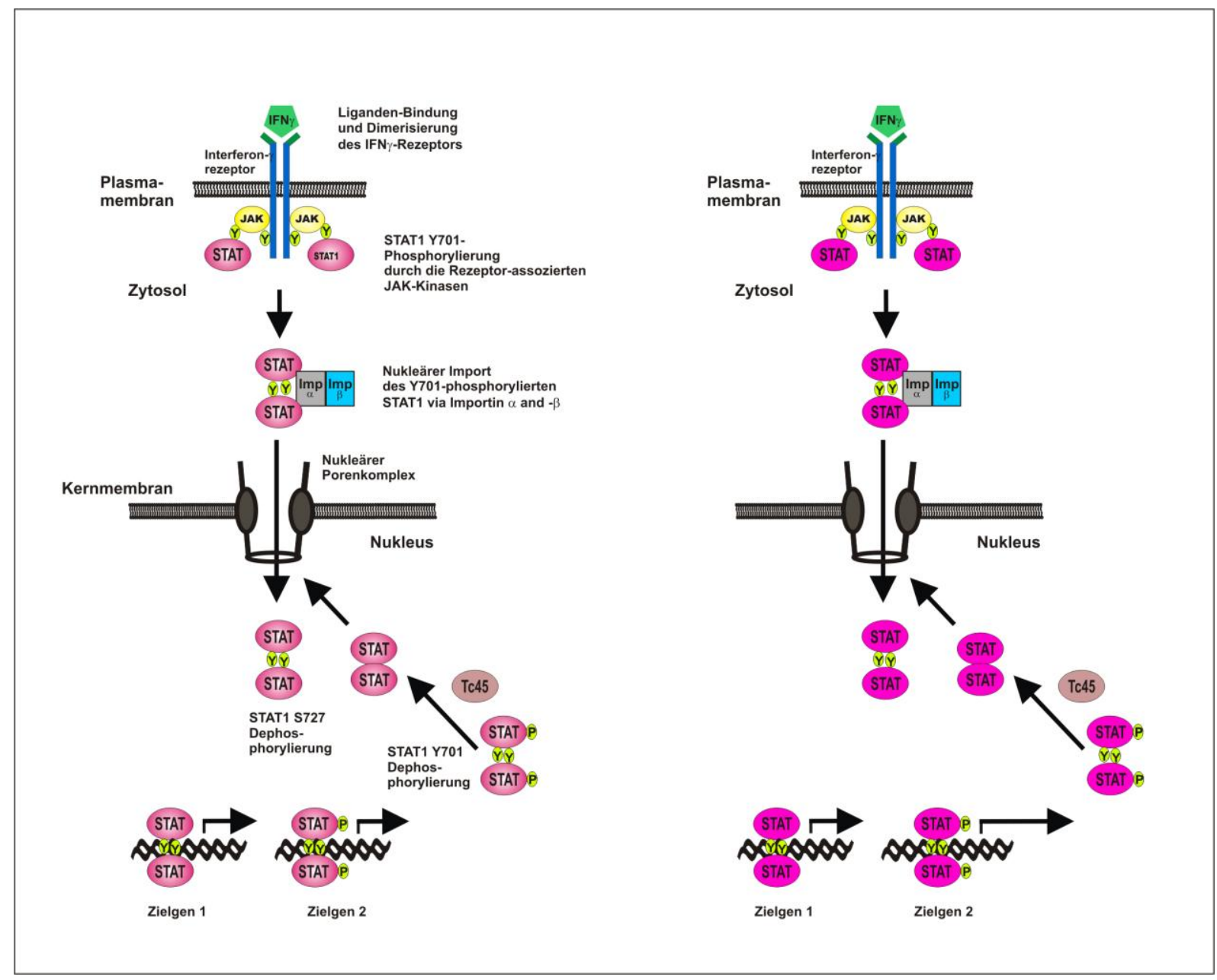

Abb. 17: Schematische Darstellung des IFN $\gamma$-vermittelten JAK-STAT-Signalwegs durch STAT1-WT (linke Seite) und die Mutante STAT1-E585A (rechte Seite). Die Bindung von IFNy an seinen Rezeptor führt zur Rezeptor-Dimerisierung, wodurch die Auto- und Transphosphorylierung der Rezeptor-assoziierten Janus-Kinasen ausgelöst wird. Die Phosphorylierung von Tyrosinresten des Rezeptors führt zur Entstehung von Andockstellen für STAT1Moleküle. Nach Rezeptorlösung bilden sich Tyrosin-phosphorylierte Homodimere aus, die in den Nukleus transportiert werden. Dort erfolgt die Bindung an spezifische Zielsequenzen, die sogenannten Gamma-aktivierten Sequenzen (GAS), und die Transkription wird induziert. Die 
beobachtete Hyperphosphorylierung führt bei der E585A-Mutante (rechtes Schema) zu einer promotorspezifisch veränderten transkriptionellen Aktivierung der beiden Zielgene 1 und 2 gegenüber dem Wildtyp-Molekül (linkes Schema).

Eine STAT1-Mutante, die eine verbesserte transkriptionelle Leistung besitzt, kann für die Forschung von großer Bedeutung sein, z.B. um neue Wirkstoffe oder Zytokine im Rahmen der Immunsuppression effektiv testen zu können. Ein Nachteil der erhöhten transkriptionellen Aktivität allerdings könnte darin liegen, dass das Signal für die Transkription länger vorhanden wäre. Dadurch reagiert das System weniger flexibel auf Veränderungen der extrazellulären IFN $\gamma$-Konzentration.

In der vorliegenden Arbeit konnte demonstriert werden, dass Veränderungen in der flexiblen Domänenarchitektur der SH2-Domäne zwangsläufig Alterationen in der IFN $\gamma$-vermittelten Signaltransduktion zur Folge haben können. Durch den Austausch eines Glutaminsäurerestes wurde eine Punktmutante generiert, die eine Veränderung im Phänotyp des STAT-Moleküls hervorruft. Anhand dieser Mutante konnte unterstrichen werden, dass die SH2-Domäne von STAT1 an der Regulation der Phosphorylierung und der differentiellen Zielgenerkennung beteiligt ist, die über die unmittelbare Erkennung des kritischen Tyrosinrestes 701 hinausgeht. Die Mutation in Position 585 der SH2-Domäne zu Alanin resultierte in einer Hyperphosphorylierung von STAT1 und einer erhöhten Induktion des mcp1-Gens nach Stimulation der Zellen mit IFN $\gamma$. Die Mutante kann somit als zumindest partielle Gain-of-function-Mutante attributiert werden und könnte sich als interessantes Werkzeug für die Erforschung der Wirkungsweise von Interferonen erweisen.

Dem molekularen Mechanismus könnte eine Stabilisierung der SH2-PhosphotyrosinInteraktion mit einer Verlagerung des Gleichgewichtes der Dimer-Konformere zu Gunsten der parallelen Dimerausrichtung zugrunde liegen. Die hier vorgestellten Resultate weisen darauf hin, dass stabile Phosphotyrosin-SH2-Bindungen eine optimale STAT1-induzierte Genexpression nicht erzwingen können. Die Weiterleitung der Signalstärke könnte demnach vielmehr von der Flexibilität bei der Bildung und Lösung von transkriptionell aktiven Dimeren profitieren und weniger von einer strengen Molekülstruktur der dimeren STAT1-Moleküle. Ein dynamischer Wechsel zwischen antiparalleler und paralleler Dimer-Konfiguration scheint somit essentiell für eine effiziente STAT1-vermittelte Signaltransduktion zu sein. Welcher molekulare 
Mechanismus jedoch der Konformationsänderung von phosphorylierten STAT1Dimeren zu Grunde liegt, konnte bis dato nicht im Detail erklärt werden. Um den Vorgang des Konformationswechsels im Detail analysieren zu können, müssten sich weitere Experimente unter Beachtung des Volle-Länge-Proteins anschließen. Andere Mutationsexperimente könnten eventuell andere Aminosäurereste identifizieren, die eine unterschiedliche Wirkung auf die Stabilität der SH2-Phosphotyrosin-Interaktion haben. Das hier vorgeschlagene Modell, welches der SH2-Domäne eine essentielle Funktion beim Wechsel zwischen zwei Dimer-Konfigurationen und gegebenenfalls auch einem Monomerenaustausch zuweist, könnte möglicherweise durch die Identifizierung einer Punktmutante in der SH2-Domäne mit entgegengesetztem Phänotyp, nämlich einer Destabilisierung der SH2-pTyr-Interaktion, bestätigt werden. Die Destabilisierung der antiparallelen Konformation würde bei dieser Mutante ein verringertes Phosphorylierungsniveau aufweisen, besäße wahrscheinlich eine verkürzte Phase der Kernakkumulation nach IFN-Stimulation und hätte eine insgesamt erhöhte Sensitivität gegenüber Staurosporin zur Folge, was eine verringerte Bindung an GAS-Elemente mit sich bringen würde. Erwartet wird, dass eine solche Mutante mit einer reduzierten Genexpression verbunden wäre. 


\section{$5 \quad$ Literaturverzeichnis}

Alonzi T, Maritano D, Gorgoni B, Rizzuto G, Libert C, Poli, V (2001): Essential role of STAT3 in the control of the acute-phase response as revealed by inducible gene inactivation in the liver. Mol Cell Biol 21 (5), 1621-1632.

Bach EA, Aguet M, Schreiber RD (1997): The IFN gamma receptor: a paradigm for cytokine receptor signaling. Annu Rev Immunol $\underline{15}$, 563-591.

Baden HA, Sarma P, Kapust RB, Byrd RA, Waugh DS (1998): The amino-terminal domain of human STAT4. Overproduction, purification, and biophysical characterization. J Biol Chem 273(27), 17109-17114.

Barillas-Mury C, Han YS, Seeley D, Kafatos FC (1999): Anopheles gambiae AgSTAT, a new insect member of the STAT family, is activated in response to bacterial infection. EMBO J 18 (4), 959-967.

Becker S, Groner B, Müller CW (1998): Three-dimensional structure of the Stat3beta homodimer bound to DNA. Nature 394(6689), 145-151.

Begitt A, Meyer T, van Rossum M, Vinkemeier U (2000): Nucleocytoplasmic translocation of Stat1 is regulated by a leucine-rich export signal in the coiled-coil domain. Proc Natl Acad Sci USA 97(19), 10418-10423.

Boehm U, Klamp T, Groot M, Howard JC (1997): Cellular responses to interferongamma. Annu. Rev. Immunol. 15, 749-795.

Bromberg JF, Fan Z, Brown C, Mendelsohn J, Darnell JE Jr. (1998): Epidermal growth factor-induced growth inhibition requires Stat1 activation. Cell Growth Differ $\underline{9}(7), 505-512$.

Bromberg J, Darnell JE Jr. (2000): The role of STATs in transcriptional control and their impact on cellular function. Oncogene $\underline{19}(21), 2468-2473$.

Chang CH, Hammer J, Loh JE, Fodor WL Flavell RA (1992): The activation of major histocompatibility complex class I genes by interferon regulatory factor-1 (IRF-1). Immunogenetics 35(6), 378-384. 
Chapgier A, Wynn RF, Jouanguy E, Filipe-Santos O, Zhang S, Feinberg J, Hawkins K, Casanova JL, Arkwright PD (2006): Human complete Stat-1 deficiency is associated with defective type I and II IFN responses in vitro but immunity to some low virulence viruses in vivo. J Immunol 176(8), 5078-83.

Chen X, Vinkemeier U, Zhao Y, Jeruzalmi D, Darnell JE Jr., Kuriyan J (1998): Crystal structure of a tyrosine phosphorylated STAT-1 dimer bound to DNA. Cell $\underline{93}(5), 827-839$.

Chen X, Bhandari R, Vinkemeier U, van Den Akker F, Darnell JE Jr., Kuriyan J (2003): A reinterpretation of the dimerization interface of the $\mathrm{N}$-terminal domains of STATs. Protein Sci 12(2), 361-365.

Chin YE, Kitagawa M, Su WC, You ZH, Iwamoto Y, Fu XY (1996): Cell growth arrest and induction of cyclin-dependent kinase inhibitor p21 WAF1:CIP1 mediated by STAT1. Science 272(5262), 719-722.

Chin YE, Kitagawa M, Kuida K, Flavell RA, Fu XY (1997): Activation of the STAT signaling pathway can cause expression of caspase1 and apoptosis. Mol Cell Biol $\underline{17}(9), 5328-5337$.

Chung CD, Liao J, Liu B, Rao X, Jay P, Berta P, Shuai K (1997): Specific inhibition of Stat3 signal transduction by PIAS3. Science 278(5344), 1803-1805.

Clemens MJ (2003): Interferons and apoptosis. J Interferone Cytokine Res 23(6), 277-292.

Cohen SN, Chang AC, Hsu L (1972): Nonchromosomal antibiotic resistance in bacteria: genetic transformation of Escherichia coli by R-factor DNA. Proc Natl Acad Sci USA $\underline{69}(8), 2110-2114$.

Copeland NG, Gilbert DJ, Schindler C, Zhong Z, Wen Z, Darnell JE Jr. (1995): Distribution of the mammalian Stat gene family in mouse chromosomes. Genomics $\underline{29}(1), 225-228$.

Darnell JE Jr. (1997): STATs and gene regulation. Science 277(5332), 1630-1635. 
Darnell JE Jr., Kerr IM, Stark GR (1994): Jak-STAT pathways and transcriptional activation in response to IFNs and other extracellular signaling proteins. Science 264(5164), 1415-1421.

Decker T, Kovarik P (2000): Serine phosphorylation of STATs. Oncogene $\underline{19}(21)$, 2628-2637.

Decker T, Lew DJ, Mirkovitch J, Darnell JE Jr. (1991): Cytoplasmic activation of GAF, an IFN-gamma-regulated DNA-binding factor. EMBO J $\underline{10}(4)$, 927-932.

Decker T, Kovarik P, Meinke A (1997): GAS elements: a few nucleotides with a major impact on cytokine-induced gene expression. J Interferon Cytokine Res 17(3), 121-134.

Djeu JY, Heinbaugh JA, Holden HT, Herberman RB (1979): Augmentation of mouse natural killer cell activity by interferon and interferon induces. J Immunol $\underline{122(1), 175-181 .}$

Duncan SA, Zhong Z, Wen Z, Darnell JE Jr. (1997): STAT signaling is active during early mammalian development. Dev Dyn 208(2), 190-198.

Dupuis S, Dargemont C, Fieschi C, Thomassin N, Rosenzweig S, Harris J, Holland M, Schreiber RD, Casanova JL (2001): Impairment of mycobacterial but not viral immunity by a germline human STAT1 mutation. Science 293(5528), 300-303.

Dupuis S, Jouanguy E, Al-Hajjar S, Fieschi C, Al-Mohsen IZ, Al-Jumaah S, Yang K, Chapgier A, Eidenschenk C, Eid P (2003): Impaired response to inter-feronalpha/beta and lethal viral disease in human STAT1 deficiency. Nat Genet $\underline{33}(3)$, 388-391.

Durbin JE, Hackenmiller R, Simon MC, Levy DE (1996): Targeted disruption of the mouse Stat1 gene results in compromised innate immunity to viral disease. Cell 84(3), 443-450.

Ealick SE, Cook WJ, Vijay-Kumar S, Carson M, Nagabhushan TL, Trotta PP, Bugg CE (1991): Three-dimensional structure of recombinant human interferongamma. Science $\underline{252}$ (5006), 698-702. 
Evinger M, Rubinstein M, Pestka S (1981): Antiproliferative and antiviral activities of human leukocyte interferons. Arch Biochem Biophys 210(1), 319-329.

Fagerlund R, Mélen K, Kinnunen L, Julkunen I (2002): Arginine/lysine-rich nuclear localization signals mediate interactions between dimeric STATs and importin alpha 5. J Biol Chem 277(33), 30072-30078.

Fahrenkrog B, Köser J, Aebi U (2004): The nuclear pore complex: a jack of all trades? Trends Biochem Sci 29(4), 175-182.

Farrar MA, Schreiber RD (1993): The molecular cell biology of interferon-gamma and its receptor. Annu Rev Immunol 11, 571-611.

Fu XY (1992): A transcription factor with SH2 and SH3 domains is directly activated by an interferon alpha-induced cytoplasmic protein tyrosine kinase(s). Cell $\underline{70}(2)$, 323-335.

Fu XY, Kessler DS, Veals SA, Levy DE, Darnell JE Jr. (1990): ISGF3, the transcriptional activator induced by interferon alpha, consists of multiple interacting polypeptide chains. Proc Natl Acad Sci USA 87(21), 8555-8559.

Fu XY, Schindler C, Improta T, Aebersold R, Darnell JE Jr. (1992): The proteins of ISGF-3, the interferon alpha-induced transcriptional activator, define a gene family involved in signal transduction. Proc Natl Acad Sci USA $\underline{89}$ (16), 7840-7843.

Gao Q, Hua J, Kimura R, Headd JJ, Fu X, Chin YE (2004): Identification of the linker-SH2 domain of STAT as the origin of the SH2 domain using two-dimensional structural alignment. Mol. Cell. Proteomics $\underline{3}(7), 704-714$.

Gidlund M, Orn A, Wigzell H, Senik A, Gresser I (1978): Enhanced NK cell activity in mice injected with interferon and interferon inducers. Nature $\underline{273}(5665), 759-761$.

Görlich D, Kutay U (1999): Transport between the cell nucleus and the cytoplasm. Annu Rev Cell Dev Biol 15, 607-660.

Greenlund AC, Schreiber RD, Goeddel DV, Pennica D (1993): Interferon-gamma induces receptor dimerization in solution and on cells. J Biol Chem 268(24), 1810318110. 
Greenlund AC, Farrar MA, Viviano BL, Schreiber RD (1994): Ligand-induced IFN gamma receptor tyrosine phosphorylation couples the receptor to its signal transduction system (p91). EMBO J $\underline{13}(7), 1591-1600$.

Greenlund AC, Morales MO, Viviano BL, Yan H, Krolewski J, Schreiber RD (1995): Stat recruitment by tyrosine-phosphorylated cytokine receptors: an ordered reversible affinity-driven process. Immunity $\underline{2}(6)$, 677-687.

Haspel RL, Darnell JE Jr. (1999): A nuclear protein tyrosine phosphatase is required for the inactivation of Stat1. Proc Natl Acad Sci USA 96(18), 10188-10193.

Haspel RL, Salditt-Georgieff M, Darnell JE Jr. (1996): The rapid inactivation of nuclear tyrosine phosphorylated Stat1 depends upon a protein tyrosine phosphatase. EMBO J 15(22), 6262-6268.

Herberman RB, Ortaldo JR, Mantovani A, Hobbs DS, Kung HF, Pestka S (1982): Effect of human recombinant interferon on cytotoxic activity of natural killer (NK) cells and monocytes. Cell Immunol $\underline{67}(1), 160-167$.

Herrington J, Rui L, Luo G, Yu-Lee LY, Carter-Su C (1999): A functional DNA binding domain is required for growth hormone-induced nuclear accumulation of Stat5B. J Biol Chem 274(8), 5138-5145.

Horvath CM (2000): STAT proteins and transcriptional responses to extracellular signal Trends Biochem Sci 25(10), 496-502.

Horvath CM, Darnell JE Jr. (1996): The antiviral state induced by alpha interferon and gamma interferon requires transcriptionally active Stat1 protein. J Virol $\underline{70}(1)$, 647-650.

Hou XS, Perrimon N (1997): The JAK-STAT pathway in Drosophila. Trends Genet 13(3), 105-110.

Isaacs A, Lindenmann J (1987): Virus interference. I. The interferon. J Interferon Res $\underline{7}(5), 429-438$. 
Janjua S, Stephanou A, Latchman DS (2002): The C-terminal activation domain of the STAT-1 transcription factor is necessary and sufficient for stress-induced apoptosis. Cell Death Differ $\underline{9}(10), 1140-1146$.

Joazeiro CA, Wing SS, Huang H, Lerson JD, Hunter T, Liu YC (1999): The tyrosine kinase negative regulator C-Cbl as a RING-type, E2-dependent ubiquitin-protein ligase. Science $\underline{286}(5438), 309-312$.

John S, Vinkemeier U, Soldaini E, Darnell JE. Jr, Leonard WJ (1999): The significance of tetramerization in promoter recruitment by STAT5. Mol Cell Biol $\underline{19}(3)$, 1910-1918.

Kalab P, Weis K, Heald R (2002): Visualization of a Ran-GTP gradient in interphase and mitotic Xenopus egg extracts. Science 295(5564), 2452-2456.

Kaplan MH, Schindler U, Smiley ST, Grusby MJ (1996a): Stat6 is required for mediating responses to IL-4 and for development of Th2 cells. Immunity $\underline{4}(3), 313-319$.

Kaplan MH, Sun YL, Hoey T, Grusby, MJ (1996b): Impaired IL-12 responses and enhanced development of Th2 cells in Stat4-deficient mice. Nature $\underline{382(6587), 174-}$ 177.

Kaplan DH, Shankaran V, Dighe A, Stockert E, Aguet M, Old LJ, Schreiber RD (1998): Demonstration of an interferon gamma-dependent tumor surveillance system in immunocompetent mice. Proc Natl Acad Sci USA 95(13), 7556-7561.

Kawata T, Shevchenko A, Fukuzawa M, Jermyn KA, Totty NF, Zhukovskaya NV, Sterling AE, Mann M, Williams JG (1997): SH2 signaling in a lower eukaryote: a STAT protein that regulates stalk cell differentiation in dictyostelium. Cell $\underline{89}(6), 909$ 916.

Kelker HC, Yip YK, Anderson P, Vilček J (1983): Effects of glycosidase treat-ment on the physicochemical properties and biological activity of human interferon-gamma. J Biol Chem 258(13), 8010-8013.

Kelker HC, Le J, Rubin BY, Yip YK, Nagler C, Vilček J (1984): Three molecular weight forms of natural human interferon-gamma revealed by immunoprecipitation with monoclonal antibody. J Biol Chem 259(7), 4301-4304. 
Koch CA, Moran M, Sadowski I, Pawson T (1989): The common src homology region 2 domain of cytoplasmic signaling proteins is a positive effector of $\mathrm{v}$-fps tyrosine kinase function. Mol Cell Biol $\underline{9}(10), 4131-4140$.

Koch CA, Anderson D, Moran MF, Ellis C, Pawson T (1991): SH2 and SH3 domains: elements that control interactions of cytoplasmic signaling proteins. Science 252(5006), 668-674.

Körner C, Guan T, Gerace L, Cingolani G (2003): Synergy of silent and hot spot mutations in importin $\beta$ reveals a dynamic mechanism for recognition of a nuclear localization signal. J Biol Chem $\underline{278}(18)$, 16216-16221.

Kotenko SV, Gallagher G, Baurin VV, Lewis-Antes A, Shen M, Shah NK, Langer JA, Sheikh F, Dickensheets H, Donnelly RP (2003): IFN-lambdas mediate antiviral protection through a distinct class II cytokine receptor complex. Nat Immunol $\underline{4}(1)$, 69-77.

Köster M, Hauser H (1999): Dynamic redistribution of STAT1 protein in IFN signaling visualized by GFP fusion proteins. Eur J Biochem 260(1), 137-144.

Krebs DL, Hilton DJ (2001): SOCS proteins: negative regulators of cytokine signaling. Stem Cells $\underline{19}(5), 378-387$.

Kumar A, Commane M, Flickinger TW, Horvath CM, Stark GR. (1997): Defective TNF-a-induced apoptosis in STAT1-null cells due to low constitutive levels of caspases. Science $\underline{278}(5343), 1630-1632$.

Langer JA, Pestka S (1988): Interferon receptors. Immunol Today $\underline{9}(12), 393-400$.

Lee CK, Rao DT, Gertner R, Gimeno R, Frey AB, Levy DE (2000b): Distinct requirements for IFNs and STAT1 in NK cell function. J Immunol 165(7), 3571-3577.

Lee CK, Smith E, Gimeno R, Gertner R, Levy DE (2000a): STAT1 affects lymphocyte survival and proliferation partially independent of its role downstream of IFN- $\mathrm{Y}$. J Immunol 164(3), 1286-1292.

Lefèvre F, Boulay V (1993): A novel and atypical type one interferon gene expressed by trophoblast during early pregnancy. J Biol Chem 268(26), 19760-19768. 
Lefèvre F, Guillomot M, D'Andréa S, Battegay S, La Bonnardière C (1998): Interferon-delta: the first member of a novel type I interferon family. Biochimie $\underline{80}(8-9)$ 779-788.

Leung S, Li X, Stark GR (1996): STATs find that hanging together can be stimulating. Science $\underline{273}(5276), 750-751$.

Levy DE, Darnell JE Jr. (2002): Stats: transcriptional control and biological impact. Nat Rev Mol Cell Biol $\underline{3}(9), 651-662$.

Levy DE, Kessler DS, Pine R, Reich N, Darnell JE Jr. (1988): Interferon-induced nuclear factors that bind a shared promoter element correlate with positive and negative transcriptional control. Genes Dev 2(4), 383-393.

Levy DE, Kessler DS, Pine R, Darnell JE Jr. (1989): Cytoplasmic activation of ISGF3, the positive regulator of interferon-alpha-stimulated transcription, reconstituted in vitro. Genes Dev $\underline{3}(9), 1362-1371$.

Liao J, Fu Y, Shuai K (2000): Distinct roles of the NH2- and $\mathrm{COOH}$-terminal domains of the protein inhibitor of activated signal transducer and activator of transcription (STAT1) (PIAS1) in cytokine-induced PIAS1-Stat1 interaction. Proc Natl Acad Sci USA $\underline{97}(10), 5267-5272$.

Lim, CP, Cao, X (2006): Structure, function, and regulation of STAT proteins. Mol Biosyst $\underline{2}(11), 536-550$.

Litterst, CM, Pfitzner, E (2001): Transcriptional activation by STAT6 requires the direct interaction with NCoA-1. J Biol Chem 276(49), 45713-45721.

Liu B, Liao J, Rao X, Kushner SA, Chung CD, Chang DD, Shuai K (1998): Inhibition of Stat1-mediated gene activation by PIAS1. Proc Natl Acad Sci USA 95(18), 10626-10631.

Liu L, Okada S, Kong XF, Kreins AY, Cypowyj S, Abhyankar A, Toubiana J, Itan $Y$, Audry M, Nitschke $P$, Masson $C$, Toth B, Flatot J, Migaud M, Chrabieh M, Kochetkov T, Bolze A, Borghesi A, Toulon A, Hiller J, Eyerich S, Eyerich K, Gulácsy V, Chernyshova L, Chernyshov V, Bondarenko A, Grimaldo RM, Blancas-Galicia L, Beas IM, Roesler J, Magdorf K, Engelhard D, Thumerelle, 
C, Burgel PR, Hoernes M, Drexel B, Seger R, Kusuma T, Jansson AF, SawalleBelohradsky J, Belohradsky B, Jouanguy E, Bustamante J, Bué M, Karin $\mathrm{N}$, Wildbaum G, Bodemer C, Lortholary O, Fischer A, Blanche S, Al-Muhsen S, Reichenbach J, Kobayashi M, Rosales FE, Lozano CT, Kilic SS, Oleastro M, Etzioni A, Traidl-Hoffmann C, Renner ED, Abel L, Picard C, Maródi L, Boisson-Dupuis S, Puel A, Casanova JL (2011): Gain-of-function human STAT1 mutations impair IL-17 immunity and underlie chronic mucocutaneous candidiasis. J Exp Med 208(8), 1635-1648.

Liu X, Quinn AM, Chin YE, Fu XY (1999): STAT genes found in C. elegans. Science $\underline{285}(5425), 167 a$.

Liu X, Robinson GW, Wagner KU, Garrett L, Wynshaw-Boris A, Hennighausen L. (1997): Stat5a is mandatory for adult mammary gland development and lactogenesis. Genes Dev 11(12), 179-186.

Lödige I, Marg A, Wiesner B, Malecova B, Oelschläger T, Vinkemeier U (2005): Nuclear export determines the cytokine sensitivity of STAT transcription factors. J Biol Chem 280(52), 43087-43099.

Loppnow, H. (2001): Zytokine: Klassifikation, Rezeptoren, Wirkungsmechanismen. Internist $\underline{42}$, 13-27.

Macara IG (2001): Transport into and out of the nucleus. Microbiol Mol Biol Rev $\underline{65}(4), 570-594$.

Mach B, Steimle V, Martinez-Soria EW (1996): Regulation of MHC class II genes: lessons from a disease. Annu Rev Immunol 14, 301-331.

Mao X, Ren Z, Parker GN, Sondermann H, Pastorello MA, Wang W, McMurray, JS, Demeler B, Darnell JE Jr., Chen X (2005): Structural bases of unphosphorylated STAT1 association and receptor binding. Mol Cell 17(6), 761-771.

Marg A, Shan Y, Meyer T, Meissner T, Brandenburg M, Vinkemeier U (2004): Nucleocytoplasmic shuttling by nucleoporins Nup153 and Nup214 and CRM1dependent nuclear export control the subcellular distribution of latent Stat1. J Cell Biol 165(6), 823-833. 
Mattaj IW, Englmeier L (1998): Nucleocytoplasmic transport: the soluble phase. Annu Rev Biochem 67, 265-306.

McBride KM, Banninger G, McDonald C, Reich NC (2002): Regulated nuclear import of the STAT1 transcription factor by direct binding of importin-alpha. EMBO $\mathrm{J}$ 21(7), 1754-1763.

Meissner T, Krause E, Lödige I, Vinkemeier U (2004): Arginine methylation of STAT1: a reassessment. Cell 119(5), 587-589.

Melen K, Kinnunen L, Julkunen I (2001): Arginine/lysine-rich structural element is involved in interferon-induced nuclear import of STATs. J Biol Chem 276(19), 1644716455.

Meraz MA, White JM, Sheehan KC, Bach EA, Rodig SJ, Dighe AS, Kaplan DH, Riley JK, Greenlund AC, Campbell D, Carver-Moore K, DuBois RN, Clark R, Aguet M, Schreiber RD (1996): Targeted disruption of the Stat1 gene in mice reveals unexpected physiologic specificity in the JAK-STAT signaling pathway. Cell 84(3), 431-442.

Mertens C, Zhong M, Krishnaraj R, Zou W, Chen X, Darnell JE Jr. (2006): Dephosphorylation of phosphotyrosine on STAT1 dimers requires extensive spatial reorientation of the monomers facilitated by the N-terminal domain. Genes Dev 20. (24), 3372-3381.

Meyer T, Vinkemeier U (2004): Nucleocytoplasmic shuttling of STAT transcription factors. Eur J Biochem 271(23-24), 4606-4612.

Meyer T, Begitt A, Lödige I, van Rossum M, Vinkemeier U (2002): Constitutive and IFN-gamma-induced nuclear import of STAT1 proceed through independent pathways. EMBO J 21 (3), 344-354.

Meyer T, Marg A, Lemke P, Wiesner B, Vinkemeier U (2003): DNA binding controls inactivation and nuclear accumulation of the transcription factor Stat1. Genes Dev 17(16), 1992-2005. 
Meyer T, Hendry L, Begitt A, John S, Vinkemeier U (2004): A single residue modulates tyrosine dephosphorylation, oligomerization, and nuclear accumulation of stat transcription factors. J Biol Chem $\underline{279}(18), 18998-19007$.

Meyer T, Begitt A, Vinkemeier U (2007): Green fluorescent protein-tagging reduces the nucleocytoplasmic shuttling specifically of unphosphorylated STAT1. FEBS $\mathrm{J}$ $\underline{274}(3), 815-826$.

Mowen K, David M (1998): Role of the STAT1-SH2 domain and STAT2 in the activation and nuclear translocation of STAT1. J Biol Chem 273(46), 30073-30076.

Mui AL, Wakao H, O'Farrell AM, Harada N, Miyajima A (1995): Interleukin-3, granulocyte-macrophage colony stimulating factor and interleukin-5 transduce signals through two STAT5 homologs. EMBO J 14(6), 1166-1175.

Müller M, Briscoe J, Laxton C, Guschin D, Ziemiecki A, Silvennoinen O, Harpur, AG, Barbieri G, Witthuhn BA, Schindler C, Pellegrini S, Wilks AF, Ihle JN, Stark GR, Kerr LM (1993): The protein tyrosine kinase JAK1 complements defects in interferon-alpha/beta and -gamma signal transduction. Nature 366(6451), 129-135.

Murphy TL, Geissal ED, Farrar JD, Murphy KM (2000): Role of the Stat4 N-domain in receptor proximal tyrosine phosphorylation. Mol Cell Biol $\underline{20}(19), 7121-7131$.

Nardozzi J, Wenta N, Yashuhara N, Vinkemeier U, Cingolani G (2010): Molecular basis for the recognition of phosphorylated STAT1 by importin $\alpha 5$. J Mol Biol 402(1), 83-100.

Nguyen KB, Watford WT, Salomon R, Hofmann SR, Pien GC, Morinobu A, Gadina M, O'Shea JJ, Biron CA (2002): Critical role for STAT4 activation by type 1 interferons in the interferon-gamma response to viral infection. Science 297(5589), 2063-2066.

Nicola NA (1994): Cytokine pleiotropy and redundancy: a view from the receptor. Stem Cells 12, Suppl 1:3-12; discussion 12-4.

Novick D, Cohen B, Rubinstein M (1994): The human interferon alpha/beta receptor: characterization and molecular cloning. Cell $\underline{77}(3), 391-400$. 
Oates AC, Wollberg P, Pratt SJ, Paw BH, Johnson SL, Ho RK, Postlethwait JH, Zon LI, Wilks AF (1999): Zebrafish stat3 is expressed in restricted tissues during embryogenesis and stat1 rescues cytokine signaling in a STAT1-deficient human cell line. Dev Dyn 215(4), 352-370.

Oritani K, Tomiyama $Y$ (2004): Interferon-zeta/limitin: novel type I interferon that displays a narrow range of biological activity. Int $\mathrm{J}$ Hematol 80(4), 325-331.

Ortaldo JR, Mantovani A, Hobbs D, Rubinstein M, Pestka S, Herberman RB (1983): Effects of several species of human leukocyte interferon on cytotoxic activity of NK cells and monocyte Int. J Cancer 31(3), 285-289.

Ouchi T, Lee SW, Ouchi M, Aaronson SA, Horvath CM (2000): Collaboration of signal transducer and activator of transcription 1 (STAT1) and BRCA1 in differential regulation of IFN-gamma target genes. Proc Natl Acad Sci USA 97(10), 5208-5213.

Paine PL, Feldherr CM (1972): Nucleocytoplasmic exchange of macromolecules. Exp Cell Res 74(1), 81-98.

Park C, Li S, Cha E, Schindler C (2000): Immune response in Stat2 knockout mice. Immunity $\underline{13}(6), 795-804$.

Pascal A, Riou JF, Carron C, Boucaut JC, Umbhauer M (2001): Cloning and developmental expression of STAT5 in Xenopus laevis. Mech Dev 106(1-2), 171-174.

Paulson M, Pisharody S, Pan L, Guadagno S, Mui AL, Levy DE (1999): Stat protein transactivation domains recruit p300/CBP through widely divergent sequences. $J$ Biol Chem 274(36), 25343-25349.

Pawson T (1988): Non-catalytic domains of cytoplasmic protein-tyrosine kinases: regulatory elements in signal transduction. Oncogene $\underline{3}(5), 491-495$.

Pawson T, Gish GD, Nash P (2001): SH2 domains, interaction modules and cellular wiring. Trends Cell Biol 11(12), 504-511.

Pestka S (1983): The human interferons--from protein purification and sequence to cloning and expression in bacteria: before, between, and beyond. Arch Biochem Biophy 221(1), 1-37. 
Pestka S, Langer JA, Zoon KC, Samuel CE (1987): Interferons and their action Annu Rev Biochem 56, 727-777.

Pestka S, Krause CD, Walter MR (2004): Interferons, interferon-like cytokines, and their receptors. Immunol Rev. 202, 8-32.

Platanias LC. (2005): Mechanisms of type-I- and type-II-interferon-mediated signaling. Nat. Rev Immunol $\underline{5}(5), 375-386$.

Rane SG, Reddy EP (2000): Janus kinases: components of multiple signaling pathways. Oncogene $\underline{19}(79), 5662-5679$.

Rawlings JS, Rosler KM, Harrison DA (2004): The JAK/STAT signaling pathway. J Cell Sci 117(pt 8), 1281-1283.

Ribbeck K, Görlich D (2001): Kinetic analysis of translocation through nuclear pore complexes. EMBO J 므(6), 1320-1330.

Roberts RM, Cross JC, Leaman DW (1991): Unique features of the trophoblast

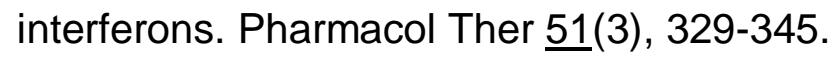

Rout MP, Aitchison JD, Magnasco MO, Chait BT (2003): Virtual gating and nuclear transport: the hole picture. Trends Cell Biol 13(12), 622-628.

Sadowski I, Stone JC, Pawson T (1986): A noncatalytic domain conserved among cytoplasmic protein-tyrosine kinases modifies the kinase function and transforming activity of Fujinami sarcoma virus P130gag-fps. Mol Cell Biol $\underline{6}(12), 4396-4408$.

Sakatsume M, Stancato LF, David M, Silvennoinen O, Saharinen P, Pierce J, Larner AC, Finbloom DS (1998): Interferon-gamma activation of Raf-1 is Jak1dependent and p21ras-independent. J Biol Chem 273(5), 3021-3026.

Sampaio EP, Bax HI, Hsu AP, Kristosturyan E, Pechacek J, Chandrasekaran P, Paulson ML, Dias DL, Spalding C, Uzel G (2012): A novel STAT1 mutation associated with disseminated mycobacterial disease. J Clin Immunol 32(4), 681-689.

Schaefer T, Sanders L, Nathans D (1995): Cooperative transcriptional activity of Jun and Stat3 $\beta$, a short form of Stat3. Proc Natl Acad Sci USA 92(20), 9097-9101. 
Schindler C, Darnell JE Jr. (1995): Transcriptional responses to polypeptide ligands: the JAK-STAT pathway. Annu Rev Biochem 64, 621-651.

Schindler C, Plumlee C (2008): Inteferons pen the JAK-STAT pathway. Semin Cell Dev Biol 19(4), 311-318.

Schindler C, Fu XY, Improta T, AebersoldR, Darnell JE Jr. (1992a): Proteins of transcription factor ISGF-3: one gene encodes the 91-and 84-kDa ISGF-3 proteins that are activated by interferon alpha. Proc Natl Acad Sci USA 89(16), 7836-7839.

Schindler C, Shuai K, Prezioso VR, Darnell JE Jr. (1992b): Interferon-dependent tyrosine phosphorylation of a latent cytoplasmic transcription factor. Science 257(5071), 809-813.

Schooltink H, Rose-John S (2002): Cytokines as therapeutic drugs. J. Interferon Cytokine Res $\underline{22}(5), 505-516$.

Seger R, Krebs EG (1995): The MAPK signaling cascade. FASEB J 9(9), 726-735.

Sekimoto T, Imamoto N, Nakajima K, Hirano T, Yoneda Y (1997): Extracellular signal-dependent nuclear import of Stat1 is mediated by nuclear pore-targeting complex formation with NPI-1, but not Rch1. EMBO J $\underline{16}(23), 7067-7077$.

Senda T, Shimazu T, Matsuda S, Kawano G, Shimizu H, Nakamura KT, Mitsui $Y$ (1992): Three-dimensional crystal structure of recombinant murine interferon-beta. EMBO J 11(9), 3193-3201.

Shankaran V, Ikeda H, Bruce AT, White JM, Swanson PE, Old LJ, Schreiber RD (2001): IFNgamma and lymphocytes prevent primary tumour development and shape tumour immunogenicity. Nature $\underline{410}(6832), 1107-1111$.

Sheppard P, Kindsvogel W, Xu W, Henderson K, Schlutsmeyer S, Whitmore TE, Kuestner R, Garrigues U, Birks C, Roraback J, Ostrander C, Dong D, Shin J, Presnell S, Fox B, Haldeman B, Cooper E, Taft D, Gilbert T, Grant FJ, Tackett M, Krivan W, McKnight G, Clegg C, Foster D, Klucher KM (2003): IL-28, IL-29 and their class II cytokine receptor IL-28R. Nat Immunol 4(1), 63-68. 
Shuai K (2000): Modulation of STAT signaling by STAT-interacting proteins. Oncogene $\underline{19}(21)$, 2638-2644.

Shuai K, Schindler C, Prezioso VR, Darnell JE Jr. (1992): Activation of transcription by IFN-gamma: tyrosine phosphorylation of a $91-\mathrm{kD}$ DNA binding protein. Science $\underline{258}(5089), 1808-1812$.

Shuai K, Stark GR, Kerr IM, Darnell JE Jr. (1993a): A single phosphotyrosine residue of Stat91 required for gene activation by interferon-gamma. Science 261(5129), 1744-1746.

Shuai K, Ziemiecki A, Wilks AF, Harpur AG, Sadowski HB, Gilman MZ, Darnell JE Jr. (1993b): Polypeptide signalling to the nucleus through tyrosine phosphorylation of Jak and Stat proteins. Nature $\underline{366}(6455), 580-583$.

Shuai K, Horvath CM, Huang LH, Qureshi SA, Cowburn D, Darnell JE Jr. (1994): Interferon activation of the transcription factor Stat91 involves dimerization through SH2-phosphotyrosyl peptide interactions. Cell $\underline{76}(5), 821-828$.

Shuai K, Liao J, Song MM (1996): Enhancement of antiproliferative activity of gamma interferon by the specific inhibition of tyrosine dephosphorylation of Stat1. Mol Cell Biol 16(9), 4932-4941.

Simoncic PD, Lee-Loy A, Barber DL, Tremblay ML, McGlade CJ (2002): The T cell protein tyrosine phosphatase is a negative regulator of janus family kinases 1 and 3 . Curr Biol 12(6), 446-453.

Smeekens SP, Plantinga TS, van de Veerdonk FL, Heinhuis $B$, Hoischen $A$,Joosten LA, Arkwright PD, Gennery A, Kullberg BJ, Veltman JA, Lilic D, van der Meer JW, Netea MG (2011): STAT1 hyperphosphorylation and defective IL12R/L23R signaling underlie defective immunity in autosomal dominant chronic mucocutaneous candidiasis. PLoS One $\underline{6}(12)$, e29248.

Snapper CM, Paul, WE (1987): Interferon-gamma and B cell stimulatory factor-1 reciprocally regulate Ig isotype production. Science $\underline{236}$ (4804), 944-947.

Songyang Z, Shoelson SE, Chaudhuri M, Gish G, Pawson T, Haser WG, King F, Roberts T, Ratnofsky S, Lechleider RJ, Neel BG, Birge RB, Fajardo, JE, Chou 
MM, Hanafusa H, Schaffhausen B, Cantley LC (1993): SH2 domains recognize specific phosphopeptide sequences. Cell $\underline{72}(5)$, 767-778.

Stancato LF, Sakatsume M, David M, Dent P, Dong F, Petricoin EF, Krolewski JJ, Silvennoinen O, Saharinen P, Pierce J, Marshall CJ, Sturgill T, Finbloom DS, Larner AC (1997): Beta interferon and oncostatin M activate Raf-1 and mitogenactivated protein kinase through a JAK1-dependent pathway. Mol Cell Biol 17(7), 3833-3840.

Stark GR, Darnell JE Jr. (2012): The JAK-STAT pathway at twenty. Immunity $\underline{36}(4)$, 503-514.

Starr R, Hilton DJ (1999): Negative regulation of the Jak/STAT-Pathway. Bioessays 21(1), 47-51.

Stark GR, Kerr IM, Williams BR, Silverman RH, Schreiber RD (1998): How cells respond to interferons. Annu Rev Biochem $\underline{67}$, 227-264.

Stephanou A, Latchman DS (2003): STAT-1: a novel regulator of apoptosis. Int J Exp Patho 84(6), 239-244.

Strehlow I, Schindler C (1998): Amino-terminal signal transducer and activator of transcription (STAT) domains regulate nuclear translocation and STAT deactivation. J Biol Chem 273(43), 28049-28056.

Sung SC, Fan TJ, Chou CM, Leu JH, Hsu YL, Chen T, Hsieh YC, Huang CJ (2003): Genomic structure, expression and characterization of a STAT5 homologue from pufferfish (Tetraodon fluviatilis). Eur J Biochem 270(2), 239-252.

Takeda K, Tanaka T, Shi W, Matsumoto M, Minami M, Kashiwamura S, Nakanishi K, Yoshida N, Kishimoto T, Akira S (1996): Essential role of Stat6 in IL-4 signalling. Nature $\underline{380}(6575), 627-630$.

Takeda K, Noguchi K, Shi W Tanaka T, Matsumoto M, Yoshida N, Kishimoto T Akira S (1997): Targeted disruption of the mouse Stat3 gene leads to early embryonic lethality. Proc Natl Acad Sci USA 94(8), 3801-3804. 
Takeda K, Kaisho T, Yoshida N, Takeda J, Kishimoto T, Akira S (1998): Stat3 activation is responsible for IL-6-dependent T cell proliferation through preventing apoptosis: generation and characterization of $T$ cell-specific Stat3-deficient mice. $J$ Immunol 161(9), 4652-4660.

Takezaki S, Yamada M, Kato M, Park MJ, Maruyama K, Yamazaki Y, Chida N, Ohara O, Kobayashi I, Ariga T (2012): Chronic mucocutaneous candidiasis caused by a gain-of-function mutation in the STAT1 DNA-binding domain. J Immunol 189(3), 1521-1526.

ten Hoeve J, Jesus Ibarra-Sanchez M, Fu Y, Zhu W, Tremblay M, David M, Shuai K (2002): Identification of a nuclear Stat1 protein tyrosine phosphatase. Mol Cell Biol $\underline{22}(16), 5662-5668$.

Thierfelder WE, van Deursen JM, Yamamoto K, Tripp RA, Sarawar SR, Carson RT, Sangster MY, Vignali DA, Doherty PC, Grosveld GC, Ihle JN (1996): Requirement for Stat4 in interleukin-12-mediated responses of natural killer and T cells. Nature $\underline{382}(6587), 171-174$.

Thomson A. (1998): The cytokine handbook, 3rd Ed. Academic Press, San Diego.

Tsumura M, Okada S, Sakai H, Yasunaga S, Ohtsubo M, Murata T, Obata H, Yasumi T, Kong XF, Abhyankar A (2012): Dominant-negative STAT1 SH2 domain mutations in unrelated patients with Mendelian susceptibility to mycobacterial disease. Hum Mutat $\underline{33}(9), 1377-1387$

van de Veerdonk FL, Plantinga TS, Hoischen A, Smeekens SP, Joosten LA, Gilissen C, Arts P, Rosentul DC, Carmichael AJ, Smits-van der Graaf CA, Kullberg BJ, van der Meer JW, Lilic D, Veltman JA, Netea MG (2011): STAT1 mutations in autosomal dominant chronic mucocutaneous candidiasis. $\mathrm{N}$ Engl $\mathrm{J}$ Med $\underline{365}(1), 54-61$.

Velazquez L, Fellous M, Stark GR, Pellegrini S (1992): A protein tyrosine kinase in the interferon alpha/beta signaling pathway. Cell $\underline{70}(11), 313-322$.

Vinkemeier U, Cohen L, Moarefi I, Chait BT, Kuriyan J, Darnell JE Jr. (1996): DNA binding of in vitro activated Stat1 alpha, Stat1 beta and truncated Stat1: Interaction 
between NH2-terminal domains stabilizes binding of two dimers to tandem DNA sites. EMBO J 15(20), 5616-5626.

Vinkemeier U, Moarefi I, Darnell JE Jr., Kuriyan J (1998): Structure of the aminoterminal protein interaction domain of STAT-4. Science $\underline{279}$ (5353), 1048-1052.

Waksman G, Kominos D, Robertson SC, Pant N, Baltimore D, Birge RB, Cowburn D, Hanafusa H, Mayer BJ, Overduin M, Resh MD, Rios CB, Silverman L, Kuriyan J (1992): Crystal structure of the phosphotyrosine recognition domain $\mathrm{SH} 2$ of $\mathrm{v}$-src complexed with tyrosine-phosphorylated peptides. Nature 358(6388), 646-653.

Wang D, Stravopodis D, Teglund S, Kitazawa J, Ihle JN (1996): Naturally occurring dominant negative variants of Stat5. Mol Cell Biol 16(11), 6141-6148.

Watling D, Guschin D, Müller M, Silvennoinen O, Witthuhn BA, Quelle FW, Rogers NC, Schindler C, Stark GR, Ihle JN, Kerr LM (1993): Complementation by the protein tyrosine kinase JAK2 of a mutant cell line defective in the interferon-gamma signal transduction pathway. Nature $\underline{366}(6451), 166-170$.

Weis K (1998): Importins and exportins: how to get in and out of the nucleus. Trends Biochem Sci 23(5), 185-189.

Wen Z, Darnell JE Jr. (1997): Mapping of Stat3 serine phosphorylation to a single residue (727) and evidence that serine phosphorylation has no influence on DNA binding of Stat1 and Stat3. Nucleic Acids Res 25 (11), 2062-2067.

Wen Z, Zhong Z, Darnell JE Jr. (1995): Maximal activation of transcription by Stat1

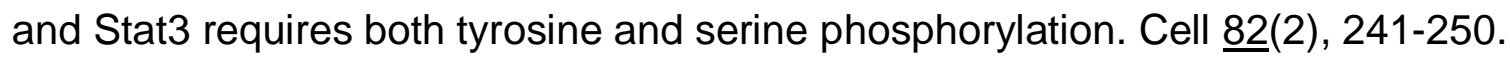

Wenta N, Strauss H, Meyer S, Vinkemeier U (2008): Tyrosine phosphorylation regulates the partitioning of STAT1 between different dimer conformations. Proc Natl Acad Sci USA 105(27), 9238-9243.

Wilks AF, Harpur AG, Kurban RR, Ralph SJ, Zürcher G, Ziemiecki A (1991): Two novel protein-tyrosine kinases, each with a second phosphotransferase-related cataIytic domain, define a new class of protein kinase. Mol Cell Biol 11(4), 2057-2065. 
Williams JG (2000): STAT signalling in cell proliferation and development. Curr Opin Gen Dev 10(5), 503-507.

Wu TR, Hong YK, Wang X, Ling MY, Dragoi AM, Chung AS, Campbell AG, Han ZY, Feng GS, Chin YE (2002): SHP-2 is a dual-specificity phosphatase involved in Stat1 dephosphorylation at both tyrosine and serine residues in nuclei. J Biol Chem $\underline{277}(49)$, 47572-47580.

Xu X, Sun YL, Hoey T (1996): Cooperative DNA binding and sequence-selective recognition conferred by the STAT amino-terminal domain. Science $\underline{273}(5276), 794-$ 797.

Yan R, Small S, Desplan C, Dearolf CR, Darnell JE Jr. (1996): Identification of a Stat gene that functions in Drosophila development. Cell 84(3), 421-430.

Yang E, Wen Z, Haspel RL, Zhang JJ, Darnell JE Jr. (1999): The linker domain of Stat1 is required for gamma interferon-driven transcription. Mol Cell Biol 19(7), 51065112.

Yang E, Henriksen MA, Schaefer O, Zakharova N, Darnell JE Jr. (2002): Dissociation time from DNA determines transcriptional function in a STAT1 linker mutant. J Biol Chem 277(16), 13455-13462.

Zhang JJ, Vinkemeier U, Gu W, Chakravarti D, Horvath CM, Darnell JE Jr. (1996): Two contact regions between Stat1 and CBP/p300 in interferon gamma signaling. Proc Natl Acad Sci USA 93(26), 15092-15096.

Zhang JJ, Zhao Y, Chait BT, Lathem WW, Ritzi M, Knippers R, Darnell JE Jr. (1998): Ser727-dependent recruitment of MCM5 by Stat1alpha in IFN-gammainduced transcriptional activation. EMBO J 17(23), 6963-6971.

Zhang X, Blenis J, Li H.C, Schindler C, Chen-Kiang S (1995): Requirement of ser-

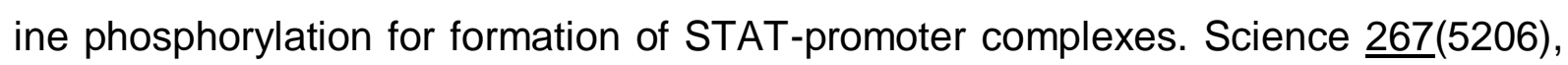
1990-1994.

Zhao W, Cha EN, Lee C, Park CY, Schindler C (2007): Stat2-dependent regulation of MHC class II expression. J Immunol 179(1), 463-471. 
Zhong M, Henriksen MA, Takeuchi K, Schaefer O, Liu B, Hoeve J ten, Ren Z, Mao X, Chen X, Shuai K, Darnell JE Jr. (2005): Implications of an antiparallel dimeric structure of nonphosphorylated STAT1 for the activation-inactivation cycle. Proc Natl Acad Sci USA 102(11), 3966-3971.

Zimmermann $A$, Trilling $M$, Wagner $M$, Wilborn $M$, Bubic $I$, Jonjic $S$, Koszinowski U, Hengel H (2005): A cytomegaloviral protein reveals a dual role for STAT2 in IFN-y signaling and antiviral responses. J Exp Med 201(10), 1543-1553. 


\section{Zusammenfassung}

Der durch Interferone induzierbare Transkriptionsfaktor STAT1 (Signal-Transduktor und Aktivator der Transkription 1) spielt eine wichtige Rolle in der Abwehr von viralen, bakteriellen und Parasiteninfektionen. Gut beschrieben ist die durch ZytokinStimulation ausgelöste Phosphorylierung eines singulären Tyrosinrestes (Y701) im Carboxyterminus von STAT1, die zur Ausbildung von transkriptionell aktiven, parallelen STAT1-Dimerkomplexen führt. In dieser Arbeit wurde durch gezielte Mutagenese eine bei den Familienmitgliedern STAT1 bis STAT4 konservierte Aminosäure (E585) nach Alanin ausgetauscht und die Punktmutante in verschiedenen Transfektionsexperimenten funktionell charakterisiert. Anders als das Wildtyp-Protein oder eine weitere, hier ebenfalls generierte STAT1-Mutante (E524A) zeigte STAT1-E585A ein nach Interferon- $\gamma(\mathrm{IFN} \gamma)$-Stimulation der Zellen nachweisbares verstärktes und verlängertes Phosphorylierungsniveau. Dabei hatte die Substitution des oberflächenexponierten Glutaminsäurerestes 585 in der SH2-Domäne von STAT1 unerwartet eine differenzielle Änderung im Transkriptionsverhalten dieser Mutante zur Folge. Während eine Reihe bekannter endogener STAT1-Zielgene (irf1, gbp1 und mig1) durch die Einführung der Punktmutation in ihrem Expressionsverhalten nicht signifikant anders als durch das Wildtyp-Molekül aktiviert wurden, konnte in Real-Time-PCR-Messungen für das mcp1-Gen eine deutlich erhöhte Expressionsrate durch die E585-Mutante dokumentiert werden. Deshalb lässt sich die von mir in dieser Arbeit untersuchte Mutante als eine partielle Gain-of-Funktion-Mutante beschreiben; dieses gilt aber strenggenommen nicht für das stat1-Gen selbst. Als mögliche molekulare Ursache für die beobachtete Hyperphosphorylierung der E585AMutante wird eine vermindere Rate einer Konformationsänderung von einer parallelen in eine antiparallele Dimerkonfiguration vermutet, wobei Letztere für die Tyrosin-Dephosphorylierung benötigt wird. Zusammenfassend konnten meine Ergebnisse also den Einfluss eines kritischen Aminosäurerestes in der SH2-Domäne auf transkriptionelle Antworten im IFN $\gamma$-Signalweg aufzeigen, wodurch die zentrale Bedeutung der Tyrosin-Phosphorylierung moduliert wird. 


\section{Summary}

The interferon-inducible transcription factor STAT1 (signal transducer and activator of transcription 1) plays an important role in the defense against viral, bacterial and parasitic infections. Well studied is the phosphorylation of a signature tyrosine residue (Y701) in the carboxy-terminus of STAT1 upon stimulation of cells with cytokines, leading to the formation of transcriptionally active, parallel STAT1 dimers. In this thesis, a residue in the STAT1 molecule conserved among the family members STAT1 to STAT4 was replaced with alanine by site-directed mutagenesis, and the corresponding point mutant (E585A) was functionally characterized in various experimental approaches. Other than the wild-type protein or an additionally generated point mutant (E524A), STAT1-E585A was hyperphosphorylated upon stimulation of cells with interferon (IFN $\gamma$ ). The exchange of the surface-exposed glutamic acid residue 585 in the SH2 domain of STAT1 unexpectedly resulted in a differential transcriptional behavior. While numerous known endogenous STAT1 target genes (irf1, gbp1, and mig1) were activated normally by the point mutant, real-time PCR measurements showed a significantly higher expression rate for the mcp1 gene. Therefore, STAT1-E585A characterized in this study can be regarded as a partial gain-offunction mutant, although the stat1 gene itself was not over-expressed. The molecular basis underlying the observed hyperphosphorylation of the E585A mutant possibly results from a reduced rate of conformational exchange between a DNA-bound parallel and an anti-parallel dimer configuration, with the latter being required for tyrosine dephosphorylation. In summary, my data demonstrate the role of a critical amino acid residue in the STAT1 SH2 domain in transcriptional responses in IFN $\gamma$ signaling, thereby modifying the central impact of tyrosine phosphorylation on gene activation. 


\section{Danksagung}

An erster Stelle gilt mein Dank Prof. Dr. Dr. Dr. Thomas Meyer für die Einarbeitung in die Grundlagenforschung und die Bereitstellung dieses hochinteressanten Dissertationsthemas. Den Erfolg dieser Arbeit verdanke ich vor allem seinen motivierenden Anregungen, den freundlichen Ermutigungen und seiner ständigen Diskussionsbereitschaft. Ich möchte mich außerdem für das mir entgegengebrachte Vertrauen, die sehr gute wissenschaftliche Betreuung und die Übernahme des Erstgutachtens bedanken.

Weiterhin möchte ich mich bei Herrn Prof. Dr. Herrmann-Lingen für die wissenschaftliche Unterstützung und sein stetes Interesse an meiner Arbeit bedanken.

Mein besonderer Dank gilt Frau Dr. Julia Staab für ihre verständnisvolle und ermutigende Unterstützung bei der RT-PCR und den vielen fachlichen Hilfestellungen.

Ein großes Dankeschön geht ferner an Frau Anke Gregus und Frau Heike Hühn für ihre freundliche Einarbeitung in den Laboralltag, ihre Unterstützung bei einigen Experimenten sowie die nette und produktive Zusammenarbeit.

Bei den Arbeitsgruppen der Abteilung Neurodegeneration, Neuroimmunologie/IMSF und Neurophysiologie bedanke ich mich ganz herzlich für die vielen wissenschaftlichen Anregungen und die Nutzung ihrer Laborgeräte.

Nicht zuletzt möchte ich meiner Familie danken, die mich in der Zeit meines Studiums und meiner Promotion immerwährend unterstützte und motivierte und damit wesentlich zur Fertigstellung meiner Dissertation beigetragen haben. 


\section{Lebenslauf}

Ich, Talayeh Giveh Chian Zadeh, wurde am 15.09.1984 in Teheran als erstes von zwei Kindern der Eheleute Shohreh Hamzehloo und Morteza Giveh Chian Zadeh geboren.

Die Allgemeine Hochschulreife erlangte ich im Juni 2006 an der UNESCO-Schule in Essen. Zum Sommersemester 2007 nahm ich das Studium der Zahnmedizin an der Georg-August-Universität in Göttingen auf und legte am März 2010 den ersten Abschnitt der Ärztlichen Prüfung mit der Note „sehr gut“ ab. Mein Staatsexamen legte ich am 07.Dezember 2012 mit der Note „gut" ab.

Im Februar 2012 begann ich mit meiner experimentellen Doktorarbeit in der DFGgeförderten Forschergruppe von Prof. Dr. Dr. Dr. Meyer im Labor für molekulare Psychokardiologie der Abteilung Psychosomatische Medizin und Psychotherapie der Georg-August-Universität Göttingen. 